\title{
Structural and Functional Basis of C-Methylation of Coumarin Scaffolds by NovO
}

\author{
Joanna C. Sadler, ${ }^{[\mathrm{a}],[\mathrm{b}]}$ Chun-wa H. Chung, ${ }^{[\mathrm{a}]}$ Julie E. Mosley, ${ }^{[\mathrm{a}]}$ Glenn A. Burley, ${ }^{[\mathrm{b}]^{*}}$ Luke D. Humphreys ${ }^{[\mathrm{a}] \dagger}$ \\ [a] GlaxoSmithKline Medicines Research Centre, Gunnels Wood Road, Stevenage, SG1 2NY(UK), [b] WestCHEM, \\ Department of Pure and Applied Chemistry, University of Strathclyde, 295 Cathedral Street, Glasgow G1 $1 X L$.
}

\section{Supporting Information Placeholder}

\begin{abstract}
C$-methylation of aromatic small molecules by $C$ methyltransferases (C-MTs) is an important biological transformation that involves $C$ - $C$ bond formation using $S$-adenosyl$L$-methionine (SAM) as the methyl donor. Here, two advances in the mechanistic understanding of $C$-methylation of the 8-position of coumarin substrates catalyzed by the C-MT NovO from Streptomyces Spheroides are described. First, a crystal structure of NovO reveals the Arg116-Asni17 and His120-Arg121 motifs are essential for coumarin substrate binding. Second, the active-site His12o is responsible for deprotonation of the phenolic 7 -hydroxyl group on the coumarin substrate, activating the rate-determining methyl transfer step from SAM. This work expands our mechanistic knowledge of C-MTs which could be used in the downstream development of engineered biocatalysts for small molecule C-alkylations.
\end{abstract}

Methylation is an essential biological transformation used throughout Nature. This process is catalyzed by the methyltransferase (MT) family of enzymes and is used to control key biological processes, from gene regulation and epigenetics via histone lysine N-MTs, ${ }^{1-3}$ through to key methyl transfer steps in the biosynthesis of vitamins B12 and E.4,5 This family of enzymes catalyze O-, N, C- and even S-methylation of biomacromolecules and small molecule natural products (NPs) using S-adenosyl-L-methionine (SAM) as the methyl donor. $^{6-9}$ Of the various types of biocatalytic methylation reactions catalyzed by MTs, C-methylation has gained considerable prominence as a key epigenetic regulator of gene expression by methylating the 5-position of cytosine catalyzed by DNA $\mathrm{m}^{5} \mathrm{C}$ MTs. The mechanism of $\mathrm{C}$-methylation of DNA by $\mathrm{m}^{5} \mathrm{C}$ MTs occurs via initial thiolation of the C6-position of cytosine by an active site cysteine residue, methylation using SAM as the methyl donor at the $C_{5}$-position and finally deprotonation/dethiolation to reestablish the pyrimidine aromatic system..$^{10,11}$

In contrast to numerous MTs that catalyze the SAMdependent $\mathrm{C}$-methylation to protein and nucleic acid substrates, fewer than ten NP C-MTs have been reported; the majority of which have not been structurally and mechanistically characterised. ${ }^{12-15}$ One exemplar is the C-MT NovO, which catalyses the regiospecific C-methylation of aminocoumarin $\mathbf{1}$ at the 8-position to form 2; an intermediate in the biosynthesis of the antibiotic novobiocin 3 by Streptomyces Spheroides (Scheme 1a). ${ }^{16,17}$ Work by Gruber et al. has shown that NovO catalyses the alkylation of aminocoumarin substrate analogues to provide products $4 a-c$ and dihydroxynapthalene $\mathbf{5}$ using SAM (Scheme $\mathbf{1 b}$ ) and nonnatural SAM analogues bearing a variety of alkyl groups, which opens up opportunities to undergo Friedel-Crafts-like C-alkylations on high value small molecule substrates. ${ }^{18}$

Although this study provided initial insight into the substrate scope of NovO, a detailed understanding of the structure of this NP-MT and the factors associated with substrate recognition and the catalytic mechanism of methyl transfer are not known. Furthermore, NovO displays only $10-15 \%$ sequence homology with other structurally characterized NPMTs in the Protein Data Bank (PDB, Figure S1), and as such it is difficult to gain accurate structural and mechanistic insight from homology models. ${ }^{12,13}$ In this paper, we report a detailed structural and functional study of NovO. Using a combination of crystal structure analysis, substrate docking, site directed mutagenesis, kinetic isotope effect (KIE) studies and substrate analogue screens, we show that NovO uses a

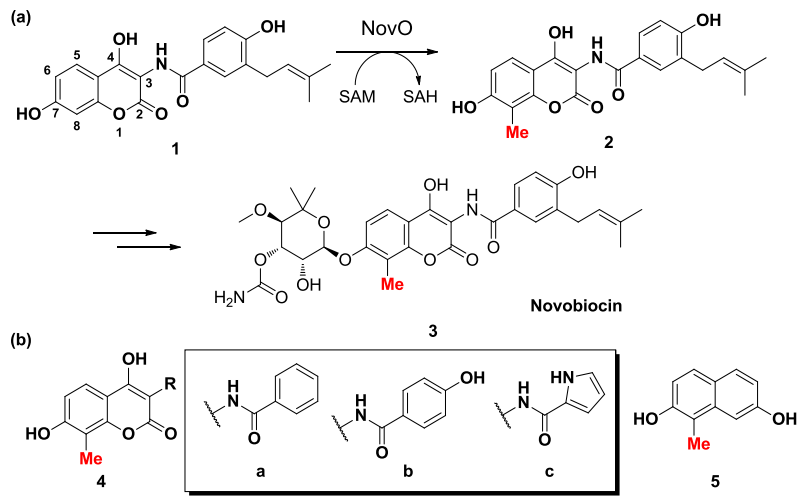

Scheme 1. (a) SAM-dependent methyl transfer catalyzed by NovO in the biosynthesis of novobiocin by Streptomyces Spheroides. (b) Non-natural product analogues accessible with NovO. ${ }^{18}$

novel His-Arg motif firstly to deprotonate (His) the phenolic $\mathrm{OH}$ in the 7-position of substrate $\mathbf{6}$, and then to lock (Arg) the 
substrate in place for $\mathrm{C}$-methylation to occur exclusively at the 8-position by SAM.

The X-ray crystal structure of selenomethionine (SelMet) substituted NovO in complex with S-adenosylhomocysteine (SAH) was determined by single-wavelength anomalous dispersion. NovO crystallized as a homodimer, in which each monomer contains the characteristic Rossmann fold found extensively in SAM-dependent MTs. ${ }^{19,20}$ This result is consistent with a previous report from Gruber et al. that NovO is active as a dimer in solution..$^{21}$ The contact interface consists of two C-terminal $\alpha$-helices (Figure 1a, shown in blue) with an average separation of $2.85 \AA$. This is atypical for Class I MTs, which usually display additional $\alpha$-helices at the $\mathrm{N}$-terminus. ${ }^{20}$ Although NovO displays very low sequence homology to other structurally characterised NP-MTs, a search for close structural analogues within the $\mathrm{PDB}$ revealed the carboxymethyl-SAM RNA MT CmoA and $\mathrm{YecO}$ from Haemophilus influenzae to be the closest analogues with $88 \%$ and $83 \%$ structural similarity, respectively.22-24 The residues forming the $\mathrm{SAH}$ binding pocket are located at flexible regions (Figure 1a, shown in green) between $\alpha$-helices and $\beta$ sheets. ${ }^{19,20}$ Extensive $\mathrm{H}$-bonding networks are formed between the SAH-carboxylate and $\mathrm{R} 116$; the adenine- $\mathrm{NH}_{2}$ and the two acidic residues $\mathrm{E}_{4}$ and $\mathrm{D} 96$; and the two ribose-hydroxyl groups with D70 (Figure $\mathbf{1 b}$ and Figure 4 ). Whilst D96 and D70 are both highly conserved across the Class 1 MT family, the other residues involved in SAH binding vary across the class (Figure S1). Another feature common to Class 1 MTs is a highly conserved, glycine rich region known as 'Motif 1' consisting of E/DXXXGXG, where $\mathrm{X}$ is any residue. ${ }^{19^{-21}} \mathrm{Gruber}$ et al. have previously proposed this motif

(a)

(b)
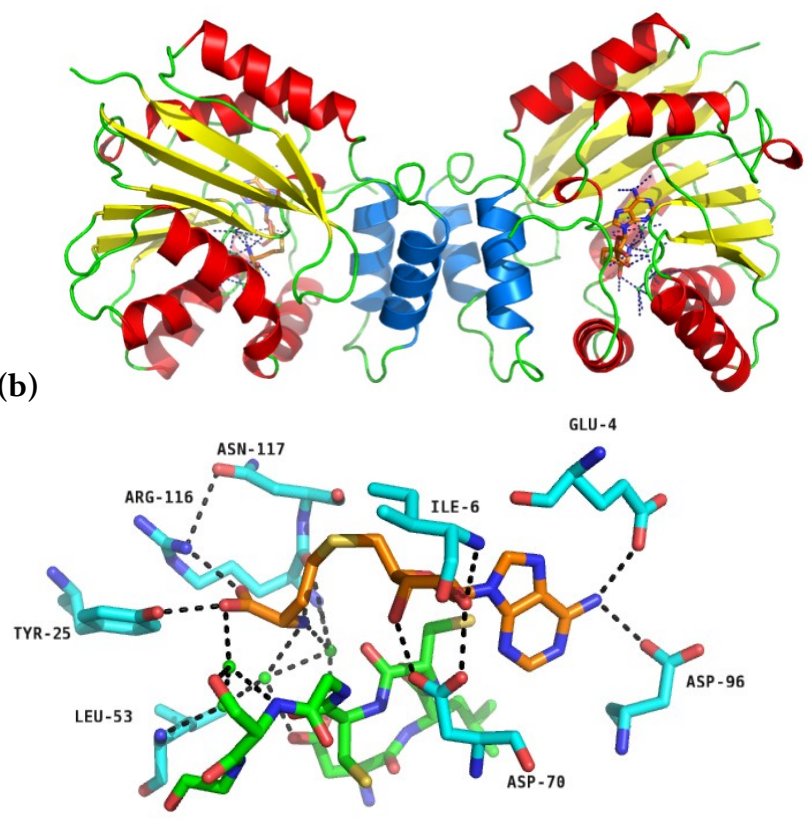

Figure 1. Crystal structure of NovO (PDB accession code: 5MGZ) (a) complexed with SAH (coloured in orange) and (b) the SAH binding site with 'Motif 1' highlighted in green ( $\mathrm{D}_{45}$, $\mathrm{L}_{46}$, $\left.\mathrm{C}_{47}, \mathrm{C}_{48}, \mathrm{G}_{49}, \mathrm{~S}_{50}, \mathrm{G}_{51}\right)$. was located between $\mathrm{D}_{45}$ and $\mathrm{G}_{51}$, with $\mathrm{D}_{45}$ and $\mathrm{G}_{49}$ being crucial for enzymatic function, and $\mathrm{C}_{47}, \mathrm{C}_{4} 8, \mathrm{G}_{51}$ and $\mathrm{D}_{70}$ critical for protein folding. With reference to our crystal structure, D45 does indeed make key hydrogen bonds with the amino acid moiety of SAH via two water molecules (Figure 1b). Analysis of the protein structure by B-value revealed Arg24 to be highly flexible with an average B-factor of $\sim 32$, compared to that of $\sim 16$ for surrounding residues (Figure $\mathbf{S}_{\mathbf{5}}$ ), and further confirmed by the existence of two conformations in the crystal structure. Given its positioning at the solvent interface, proximity to the active site and the absence of a pore for entrance of substrate to the active site, we surmise that this residue plays a gatekeeper role as has previously been described for some structurally unrelated peroxidases. ${ }^{25}$

Although attempts to obtain a crystal structure of NovO in complex with aminocoumarin substrate $\mathbf{6}^{18}$ and SAM, SAM analogues $^{26,27}$ or S-adenosylhomocysteine (SAH) were unsuccessful, a model was generated using Molecular Operating Environment (MOE) software ${ }^{28}$ using the crystal structure of the NovO-SAH complex to investigate the binding of 6 in NovO (see Supporting Information). A set of 6 residues were identified as putative active site residues (Figure 2). In particular, H12o and R121 made key hydrogen bond contacts with the phenolic group in the 7-position and R116 and N117 with the coumarin lactone. To the best of our knowledge, this is the first time that these two motifs have been implicated in a MT binding pocket. Furthermore, this model accounted for the experimentally observed regiospecificity of methyl transfer for the 8-position of the coumarin ring, as $\mathrm{C}-8$ is positioned directly above the sulfur centre of SAH. This was confirmed by modelling a methyl group onto the $\mathrm{SAH}$ to mimic the naturally-occurring diastereomer $(S-)$ of SAM (Figures S6 and $S_{7}$ ).

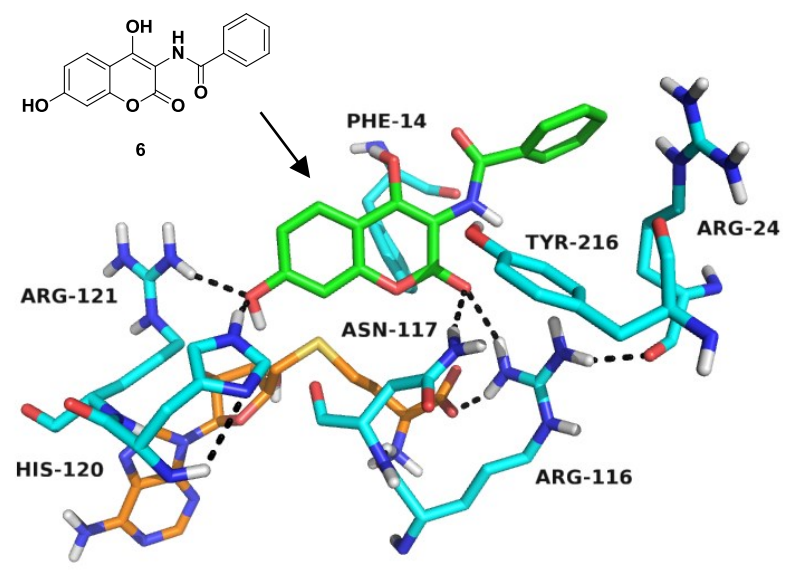

Figure 2. Substrate docking model of aminocoumarin 6 (green) in the crystal structure of NovO complexed with SAH.

In order to test the validity of our model, we probed the function of each of these residues by site-directed mutagenesis (SDM). A suite of systematic mutations were prepared to probe the electronic environment of the proposed substrate pocket and where possible, maintain a similar steric environment by mutating residues of a similar size. Furthermore, we investigated the significance of R24 as the proposed gatekeeper residue by its replacement with 
phenylalanine, which was hypothesised to inhibit entrance to the active site. ${ }^{25}$ The catalytic activity of each mutant was measured by conversion to the corresponding methylated product 4a after 24 hours (Figure 3a). ${ }^{18,21}$ All mutants resulted in a significant decrease in MT activity, with complete abolition of activity for mutants at positions R116, N117, H12O and Ri21.

These observations were consistent with our substrate binding model in which $\mathrm{F}_{14}$ takes part in end-on $\pi$-stacking interactions with the coumarin lactone ring and Y216 donates an H-bond to the amide carbonyl group (Figure 2). Whilst these residues are proposed to be involved in substrate binding, they are not essential for enzyme function as observed by a low level of conversion to product $4 \mathbf{a}$. Conversely, H12o and R121 form H-bonds with the hydroxy group adjacent to the site of methylation.

(a)

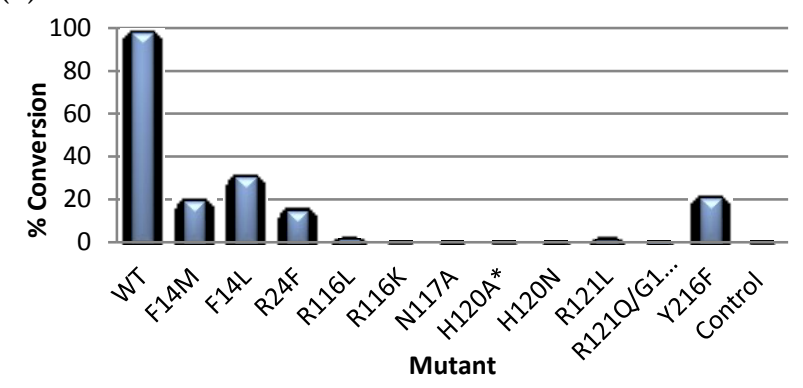

(b)

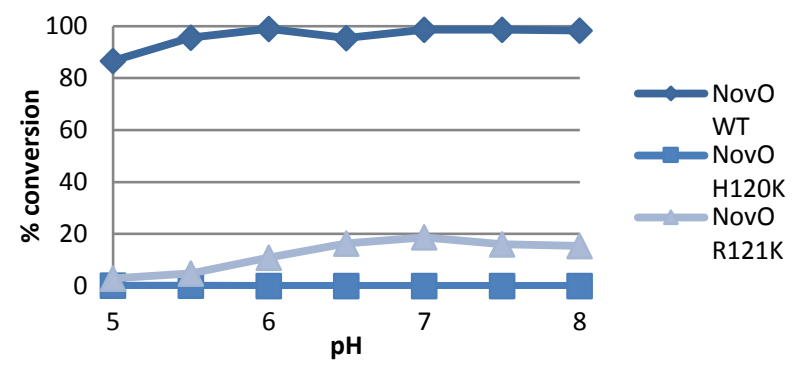

Figure 3. (a) Percentage (\%) methylation of substrate 6 to provide product $\mathbf{4 a}$ after 24 hours by NovO WT relative to NovO mutants. * Due to the low levels of soluble expression of H12oA, cell lysate was used. (b) Enzymatic activity of Cmethylation of 6 by NovO H12oK and R121K mutants relative to WT over $\mathrm{pH}$ values 5-8.

Based on these mutagenesis studies, we hypothesized that both $\mathrm{H}_{120}$ and R121 are essential for substrate activation, which was further probed by two single point mutants $\mathrm{H} 12 \mathrm{oK}$ and R121K. Whilst protonated R121K would be expected to support an H-bond to the phenolic hydroxy group in a similar manner to R121, H12oK would most likely be protonated under the assay conditions and could not act as an appropriate base in order to activate the coumarin substrate $\mathbf{6}$ towards electrophilic aromatic substitution. As shown in Figure $\mathbf{3 b}$, the H12oK mutant was inactive across a $\mathrm{pH}$ range $5-7$, whilst R121K retained $\sim 20 \%$ of the activity displayed by the WT above
$\mathrm{pH}$ 6.5. Further analysis of the NovO crystal structure around the R121 residue revealed an extensive $\mathrm{H}$-bonding network between the guanidinium moiety and nearby residues directly and via water molecules (Figure S9). Thus, the formation of a sub-optimal H-bond network in the R121K mutant could explain the lower catalytic activity observed for the Cmethylation of 6 between $\mathrm{pH}$ 6.5-8. When the $\mathrm{pH}$ was below 6.5, a drop off in C-methylation activity was observed, which aligns with the pKa of protonated histidine. With reference to this and the crystal structure, we conclude that the H12o- R121 motif plays an essential role in C-methylation of $\mathbf{6}$. To the best of our knowledge, this is the first time that such a motif has been implicated in methyl transfer by Class I MTs. ${ }^{12,13,21}$ This result is in contrast to a homology model of NovO reported by Gruber et al. (Figure S11a), in which $\mathrm{H}_{15}$ was hypothesised to be the catalytic base. ${ }^{21}$ When the position of this residue is identified in our crystal structure, it is seen to be at the solvent interface rather than in the substrate binding pocket (Figure Si1b).

Next, the role of the hydroxy group at the 7-position of the coumarin scaffold was investigated. A library of substrate analogues was prepared with electron withdrawing (substrates $7-\mathrm{Cl} \mathbf{S}_{1}$ and ${ }_{7}-\mathrm{NO}_{2} \mathbf{S}_{2}$ or an electron donating group (substrate $-\mathrm{NH}_{2} \mathbf{S}_{\mathbf{3}}$, -OMe $\mathbf{S}_{4}$ ) in the 7-position (Scheme S2). These analogues were screened under the standard assay conditions with the WT enzyme (Scheme Si). In all cases, no methylation was detected by HPLC after 24 hours, which indicates that the hydroxy group in the $7^{-}$ position of $\mathbf{6}$ is essential for catalysis. ${ }^{18}$

To better understand the nature of the transition state and rate limiting step of C-methylation of $\mathbf{6}$, primary and secondary KIEs were determined using purified NovO and SAM or the isotopic analogues ${ }^{13} \mathrm{CH}_{3}-\mathrm{SAM}$ and $\mathrm{CD}_{3}$-SAM.. Whilst with NovO exhibited a $k_{\text {cat }}$ of $20.1 \times 10^{-3} \mathrm{~s}^{-1}$ using SAM as the methyl donor, ${ }^{17,18}$ a $k_{\text {cat }}$ of $17.0 \times 10^{-3} \mathrm{~s}^{-1}$ was measured using ${ }_{13} \mathrm{CH}_{3}$-SAM resulting in a primary KIE of 1.22 . This value is notably higher than the primary KIEs for catachol $O$-MT $(\mathrm{COMT})^{29}$ and human $\mathrm{DNMT}^{11}$ reported by Schowen and Schramm, respectively. However, NovO represents a mechanistically distinct small molecule $C$-MT and to the best of our knowledge, this is the first report of KIE data for this class of MT. This KIE is indicative of methyl transfer being the rate limiting step in the catalytic cycle, as has been reported for COMT..$^{\circ}$ Furthermore, a large, normal KIE is characteristic of a symmetric transition state in the $\mathrm{S}_{\mathrm{N} 2}$ reaction..$^{30-33} \mathrm{~A} k_{\text {cat }}$ of $20.1 \times 10^{-3} \mathrm{~s}^{-1}$ was measured when $\mathrm{CD}_{3}$-SAM was used, giving a smaller secondary KIE value of 1.03, which was within the limits of the error margins (Table 1 and Figure S1o) and therefore not statistically significant.

Table 1. Kinetic Parameters and KIE values.

\begin{tabular}{cccc}
\hline & $\boldsymbol{K}_{\boldsymbol{m}}(\boldsymbol{\mu M})$ & $\boldsymbol{k}_{\boldsymbol{c a t}}\left(\mathbf{s}^{-1}\right)$ & KIE \\
\hline Me-SAM & $43.7( \pm 2.8)$ & $2.1 \times 10^{-3}( \pm 0.0004)$ & - \\
${ }^{13} \mathrm{CH}_{3}$-SAM & $41.6( \pm 5.1)$ & $1.7 \times 10^{-3}( \pm 0.0008)$ & $1.22( \pm 0.04)$ \\
$\mathrm{CD}_{3}$-SAM & $52.8( \pm 5.3)$ & $2.0 \times 10^{-3}( \pm 0.0009)$ & $1.03( \pm 0.03)$ \\
\hline
\end{tabular}



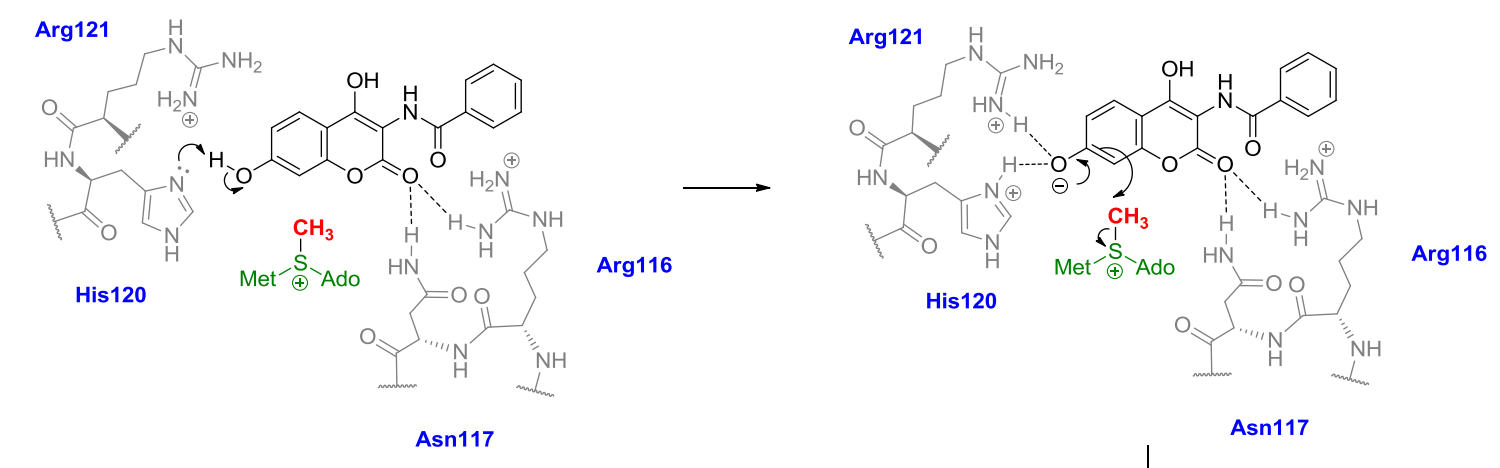

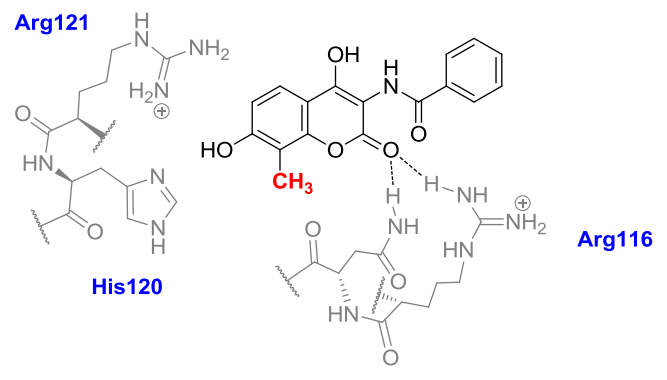

Asn117

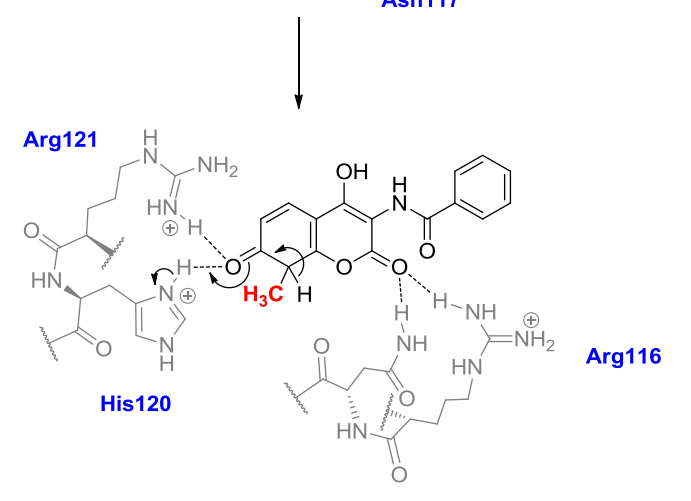

Asn117

Scheme 2. Proposed mechanism of C-methylation of substrate 6 by NovO.

Taken collectively, we propose the following catalytic mechanism of C-methylation by NovO (Scheme 2). An initial enzyme-substrate complex is formed through $\mathrm{H}$ - bonding of the C-2 carbonyl of coumarin 6 with R 116 and N117. Based on the pKa of histidine and the proximity of H12o to the phenolic proton $(\sim 1.75 \AA$ based on the substrate docking model in Figure 2) and our study of mutants $\mathrm{H}_{12} \mathrm{OK}$ and R121K, H12O deprotonates the phenolic $-\mathrm{OH}$ in the $7^{-}$position. The resulting phenoxide is stabilized by $\mathrm{H}$-bonding to protonated $\mathrm{H}_{120}$ and R121 and has sufficient nucleophilicity to effect electrophilic aromatic substitution at the 8-position by SAM as the methyl donor. Following deprotonation, it is also possible that the phenolic anion is stabilised by Argn6 and Asni17 as loss of activity was also observed when these residues were mutated. Finally, rapid deprotonation of the resulting intermediate to regain aromaticity of the system provides the enzyme-product complex.

In summary, we have shown that $C$-methylation of coumarin 6 proceeds be a novel mechanism catalysed by NovO. ${ }^{12,13,15}$ The His120-R121 motif is critical for substrate activation and docking of the coumarin substrate $\mathbf{6}$ into the active site of NovO. To the best of our knowledge, this is the first example of an His-Arg motif being implicated in the key stage of methyl transfer by a MT. Furthermore, our substrate analogue library reveals the 7-position hydroxy group is essential for substrate activation, rendering the aromatic ring susceptible to the rate-determining electrophilic aromatic substitution step at the 8-position. We envisage that this work will assist in the engineering of NovO variants that could be used in the development of a platform technology for biocatalytic Calkylation of small molecule substrates.

\section{ASSOCIATED CONTENT}

\section{Supporting Information}

The Supporting Information is available free of charge on the ACS Publications website.

Additional materials and methods and supporting data, tables and figures (PDF).

\section{AUTHOR INFORMATION}

\section{Corresponding Author}

Email: glenn.burley@strath.ac.uk.

\section{Present Addresses}

† Gilead Alberta ULC, 1021 Hayter Road NW, Edmonton, AB T6S 1 A1, Canada.

Email:

glenn.burley@strath.ac.uk

luke.humphreys@gilead.com;

\section{Notes}

The authors declare no competing financial interests.

\section{ACKNOWLEDGMENTS}

The authors thank Colin Edge and Andrew Fosberry for help with mutant library design and preparation. The authors would also like to thank Mandana Gruber for helpful discussions. J. C. S., G. A. B. and L. D. H. are grateful to GlaxoSmithKline (GSK) and the EPSRC for funding through the GSK-University of Strathclyde Industrial Ph.D. scheme.

\section{REFERENCES}

(1) Greer, E. L., and Shi, Y. (2012) Histone methylation: a dynamic mark in health, disease and inheritance. Nat. Rev. Genet. 13, 343-57.

(2) Müller, S., and Brown, P. J. (2012) Epigenetic 
chemical probes. Clin. Pharmacol. Ther. 92, 689-93.

(3) Arrowsmith, C. H., Bountra, C., Fish, P. V, Lee, K., and Schapira, M. (2012) Epigenetic protein families: a new frontier for drug discovery. Nat. Rev. Drug Discov. $11,384-400$.

(4) Hofius, D., and Sonnewald, U. (2003) Vitamin E biosynthesis: biochemistry meets cell biology. Trends Plant Sci. 8, 6-8.

(5) Warren, M. J., Raux, E., Schubert, H. L., and Escalante-Semerena, J. C. (2002) The biosynthesis of adenosylcobalamin (vitamin B12). Nat. Prod. Rep. 19, 390-412.

(6) Tengg, M., Stecher, H., Offner, L., Plasch, K., Anderl, F., Weber, H., Schwab, H., and Gruber-Khadjawi, M. (2016) Methyltransferases: Green Catalysts for FriedelCrafts Alkylations. ChemCatChem 8, 1354-136o.

(7) Ogawa, H., Gomi, T., Takusagawa, F., and Fujioka, M. (1998) Structure, function and physiological role of glycine N-methyltransferase. Int. J. Biochem. Cell Biol. 30, 13-26.

(8) Law, B. J. C., Bennett, M. R., Thompson, M. L., Levy, C., Shepherd, S. A., Leys, D., and Micklefield, J. (2016) Effects of active-site modification and quaternary structure on the regioselectivity of catechol- $\mathrm{O}$ methyltransferase. Angew. Chemie Int. Ed. 128, 27332737.

(9) Fujimori, D. G. (2013) Radical SAM-mediated methylation reactions. Curr. Opin. Chem. Biol. 17, 597604.

(10) Bujnicki, J. M., Feder, M., Ayres, C. L., and Redman, K. L. (2004) Sequence-structure-function studies of tRNA: ${ }_{5} \mathrm{C}$ methyltransferase Trm4p and its

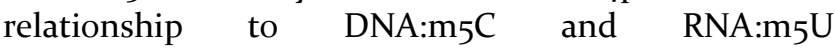
methyltransferases. Nucleic Acids Res. 32, 2453-63.

(11) Du, Q., Wang, Z., and Schramm, V. L. (2016) Human DNMT1 transition state structure. Proc. Natl. Acad. Sci. U. S. A. 113, 2916-2921.

(12) Chen, S.-C., Huang, C.-H., Lai, S.-J., Liu, J.-S., Fu, P.K., Tseng, S.-T., Yang, C. S., Lai, M.-C., Ko, T.-P., and Chen, Y. (2015) Structure and mechanism of an antibiotics-synthesizing 3-hydroxykynurenine Cmethyltransferase. Sci. Rep. 5, 10100.

(13) Dai, Y.-N., Zhou, K., Cao, D.-D., Jiang, Y.-L., Meng, F., Chi, C.-B., Ren, Y.-M., Chen, Y., and Zhou, C.-Z. (2014) Crystal structures and catalytic mechanism of the C-methyltransferase Coq5 provide insights into a key step of the yeast coenzyme $Q$ synthesis pathway. Acta Crystallogr. D. Biol. Crystallogr. 70, 2085-92.

(14) Koch, M., Lemke, R., Heise, K.-P., and Mock, H.-P. (2002) Characterization of $\gamma$-tocopherol methyltransferases from Capsicum annuum $\mathrm{L}$ and Arabidopsis thaliana. Eur. J. Biochem. 270, 84-92.

(15) Wada, K., Yamaguchi, H., Harada, J., Niimi, K., Osumi, S., Saga, Y., Oh-oka, H., Tamiaki, H., and Fukuyama, K. (2006) Crystal structures of BchU, a methyltransferase involved in bacteriochlorophyll $c$ biosynthesis, and its complex with S- adenosylhomocysteine: implications for reaction mechanism. J. Mol. Biol. 36o, 839-849.

(16) Steffensky, M., Mühlenweg, A., Wang, Z., Li, S., Mu, A., and Heide, L. (2000) Identification of the novobiocin biosynthetic gene cluster of Streptomyces spheroides. Antimicrob Agents Chemother. 44, 1214-1222.

(17) Pacholec, M., Tao, J., and Walsh, C. T. (2005) CouO and NovO: C-methyltransferases for tailoring the aminocoumarin scaffold in coumermycin and novobiocin antibiotic biosynthesis. Biochemistry 44, 14969-76.

(18) Stecher, H., Tengg, M., Ueberbacher, B. J., Remler, P., Schwab, H., Griengl, H., and Gruber-Khadjawi, M. (2009) Biocatalytic Friedel-Crafts alkylation using nonnatural cofactors. Angew. Chem. Int. Ed. Engl. 48, 95468.

(19) Schubert, H. L., Blumenthal, R. M., and Cheng, X. (2003) Many paths to methyltransfer: A chronicle of convergence. Trends Biochem. Sci. 28, 329-335.

(20) Martin, J. L., and McMillan, F. M. (2002) SAM (dependent) I AM: the S-adenosylmethioninedependent methyltransferase fold. Curr. Opin. Struct. Biol. 12, 783-793.

(21) Tengg, M., Stecher, H., Remler, P., Eiteljörg, I., Schwab, H., and Gruber-Khadjawi, M. (2012) Molecular characterization of the C-methyltransferase NovO of Streptomyces spheroides, a valuable enzyme for performing Friedel-Crafts alkylation. J. Mol. Catal. B Enzym. 84, 2-8.

(22) Kim, J., Xiao, H., Bonanno, J. B., Kalyanaraman, C., Brown, S., Tang, X., Al-Obaidi, N. F., Patskovsky, Y., Babbitt, P. C., Jacobson, M. P., Lee, Y.-S., and Almo, S. C. (2013) Structure-guided discovery of the metabolite carboxy-SAM that modulates tRNA function. Nature 498, 123-6.

(23) Kim, J., Xiao, H., Koh, J., Wang, Y., Bonanno, J. B., Thomas, K., Babbitt, P. C., Brown, S., Lee, Y. S., and Almo, S. C. (2015) Determinants of the $\mathrm{CmoB}$ carboxymethyl transferase utilized for selective tRNA wobble modification. Nucleic Acids Res. 43, 4602-4613. (24) Lim, K., Zhang, H., Tempczyk, A., Bonander, N., Toedt, J., Howard, A., Eisenstein, E., and Herzberg, O. (2001) Crystal structure of $\mathrm{YecO}$ from Haemophilus influenzae (HIo319) reveals a methyltransferase fold and a bound S-adenosylhomocysteine. Proteins 45, 397-407. (25) Iffland, A., Tafelmeyer, P., Saudan, C., and Johnsson, K. (2000) Directed Molecular Evolution of Cytochrome c Peroxidase †. Biochemistry 39, 1079010798.

(26) Joce, C., Caryl, J., Stockley, P. G., Warriner, S., and Nelson, A. (2009) Identification of stable Sadenosylmethionine (SAM) analogues derivatised with bioorthogonal tags: effect of ligands on the affinity of the E. coli methionine repressor, MetJ, for its operator DNA. Org. Biomol. Chem. 7, 635-638.

(27) Couture, J. F., Hauk, G., Thompson, M. J., Blackburn, G. M., and Trievel, R. C. (2006) Catalytic 
roles for carbon-oxygen hydrogen bonding in SET domain lysine methyltransferases. J. Biol. Chem. 281, 19280-19287.

(28) Inc., C. C. G. (2015) Molecular Operating Environment (MOE). 1010 Sherbooke St. West, Suite \#910, Montreal, QC, Canada, $\mathrm{H}_{3} \mathrm{~A}_{2} \mathrm{R}_{7}$.

(29) Hegazi, M. F., Borchardt, R. T., and Schowen, R. L. (1979) .alpha.-Deuterium and carbon-13 isotope effects for methyl transfer catalyzed by catechol Omethyltransferase. SN2-like transition state. J. Am. Chem. Soc. 101, 4359-4365.

(30) Hegazi, M., Borchardt, R., and Schowen, R. (1979) $\alpha$-Deuterium and carbon-13 isotope effects for methyl transfer catalyzed by catechol O-methyltransferase. SN2-like transition state. J. Am. Chem. Soc. 101, 43594365.
(31) Mihel, I., Knipe, J. O., Coward, J. K., and Schowen, R. L. (1979) $\alpha$-Deuterium isotope effects and transitionstate structure in an intramolecular model system for methyl-transfer enzymes. J. Am. Chem. Soc. 101, 43494351.

(32) Gray, C. H., Coward, J. K., Schowen, K. B., and Schowen, R. L. (1979) $\alpha$-Deuterium and carbon-13 isotope effects for a simple, intermolecular sulfur-tooxygen methyl-transfer reaction. Transition-state structures and isotope effects in transmethylation and transalkylation. J. Am. Chem. Soc. 101, 4351-4358.

(33) Westaway, K. C. (2006) Using kinetic isotope effects to determine the structure of the transition states of SN2 reactions. Adv. Phys. Org. Chem. 41, 217-273. 


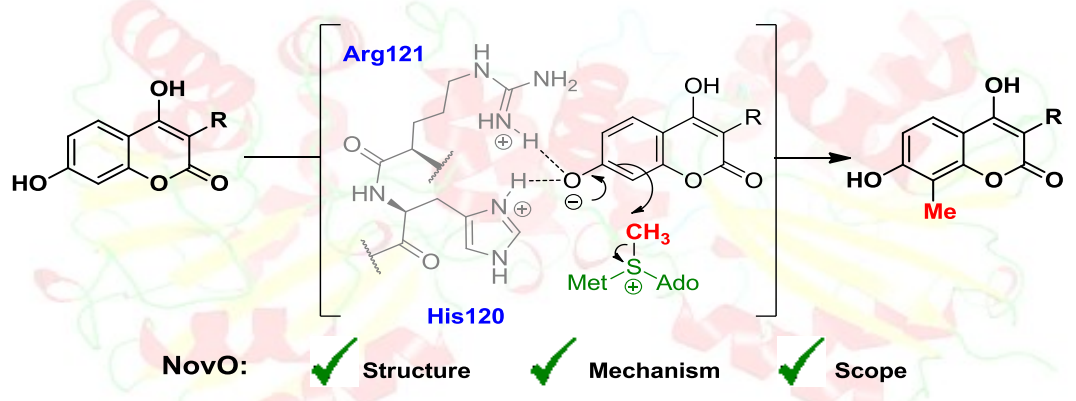




\title{
Structural and Functional Basis of C-Methylation of Coumarin Scaffolds by NovO
}

\section{Supplementary Information}

\author{
Joanna C. Sadler, ${ }^{1,3}$ Chun-wa H. Chung, ${ }^{2}$ Julie E. Mosley, ${ }^{2}$ Glenn A. Burley, ${ }^{1 *}$ Luke D. \\ Humphreys ${ }^{3,4^{*}}$
}

${ }^{1}$ WestCHEM, Department of Pure and Applied Chemistry, Thomas Graham Building, University of Strathclyde, 295 Cathedral Street, Glasgow G1 1XL, U.K., ${ }^{2}$ Computational \& Structural Chemistry, GlaxoSmithKline, Gunnels Wood Road, Stevenage, Hertfordshire, SG1 2NY, ${ }^{3}$ Global API Chemistry, GlaxoSmithKline, Gunnels Wood Road, Stevenage, Hertfordshire, SG1 2NY, U.K. ${ }^{4}$ Gilead Alberta ULC, 1021 Hayter Road NW, Edmonton, AB T6S 1A1, Canada.

\section{Contents}

1 Sequence alignment of small molecule aromatic C-MTs and BLAST results ..............................2

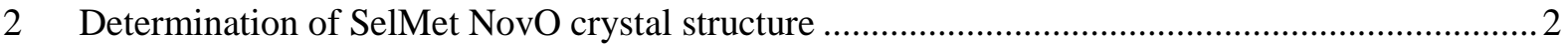

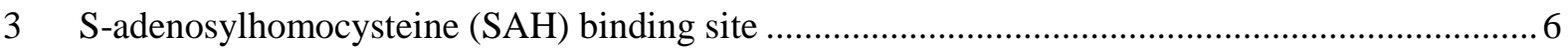

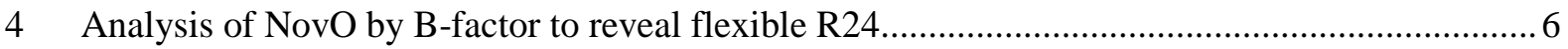

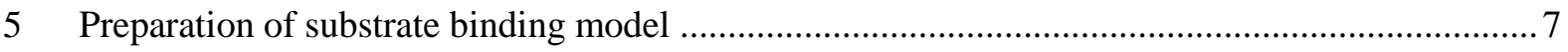

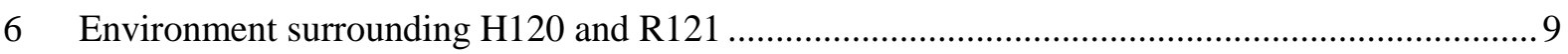

7 Analysis of substrate analogues with variation at the 7-position .............................................. 10

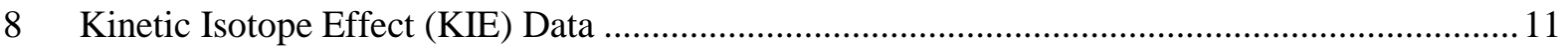

9 Comparative analysis of homology model of NovO with the X-ray crystal structure of NovO and SAH

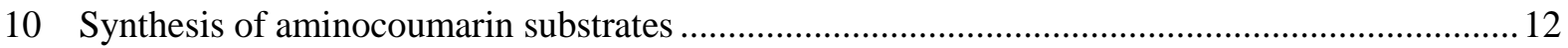

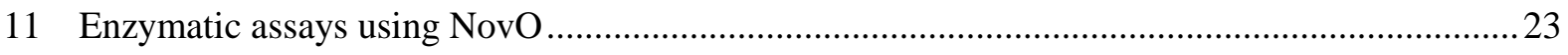

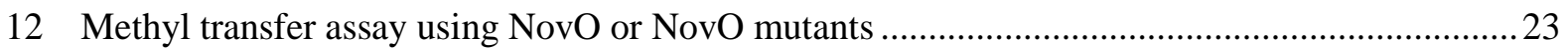

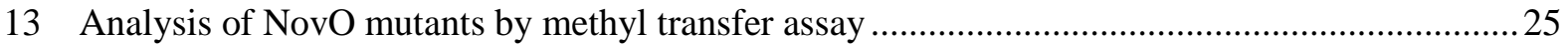

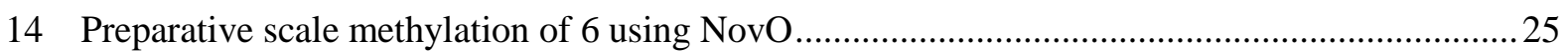

15 General procedure for the preparation of NovO mutants by Site-Directed Mutagenesis .............26

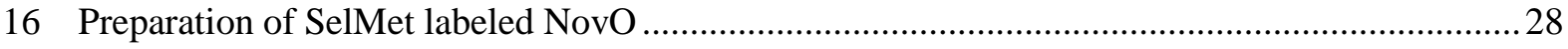

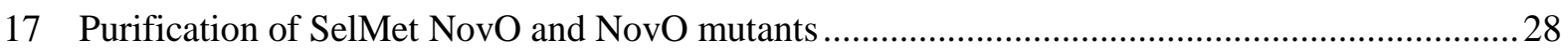

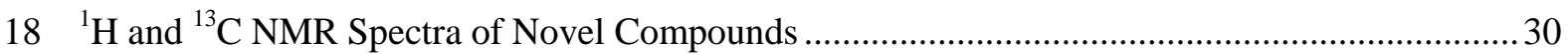

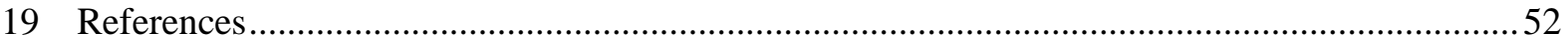




\section{Sequence alignment of small molecule aromatic C-MTs and BLAST results}

Sequence alignment carried out using MOE software (Figure S1). ${ }^{1}$ In addition to analyses of other small molecule aromatic C-MTs, the top two hits from a Basic Local Alignment Search Tool (BLAST) are shown in Figure S1 (entries 10 and 11). UniProt identifiers A0A017T191_9DELT and NAL212_0227).

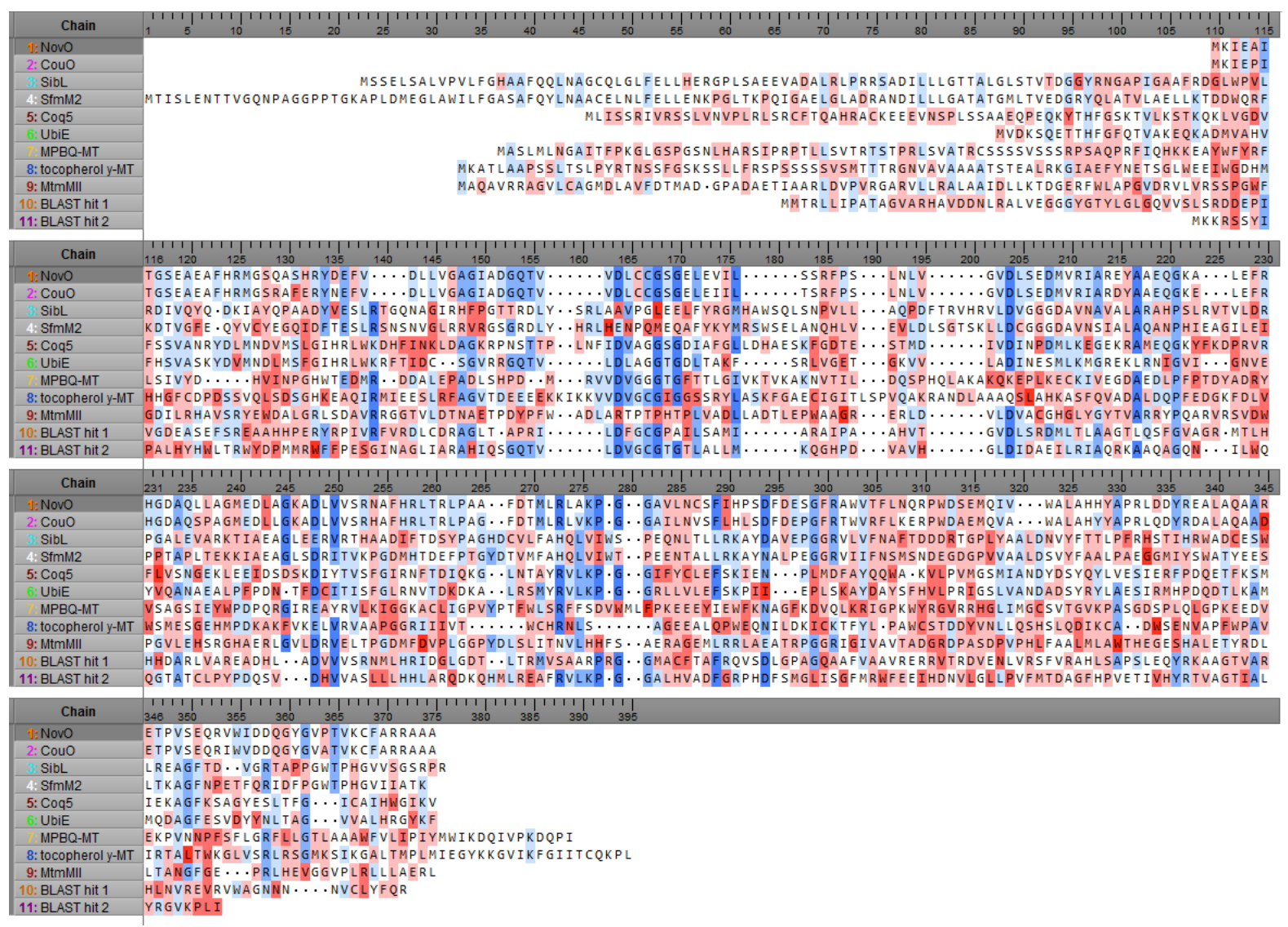

Figure S1. Sequence alignment of small molecule aromatic C-MTs (entries 2-9) and top two BLAST hits for NovO in UniProt (entries 10-11). Results coloured according to amino acid similarity (blue: high; red: low).

\section{Determination of SelMet NovO crystal structure}

\section{Crystallisation of NovO with SAH}

C-terminal His-tagged NovO 1-230 from Streptomyces spheroides at $12 \mathrm{mg} / \mathrm{mL}$ in $0.1 \mathrm{M}$ trisaminomethane hydrochloride (Tris- $\mathrm{HCl}$ ) $\mathrm{pH} 8.0,150 \mathrm{mM} \mathrm{NaCl}$ was incubated with $2 \mathrm{mM} S$ adenosylhomocysteine (SAH) and left on ice for 30 minutes. Microseeding was used to obtain reproducible SelMet crystals of good quality. Crystallisation was achieved using drops containing $120 \mathrm{~nL}$ protein, $120 \mathrm{~nL}$ well solution $(0.1 \mathrm{M}$ 2-[N-morpholino]ethanesulfonic acid, [MES] $\mathrm{pH} 6.5$, $20 \% \mathrm{w} / \mathrm{v}$ poly[ethylene glycol] [PEG]-4K, $0.6 \mathrm{M} \mathrm{NaCl}$ ) and $60 \mathrm{~nL}$ seed solution in sitting drop 
Medical Research Council (MRC) plates at $20{ }^{\circ} \mathrm{C}$. Crystals grew over a period of 18 days and were harvested into mother liquor supplemented with $15 \%$ glycerol before flash freezing.

\section{Data collection, Structure solution and refinement}

X-ray diffraction data were collected at $100 \mathrm{~K}$ at the European Synchrotron Radiation Facility (ESRF, beamline ID23.1). Selenomethionine (SelMet) datasets were collected at the SelMet absorption peak $\left(0.97916 \AA \mathrm{f}^{\prime}=-7.82, \mathrm{f}^{\prime \prime}=4.98\right), 1800$ images taken with 0.2 degree oscillations to give 360 degrees in total. The data were processed and scaled using autoPROC. ${ }^{2}$ As there was no known structure of NovO the structure was solved by Single-wavelength Anomalous Dispersion (SAD). AUTOSHARP ${ }^{3}$ and $\mathrm{CCP}^{4}$ were used for heavy atom detection, refinement, phasing and density modification. Two molecules of a homodimer were present within the asymmetric unit of the $\mathrm{P} 2{ }_{1}$ crystal, with a solvent fraction of $45.3 \%$. All 12 SelMet sites were found. The autobuilt coordinates provided a good starting point for manual rebuilding of NovO using COOT. ${ }^{5}$ Structure refinement was carried out using AUTOBUSTER ${ }^{6}$ utilising TLS refinement and automatic water fitting, with additional round of refinement and modelling were achieved using COOT and refmac ${ }^{7}$ with TLS refinement. The S-adenosylhomocysteine (SAH) was present in the active site of both chains (Figures S2-S3). MOGUL and MOLPROBITY were used to confirm the quality of the refined structure. Refinement statistics of the $1.9 \AA$ X-ray homodimeric complex of NovO with SAH are in Table S1. PDB accession code: 5MGZ.

\section{Crystallography Omit Maps}

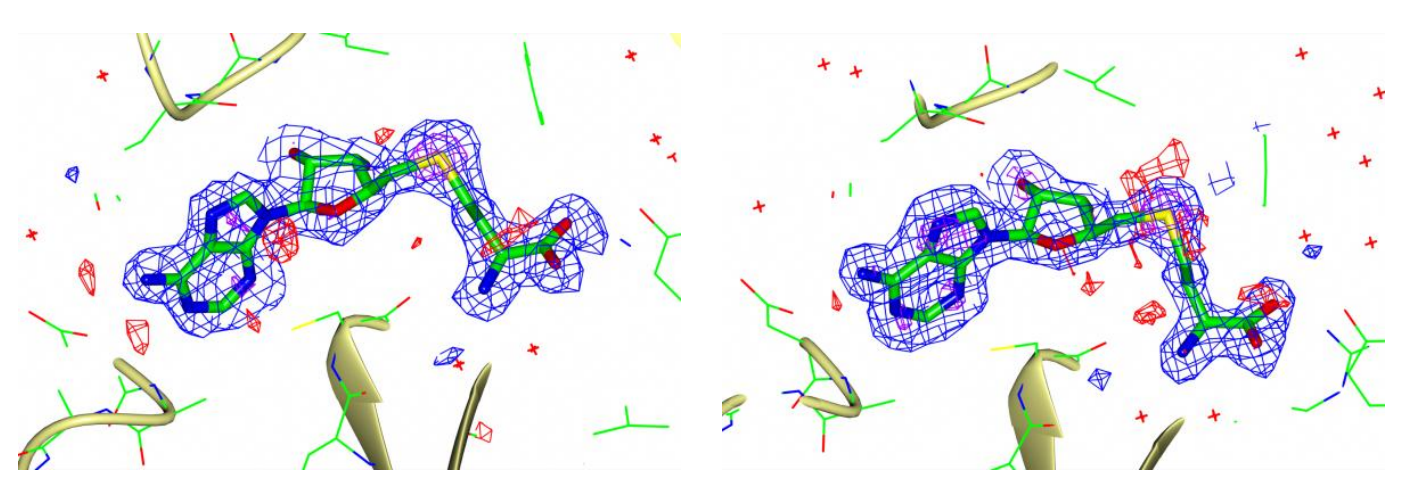

Chain A

Chain B

Figure S2. Omit (Fo-Fc) map of $\mathrm{SAH}$ in the active site contoured at \pm 3 sigma (blue/red), \pm 9 sigma (purple/orange). Conformation for the $\mathrm{SAH}$ is well defined. 


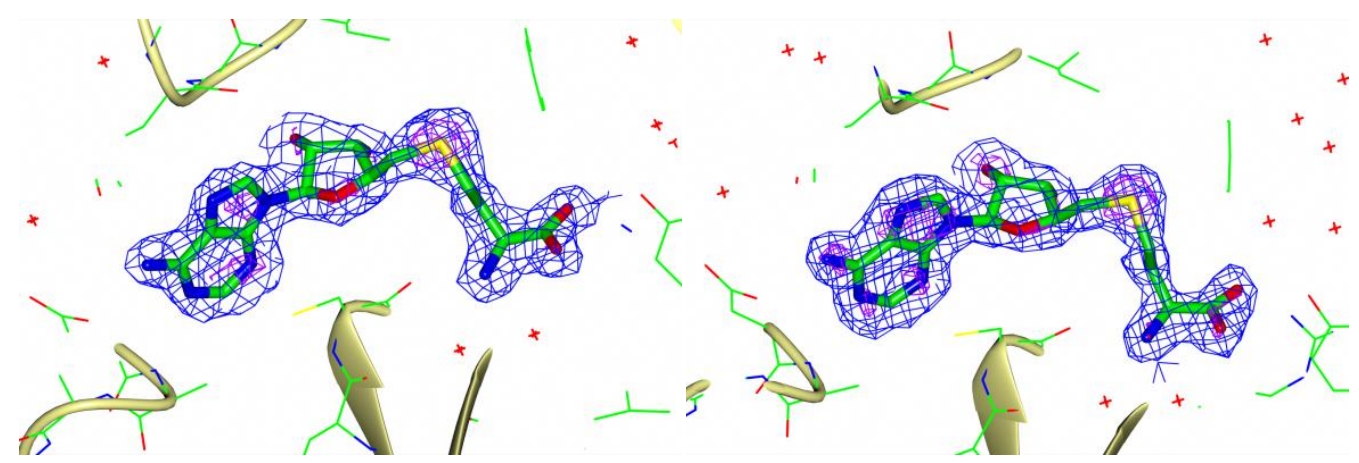

Chain A

Chain B

Figure S3. Omit $(2 \mathrm{Fo}-\mathrm{Fc})$ map of SAH in the active site contoured at +1 sigma (blue), +3 sigma (purple). Conformation for the SAH is well defined. 
Table S1: Data collection and refinement statistics

\begin{tabular}{|c|c|}
\hline (collection on a single crystal) & NovO/SAH \\
\hline \multicolumn{2}{|l|}{ Data collection } \\
\hline Space group & $\mathrm{P} 2_{1}$ \\
\hline \multicolumn{2}{|l|}{ Cell dimensions } \\
\hline$a, b, c(\AA)$ & $43.724,66.970,80.563$ \\
\hline$\alpha, \beta, \gamma\left(^{\circ}\right)$ & $90.000,92.99,90.000$ \\
\hline Resolution $(\AA)$ & $66.97-1.90(2.00-1.90)$ \\
\hline$R_{\text {merge }}$ & $0.056(0.080)$ \\
\hline$I / \sigma I$ & $22.6(10.6)$ \\
\hline $\operatorname{Mn}(\mathrm{I}) \mathrm{CC}(1 / 2)$ & $0.997(0.988)$ \\
\hline Anomalous completeness (\%) & $88.6(53.2)$ \\
\hline Completeness $(\%)$ & $90.7(58.0)$ \\
\hline Anomalous multiplicity & $3.0(1.8)$ \\
\hline Redundancy & $6.0(3.8)$ \\
\hline Wilson B-factor & 17.79 \\
\hline \multicolumn{2}{|l|}{ Refinement } \\
\hline Resolution $(\AA)$ & $66.97-1.90$ \\
\hline No. reflections & 201009 (11593) \\
\hline No. uniq reflections & $33239(3062)$ \\
\hline$R_{\text {work } /} R_{\text {free }}$ & $0.178 / 0.202$ \\
\hline No. atoms & 4330 \\
\hline Protein & 3618 \\
\hline Ligand/Other & $52 / 10$ \\
\hline Water & 650 \\
\hline \multicolumn{2}{|l|}{ Ramachandran } \\
\hline Favored $(\%)$ & 97 \\
\hline Allowed (\%) & 3 \\
\hline Outliers (\%) & 0.22 \\
\hline Rotamer outliers & 0.54 \\
\hline \multicolumn{2}{|l|}{ B-factors } \\
\hline Protein & 23.24 \\
\hline Ligand/Other & $11.13 / 26.50$ \\
\hline Water & 31.68 \\
\hline \multicolumn{2}{|l|}{ R.m.s deviations } \\
\hline Bond lengths $(\AA)$ & 0.005 \\
\hline Bond angles $\left({ }^{\circ}\right)$ & 1.032 \\
\hline
\end{tabular}

*Highest resolution shell is shown in parenthesis 


\section{S-adenosylhomocysteine (SAH) binding site}

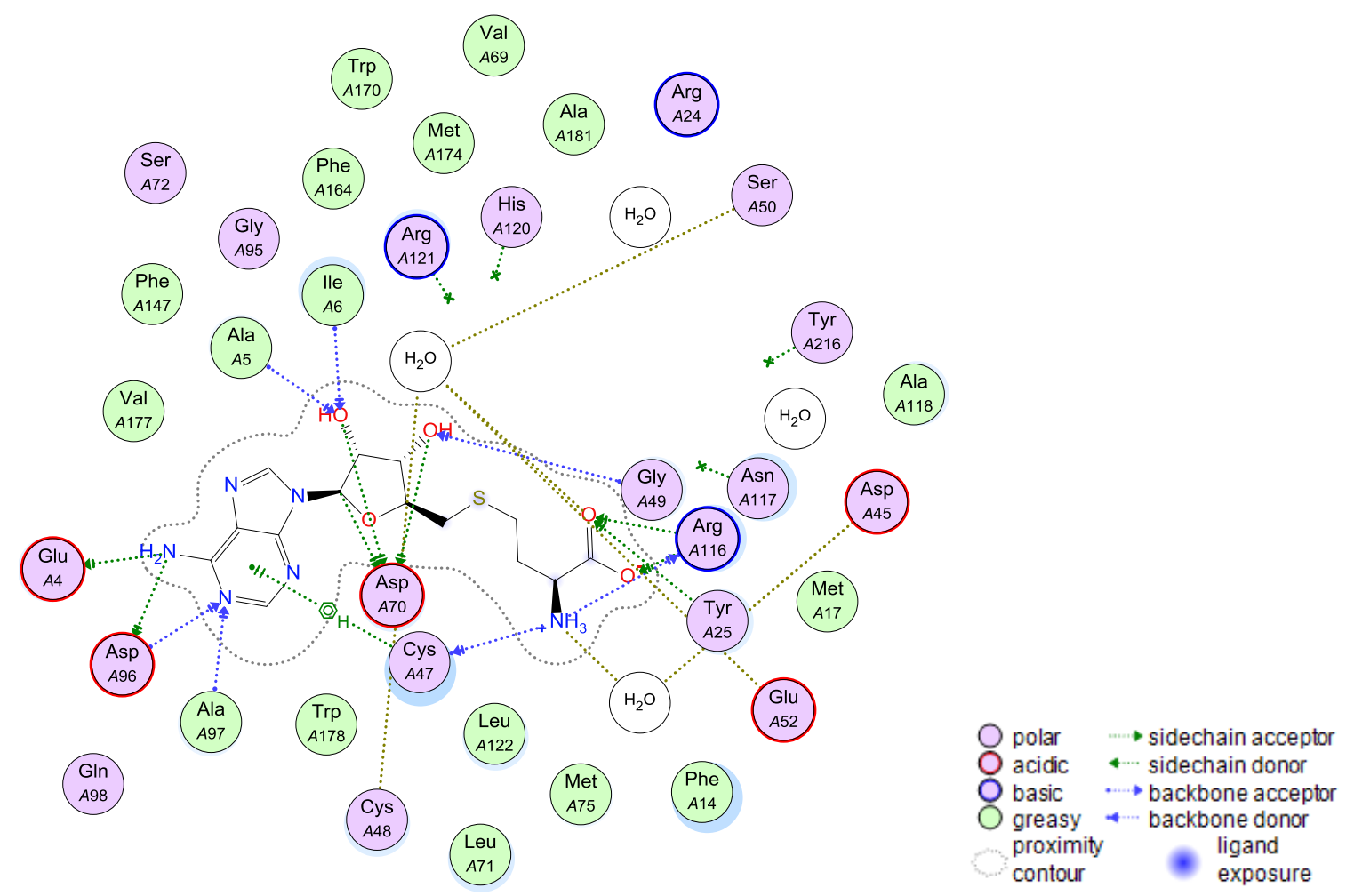

Figure S4. Interaction diagram of SAH binding site generated using Molecular Operating Environment ${ }^{1}$ software.

\section{Analysis of NovO by B-factor to reveal flexible R24}
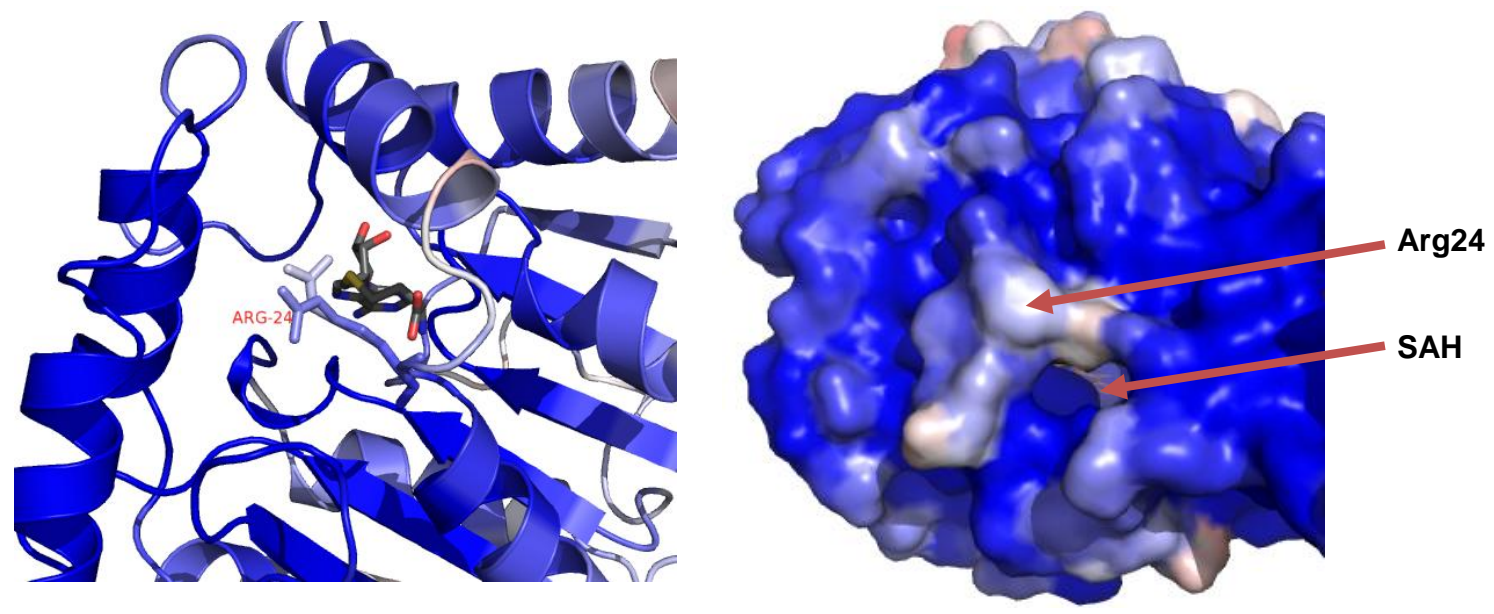

Figure S5. (a) Analysis of R24 by B-factor. Two conformations were visible in the X-ray crystal structure. SAH is shown in grey. (b) Surface of NovO (Chain A only) coloured by B-factor. Colour scale: Blue (low) - white - red (high). 


\section{Preparation of substrate binding model}

The substrate binding model was generated using Molecular Operating Environment (MOE) ${ }^{1}$ software. The X-ray crystal structure was prepared using the Stucture Preparation command followed by optimisation of the H-bonding network using the Protonate $3 \mathrm{D}^{8}(\mathrm{pH}$ 7) command, and finally calculation of partial charges. Putative binding sites in NovO were identified using the Site Finder application. ${ }^{9,10}$ The default settings for these procedures were used in all cases and SAH was retained in the crystal structure throughout the study (Table S1).

\begin{tabular}{ccc} 
Site & PLB & Residues \\
\hline $\mathbf{1}$ & 3.6 & $\begin{array}{l}\text { I6, F14, M17, G18, Q20, A21, H23, R24, Y25, R116, N117, A118, H120, R121, } \\
\text { F127, F164, Q167, R168, P169, W170, D171, M174, V177, W178, A181, Y216. }\end{array}$ \\
\hline $\mathbf{2}$ & 1.05 & $\begin{array}{c}\text { M1, K2, I3, E4, A6, I6, T7, E10, A11, H120, R121, I176, V177, L180, A181, W184, } \\
\text { A185 }\end{array}$ \\
\hline $\mathbf{3}$ & 1.05 & E155, R159 (Chain 1), M1, K2, I3, E4, A6, I6, T7, E10, A11, H120, R121, I176, \\
& & V177, L180, A181, W184, A185 (Chain 2) \\
\hline $\mathbf{4}$ & 0.77 & K2, F119, H120, L122, T123, R124, L125, P126, Y184, A185, P186, D190, E193, \\
\hline $\mathbf{5}$ & 0.13 & K2, L122, T123, R124, L125, P126, Y184, A185, P186, D190, E193, A194
\end{tabular}

Table S1. Top 5 ligand binding sites identified by the Site Finder application using MOE. PLB: propensity for ligand binding. ${ }^{10}$

The putative binding sites were further analysed manually based on their proximity to the SAH present in the crystal structure. Site 1 was found to be in a suitable location relative to SAH (Figure S5).

1.

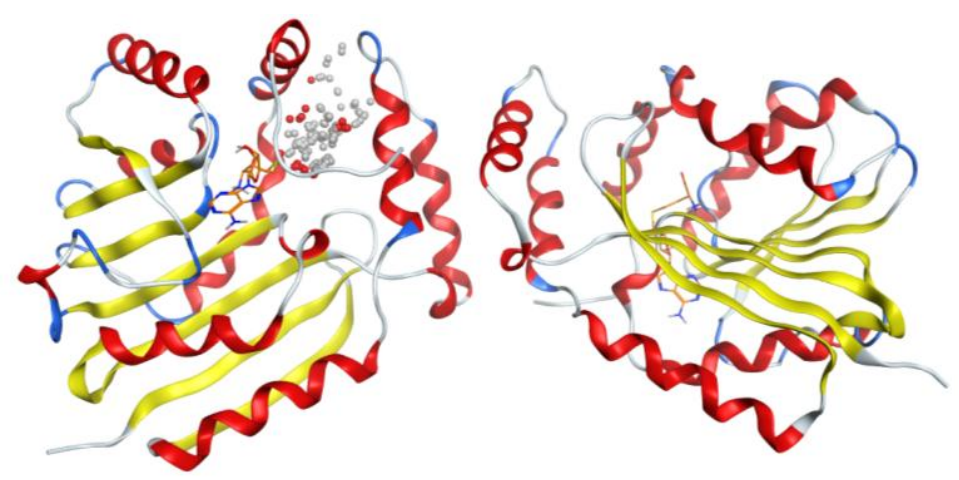


2.

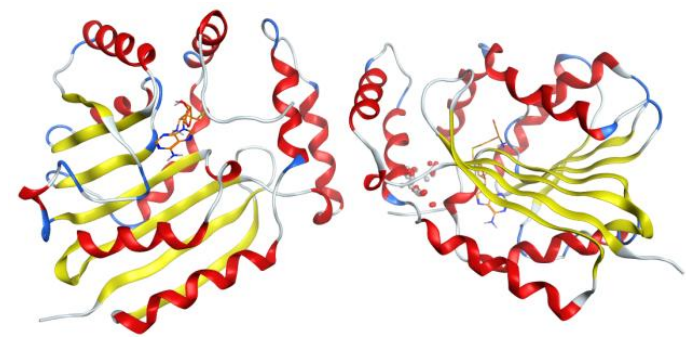

4.

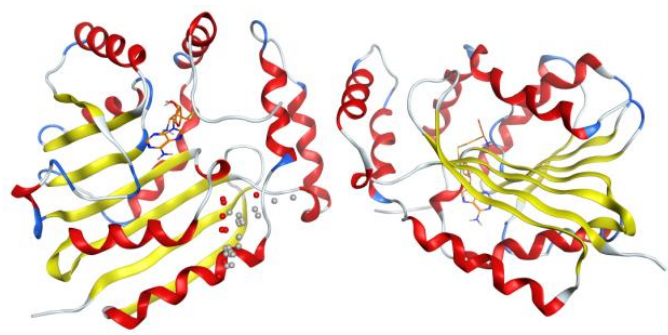

3.

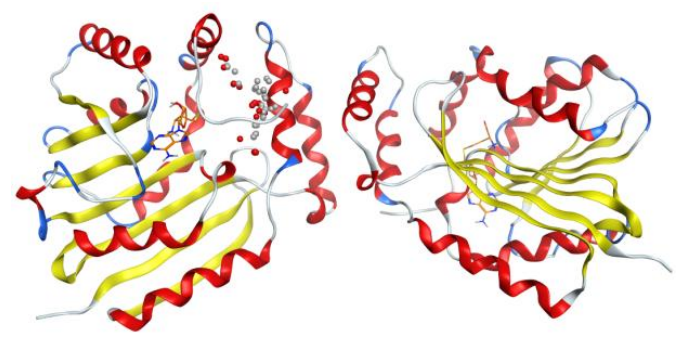

5.

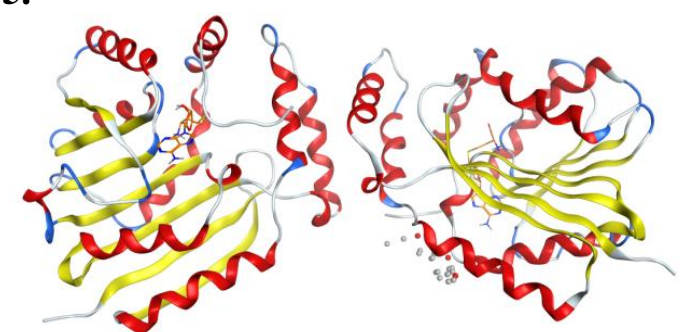

Figure S5. Top 5 results from Site Finder search using MOE software relative to the position of SAH, which is shown in orange. Dummy atoms are represented as white and red spheres.

The Dock application was employed to model substrate $\mathbf{6}$ into the putative binding site. The top 5 hits were analysed manually and the final model selected based on proximity of the coumarin C- 8 to the sulfur centre of SAH and the potential energy of the substrate, giving rise to the final model shown in Figure S6, in which the coumarin ring was adopted a planar conformation. When a methyl group was modeled onto the sulfur centre of SAH to model the naturally occurring, S- diastereomer of SAM, ${ }^{11}$ the pendant methyl group was $2.59 \AA$ from C-8, at an angle of $109^{\circ}$ from the coumarin scaffold.

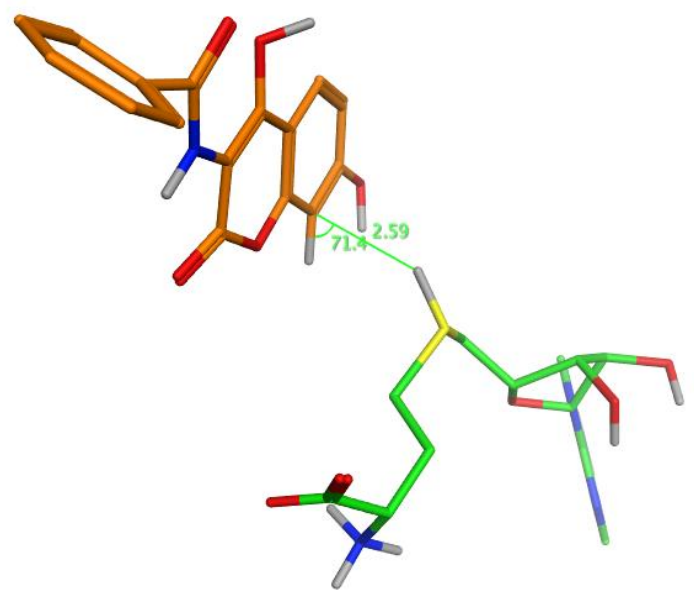

Figure S6. Conformation of substrate 6 in substrate binding model distance between coumarin C-8 and the SAM methyl group. 


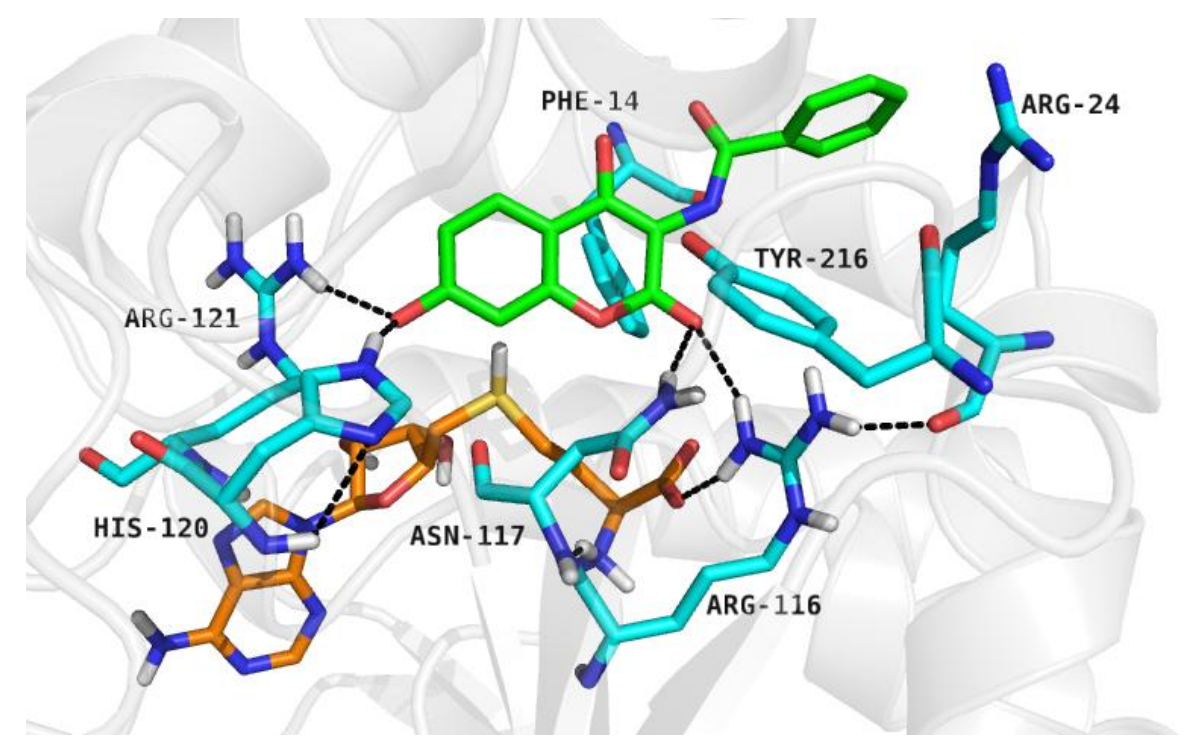

Figure S7. Substrate 4a (shown in green) docking model with SAM (shown in orange) modelled into the active site of NovO by addition of a methyl group and subsequent minimisation of the sulfonium center. The stereochemistry $(-S)$ at the sulfonium center corresponds to the natural diastereoisomer of SAM.

\section{Environment surrounding H120 and R121}

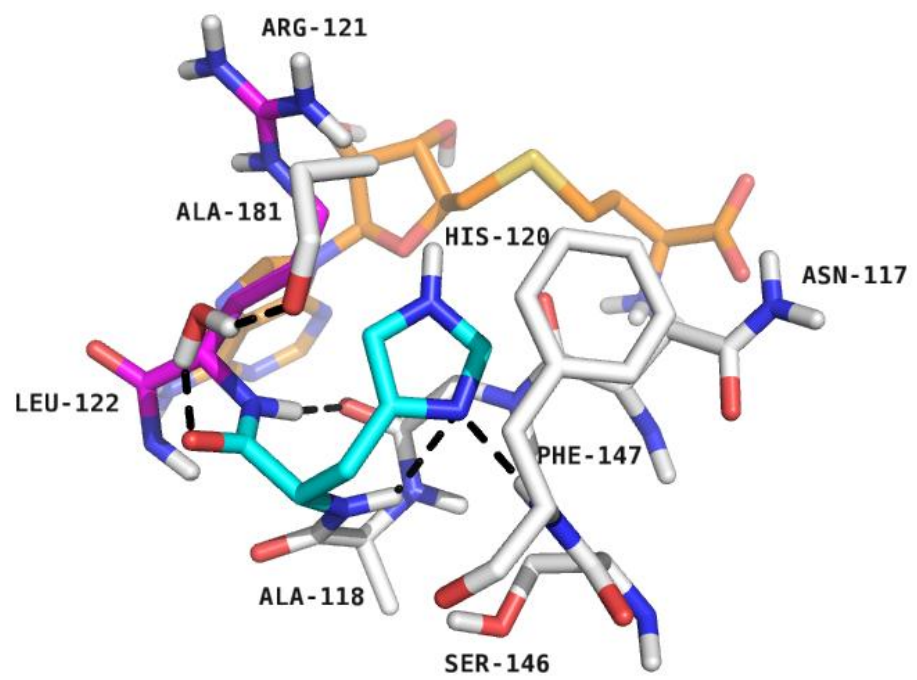

Figure S8. H-bonding network of the NovO active site residues H120. 


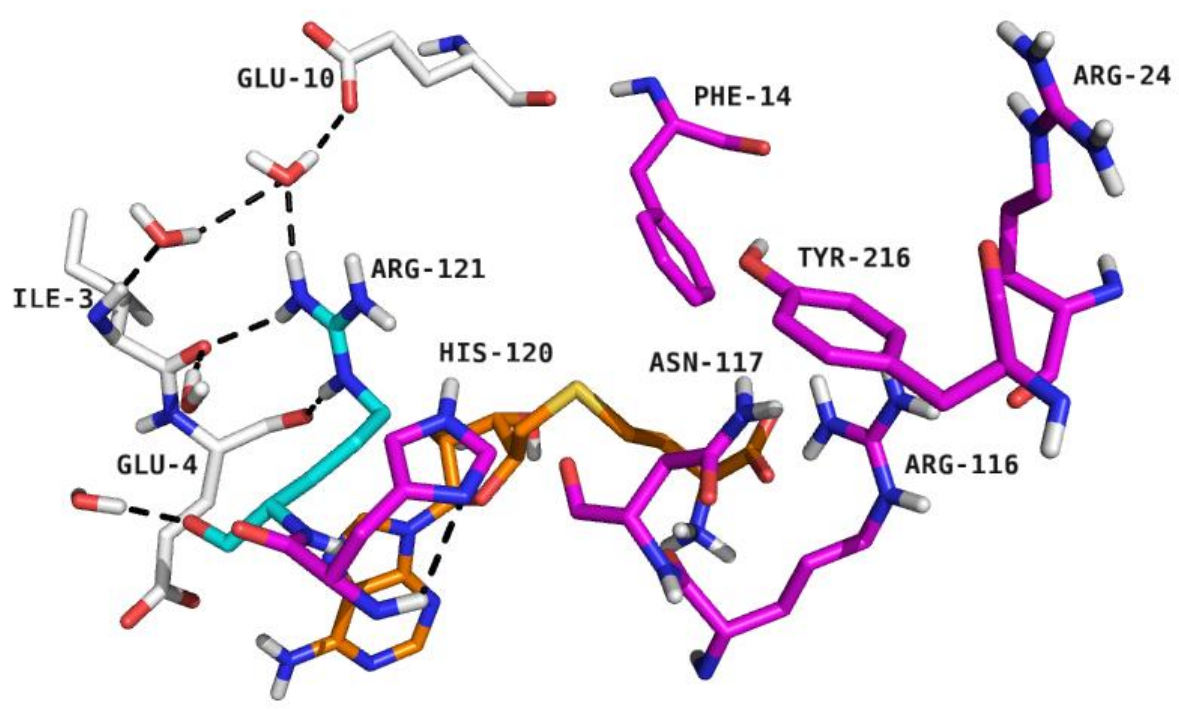

Figure S9. H-bonding network of the NovO active site residues R121.

\section{Analysis of substrate analogues with variation at the 7-position}

A suite of analogues of substrate $\mathbf{6}$ were prepared (see Scheme S2) and was used to the explore the enzymatic activity of NovO (see Section 12). All substrate analogues were inactive with NovO WT (Scheme S1).

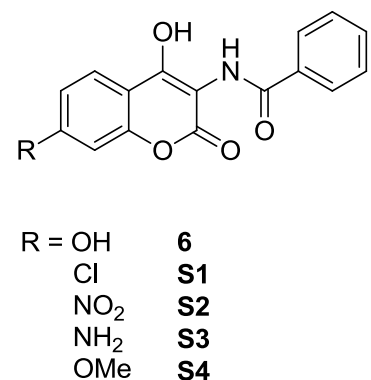

(a)<smiles>[R]c1ccc2c(O)c(NC(=O)c3ccccc3)c(=O)oc2c1[X]</smiles>

$\begin{array}{ccc}\mathrm{R}=\mathrm{OH} & \mathbf{4 a} & 98 \% \\ \mathrm{Cl} & \mathbf{S 5} & 0 \% \\ \mathrm{NO}_{2} & \mathbf{S 6} & 0 \% \\ \mathrm{NH}_{2} & \mathbf{S 7} & 0 \% \\ \mathrm{OMe} & \mathbf{S 8} & 0 \%\end{array}$

Scheme S1. Methylation of aminocoumarin substrates 6 and S1-S4 to products 4a and S5-S8 by NovO WT. Reagents and conditions: (a) NovO, SAM, bovine serum albumin, $50 \mathrm{mM}$ sodium phosphate buffer $\mathrm{pH}$ 6.5, $35^{\circ} \mathrm{C}, 24 \mathrm{~h}$. See Section 12. 


\section{Kinetic Isotope Effect (KIE) Data}<smiles>O=C(Nc1c(O)c2ccc(O)cc2oc1=O)c1ccccc1</smiles>

(a)<smiles>[R]c1c(O)ccc2c(O)c(NC(=O)c3ccccc3)c(=O)oc12</smiles>

$\mathrm{R}=\mathrm{Me},{ }^{13} \mathrm{CH}_{3}, \mathrm{CD}_{3}$

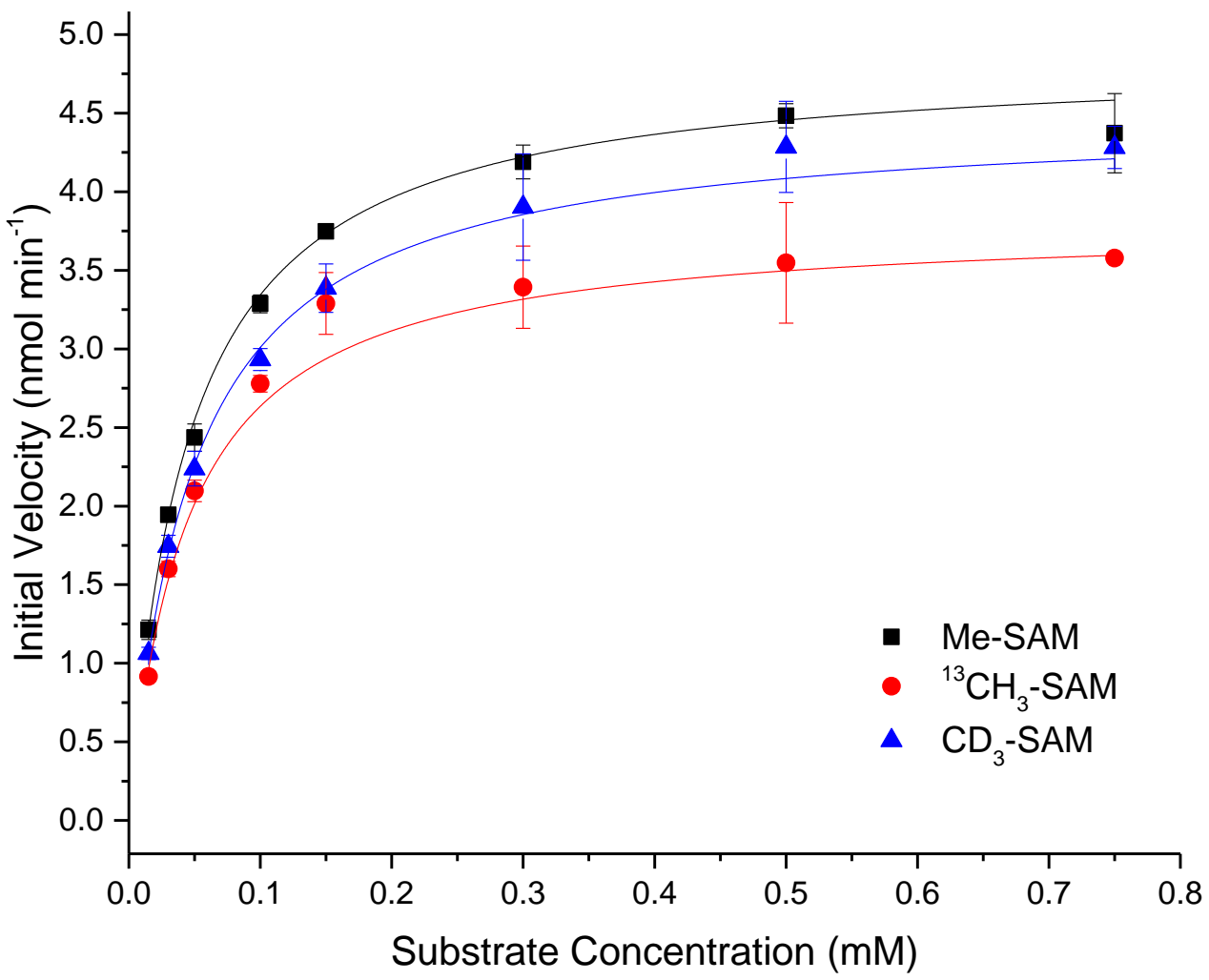

Figure S10. Michealis Menten curves for KIE data for NovO WT. The data set was collected accorded to the procedure outlined in Section 11 using purified NovO and SalL. The data set was processed using Origin ${ }^{12}$ software, using the Michealis Menton Nonlinear Curve Fit function. Reagents and conditions: (a) methionine, $(2 R, 3 R, 4 S, 5 S)-2-(6-a m i n o-9 H-$ purin-9-yl)-5-(chloromethyl)tetrahydrofuran-3,4-diol (S35), SalL ${ }^{13,14}$, potassium phophate buffer (50 mM, pH 6.5), $37{ }^{\circ} \mathrm{C}, 2$ hours, then NovO. See Section 11. 


\section{Comparative analysis of homology model of NovO with the X-ray crystal structure of NovO and SAH}

A homology model of the active site of NovO, based on the SAM-dependent MT from Pyrococcus horikoshii OT3 (PDB code 1WZN) has previously been disclosed by Tengg et al. ${ }^{15}$ The positions of putative active site residues H15 and Y184 in this model were compared to their positions in the crystal structure of $\mathrm{NovO}$ (Figure $\mathbf{S}$ ).

(a)

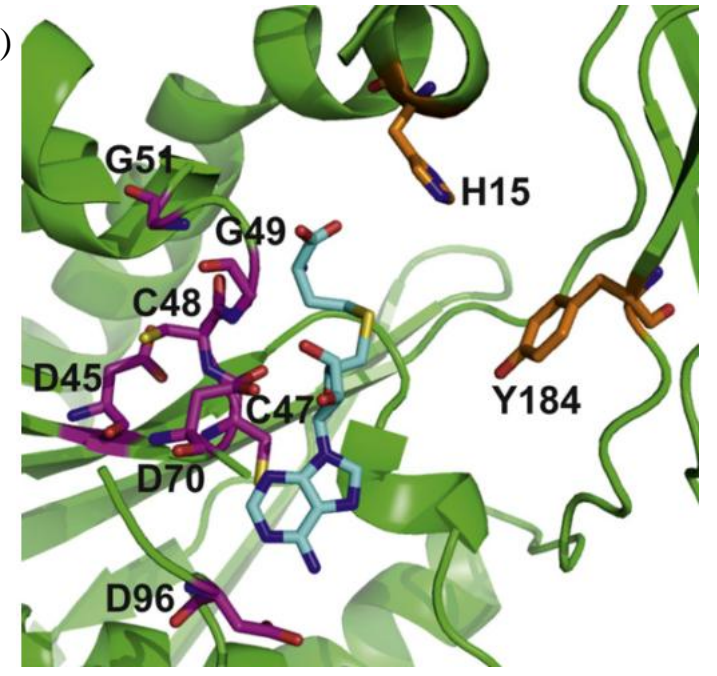

(b)

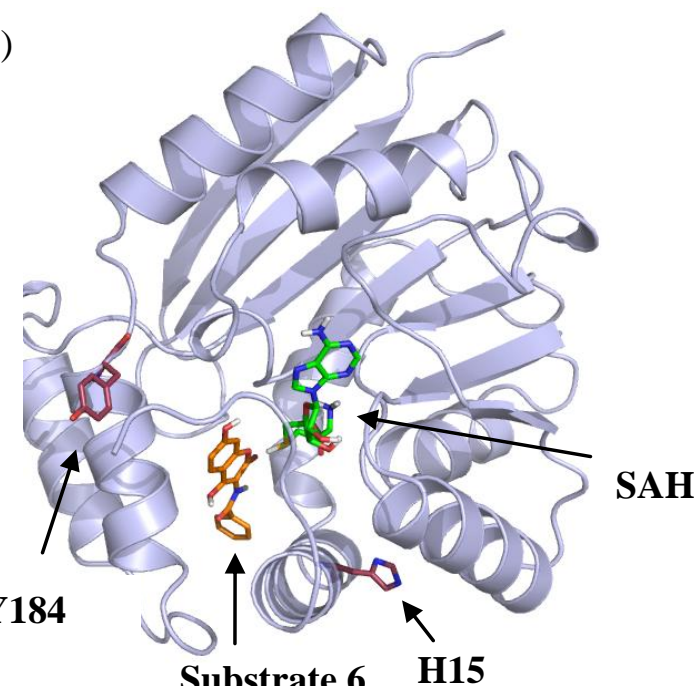

Figure S11. (a) Homology model of NovO with bound SAH based on the SAM-dependent MT derived from Pyrococcus horikoshii OT3 (PDB code 1WZN) as proposed by Tengg et al. ${ }^{15}$ Model generated using Yasara software. ${ }^{10}$ (b) Position of H15 and Y184 in NovO relative to the substrate and SAH according to the substrate binding model generated from our crystal structure of NovO.

\section{Synthesis of aminocoumarin substrates}

\section{General experimental techniques and procedures}

All reagents and solvents were used as supplied from commercial sources and used without further purification unless otherwise stated. Solvents used in the preparation of substrates 7-10 were all High Pressure Liquid Chromatography (HPLC) grade and were used without further purification unless otherwise stated. Nuclear Magnetic Resonance (NMR) spectroscopy was carried out using a Bruker 400 UltraShield $^{\mathrm{TM}}$ B-ACS 60 spectrometer. All chemical shifts $(\delta)$ were referenced to the deuterium lock and are reported in parts per million (ppm) and coupling constants are quoted in hertz $(\mathrm{Hz})$. Abbreviations for splitting patterns are br. (broad), app. (apparent), s (singlet), d (doublet), $t$ (triplet), $\mathrm{q}$ (quartet), $\mathrm{m}$ (multiplet) and dd (doublet of doublets). All NMR data was processed using Advanced Chemistry Development Inc. (ACD/Labs) 12.0 software. ${ }^{16}$ Proton and carbon chemical shifts were assigned using proton $\left({ }^{1} \mathrm{H}\right)$, carbon $\left({ }^{13} \mathrm{C}\right)$, Heteronuclear Single Quantum Coherence (HSQC), Heteronuclear Multiple-Bond Correlation Spectroscopy (HMBC), Correlation Spectroscopy (COSY) 
and Distortionless Enhancement of Polarisation Transfer (DEPT). Liquid Chromatography coupled Mass Spectrometry (LC-MS) was carried out on an Agilent 1100 HPLC instrument in conjunction with a Waters Micromass ZQ 2000/4000 mass detector. Electrospray ionization (ESI) was used in all cases. HPLC was carried out on an Agilent 1100 series instrument. Infra-Red (IR) data was collected on a Perkin Elmer Spectrum One FTIR spectrometer and the data was processed using Spectrum One software. Only major absorbances are reported. Melting points of solids were obtained using a Stuart automatic SMP40 melting point machine or a SRS OptiMelt automated melting point system.

\section{Synthesis of aminocoumarin substrates}

Aminocoumarin substrates and variants based on substitution at the 7- position were synthesised by a modified route outlined by Gruber et al. (Scheme S2). ${ }^{17}$

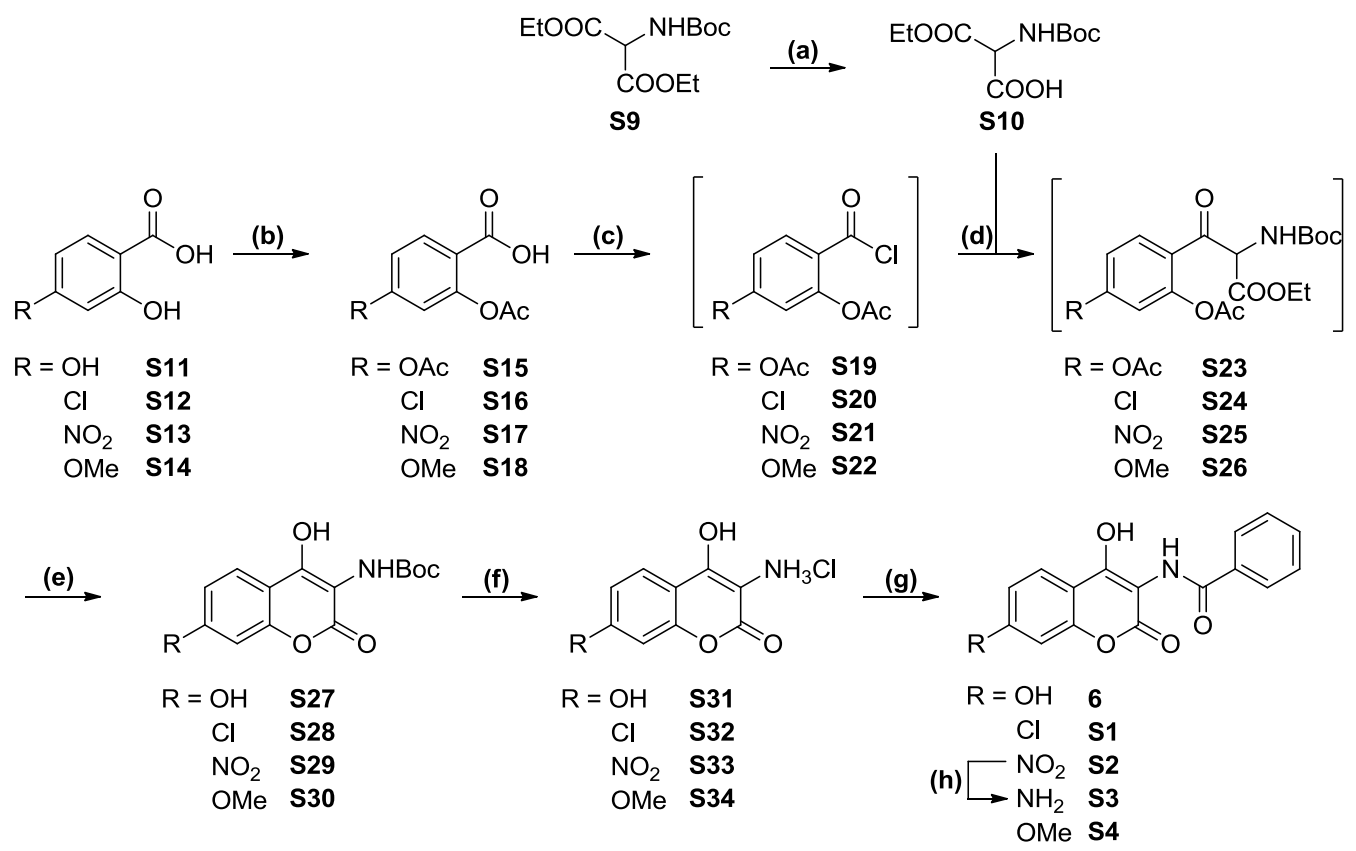

Scheme S2. Synthetic route to aminocoumarin substrates 6 and S1-S4. ${ }^{17}$ Reagents and conditions: (a) KOH, aq. EtOH, 22 ${ }^{\circ} \mathrm{C}$. (b) $\mathrm{Ac}_{2} \mathrm{O}$, 4-dimethylaminopyridine (DMAP), $\mathrm{NEt}_{3}, \mathrm{THF}, 0-22{ }^{\circ} \mathrm{C}$ or $\mathrm{AcCl}, \mathrm{NEt}_{3}, \mathrm{THF}, 0-22{ }^{\circ} \mathrm{C}$. (c) $(\mathrm{COCl})_{2}, N, N-$ dimethylformamide (DMF), $\mathrm{PhMe}, 40{ }^{\circ} \mathrm{C}$. (d) $\mathrm{MgCl}_{2}, \mathrm{NEt}_{3}$, THF, $4{ }^{\circ} \mathrm{C}$, then acid chloride. (e) aq. $\mathrm{NaOH}, \mathrm{MeOH}, 22{ }^{\circ} \mathrm{C}$. (f) $\mathrm{HCl}$ in cyclopentylmether ether (CPME), tert-butylmethyl ether, $\mathrm{MeOH}, 22{ }^{\circ} \mathrm{C} .(\mathrm{g}) \mathrm{BzCl} \mathrm{NEt}_{3}, \mathrm{EtOAc}, 22{ }^{\circ} \mathrm{C}$, then aq. $\mathrm{NaOH}, \mathrm{MeOH} 22^{\circ} \mathrm{C}$. (h) $\mathrm{Fe}, \mathrm{AcOH}$, aq. $\mathrm{HCl}, 40^{\circ} \mathrm{C}$.

\section{General procedure for the synthesis of 2, 4-diacetoxybenzoic acid (S15) and 2-acetoxy 4- methoxybenzoic acid (S18)}

To a solution of 2, 4-dihydroxybenzoic acid (S11) or 2-hydroxy 4-methoxybenzoic acid (S14) (1 eq.) in tetrahydrofuran $(10 \mathrm{~mL} / \mathrm{g})$ was added triethylamine (3.5 eq.), 4-dimethylaminopyridine ( 0.1 eq.) and acetic anhydride (5 eq.) and the reaction was stirred at $22{ }^{\circ} \mathrm{C}$ for $4 \mathrm{~h}$. The reaction mixture was acidified with aqueous $1 \mathrm{M} \mathrm{HCl}$ to $\mathrm{pH} 3$ and extracted with EtOAc (3 x $100 \mathrm{~mL})$. The combined 
organic fractions were washed with brine $(100 \mathrm{~mL})$ and dried over $\mathrm{Na}_{2} \mathrm{SO}_{4}$. The solvent was removed under reduced pressure and the resulting solid was recrystallised from EtOAc to provide the title compounds.

\section{2,4-Diacetoxybenzoic acid (S15)}<smiles>CC(=O)Oc1ccc(C(=O)O)c(OC(C)=O)c1</smiles>

Colourless crystalline solid $(12.6 \mathrm{~g}, 82 \%)$.

${ }^{1}$ H NMR: $\delta\left(400\right.$ MHz, DMSO-d $\left.{ }_{6}\right) 13.14$ (br. s, 1H, COOH), 7.98 (d, J=8.6 Hz, 1H, Ar-H), 7.18 (dd, $\left.J_{I}=8.6, J_{2}=2.3 \mathrm{~Hz}, 1 \mathrm{H}, \mathrm{Ar}-\mathrm{H}\right), 7.09(\mathrm{~d}, J=2.3 \mathrm{~Hz}, 1 \mathrm{H}, \mathrm{Ar}-\mathrm{H}), 2.29$ (s, 3H, $\left.\mathrm{CH}_{3}\right), 2.24\left(\mathrm{~s}, 3 \mathrm{H}, \mathrm{CH}_{3}\right)$.

${ }^{13}$ C NMR: $\delta\left(101 \mathrm{MHz}, \mathrm{CDCl}_{3}\right) 169.2(\mathrm{CO}), 168.3$ (CO), 168.2 (CO), 155.3 (C), 152.2 (C), 133.5 $(\mathrm{C}), 119.5(\mathrm{CH}), 119.3(\mathrm{CH}), 117.5(\mathrm{CH}), 21.2\left(\mathrm{CH}_{3}\right), 21.0\left(\mathrm{CH}_{3}\right)$.

$v_{\max }$ (neat): $2859,1773,1680,1607 \mathrm{~cm}^{-1}$.

LC-MS: $m / z 261\left(\mathrm{M}+\mathrm{Na}^{+}, 5 \%\right), 179(100 \%)$.

$\mathbf{R}_{\mathbf{f}}:(1: 1 \mathrm{EtOAc/}$ heptane) 0.16 .

M.pt.: $135-137^{\circ} \mathrm{C}\left(\right.$ lit. $\left.136-137^{\circ} \mathrm{C}\right){ }^{18}$

2-acetoxy 4-methoxybenzoic acid (S18) ${ }^{19}$<smiles>COc1ccc(C(=O)O)c(OC(C)=O)c1</smiles>

Colourless crystalline solid (4.96 g, 79\%).

${ }^{1}$ H NMR: $\delta$ (400 MHz, DMSO-d $\left.{ }_{6}\right) 12.71$ (br. S , 1H, COOH), 7.90 (d, J=8.9 Hz, 1H, Ar-H), 6.93 (dd, $\left.J_{l}=8.9, J_{2}=2.5 \mathrm{~Hz}, 1 \mathrm{H}, \mathrm{Ar}-\mathrm{H}\right), 6.77(\mathrm{~d}, J=2.5 \mathrm{~Hz}, 1 \mathrm{H}, \mathrm{Ar}-\mathrm{H}), 3.82\left(\mathrm{~s}, 3 \mathrm{H}, \mathrm{OCH}_{3}\right), 2.23\left(\mathrm{~s}, 3 \mathrm{H}, \mathrm{CH}_{3}\right)$. ${ }^{13}$ C NMR: $\delta\left(101 \mathrm{MHz}\right.$, DMSO-d $\left.{ }_{6}\right) 169.0$ (CO), 165.1 (CO), 163.4 (C), 152.2 (C), $133.0(\mathrm{C}), 115.9$ $(\mathrm{CH}), 111.7(\mathrm{CH}), 109.2(\mathrm{CH}), 55.8\left(\mathrm{CH}_{3}\right), 20.9\left(\mathrm{CH}_{3}\right)$.

$v_{\max }$ (neat): 2936, 1760, 1694, 1611, 1335, $1210 \mathrm{~cm}^{-1}$.

LC-MS: $m / z 211\left(\mathrm{M}+\mathrm{H}^{+}, 2 \%\right), 151(100 \%)$.

$\mathbf{R}_{\mathbf{f}}:(\mathrm{EtOAc}) 0.62$.

M.pt.: $144-115^{\circ} \mathrm{C}$. 
General procedure for the synthesis of 2-acetoxy 4-chlorobenzoic acid (S16) and 2-acetoxy 4nitrobenzoic acid (S17)

To an ice-cooled solution of 4-chloro-2-hydroxybenzoic acid (S12) or 4-nitro-2-hydroxybenzoic acid (S13) (1.0 eq.) in tetrahydrofuran (20 mL) was added triethylamine (3.0 eq.) and acetyl chloride (2.0 eq.) dropwise and the reaction mixture was stirred at $22{ }^{\circ} \mathrm{C}$ for 16 hours. The reaction mixture was acidified with aqueous $2 \mathrm{M} \mathrm{HCl}$ to $\mathrm{pH} 2$ and extracted with EtOAc $(3 \times 15 \mathrm{~mL})$. The combined organic fractions were washed with brine $(15 \mathrm{~mL})$ and dried over $\mathrm{Na}_{2} \mathrm{SO}_{4}$. The solvent was removed under reduced pressure and the resulting solid purified as described below.

\section{2-acetoxy 4-chlorobenzoic acid $(\mathbf{S 1 6})^{20}$}<smiles>CC(=O)Oc1cc(Cl)ccc1C(=O)O</smiles>

Purified by recrystallisation from EtOAc to provide the title compound as a colourless crystalline solid (0.54 g, 87\%). ${ }^{1} \mathbf{H}$ NMR: $\delta\left(400 \mathrm{MHz}, \mathrm{CDCl}_{3}\right) 8.06(\mathrm{~d}, J=8.5 \mathrm{~Hz}, 1 \mathrm{H}, \mathrm{Ar}-\mathrm{H}), 7.35\left(\mathrm{dd}, J_{I}=8.5\right.$, $\left.J_{2}=2.0 \mathrm{~Hz}, 1 \mathrm{H}, \mathrm{Ar}-\mathrm{H}\right), 7.18(\mathrm{~d}, J=2.0 \mathrm{~Hz}, 1 \mathrm{H}, \mathrm{Ar}-\mathrm{H}), 2.35\left(\mathrm{~s}, 3 \mathrm{H}, \mathrm{CH}_{3}\right) . \mathrm{COOH}$ signal not detected. ${ }^{13}$ C NMR: $\delta$ (101 MHz, DMSO-d ${ }_{6}$ ) 168.9 (CO), 164.8 (CO), 150.9 (C), 137.6 (C), 132.8 (C), 126.3 $(\mathrm{CH}), 124.1(\mathrm{CH}), 123.1(\mathrm{CH}), 20.8\left(\mathrm{CH}_{3}\right) \cdot v_{\max }$ (neat): 2680, 1763, $1686 \mathrm{~cm}^{-1} \cdot \mathbf{m} / \mathbf{z}:\left(\mathrm{ES}^{+}\right) 171(\mathrm{M}-$ $\left.\mathrm{CO}_{2}{ }^{-}+\mathrm{H}^{+}, 75 \%\right), 372(100 \%)$. $\mathbf{R}_{\mathbf{f}}:\left(1: 1 \mathrm{EtOAc} /\right.$ heptane) 0.22 . M.pt.: $147^{\circ} \mathrm{C}$. (lit.: $\left.133-135{ }^{\circ} \mathrm{C}\right){ }^{20}$

2-acetoxy 4-nitrobenzoic acid $(\mathbf{S 1 7})^{21}$<smiles>O=C(O)c1ccc([N+](=O)[O-])cc1C(=O)O</smiles>

Product purified by column chromatography (20-100\% EtOAc in heptane) to provide the title compound as colourless amorphous solid $(0.55 \mathrm{~g}, 89 \%) .{ }^{1} \mathbf{H}$ NMR: $\delta\left(400 \mathrm{MHz}, \mathrm{CDCl}_{3}\right) 8.28$ (d, $J=8.6 \mathrm{~Hz}, 1 \mathrm{H}, \mathrm{Ar}-\mathrm{H}), 8.19$ (dd, $\left.J_{l}=8.6, J_{2}=2.1 \mathrm{~Hz}, 1 \mathrm{H}, \mathrm{Ar}-\mathrm{H}\right), 8.02$ (d, J=2.1 Hz, 1H, Ar-H), 2.39 (s, 3 $\left.\mathrm{H}, \mathrm{CH}_{3}\right) . \mathrm{COOH}$ signal not detected. ${ }^{13} \mathrm{C}$ NMR: $\delta\left(101 \mathrm{MHz}, \mathrm{DMSO}-\mathrm{d}_{6}\right) 168.9(\mathrm{CO}), 164.8(\mathrm{CO})$, $150.9(\mathrm{C}), 137.6(\mathrm{C}), 132.8(\mathrm{C}), 126.3(\mathrm{CH}), 124.1(\mathrm{CH}), 123.1(\mathrm{CH}), 20.8\left(\mathrm{CH}_{3}\right) \cdot v_{\text {max }}$ (neat): 1768, $1701,1523,1350 \mathrm{~cm}^{-1} \cdot \mathbf{m} / z:\left(\mathrm{ES}^{+}\right) 211\left(\mathrm{M}+\mathrm{H}^{+}-16,100 \%\right) .{ }^{22} \mathbf{R}_{\mathbf{f}}:(\mathrm{EtOAc}) 0.62$.

M.pt.: $146-147^{\circ} \mathrm{C}$.

2-(tert-butoxycarbonylamino)-3-ethoxy-3-oxopropanoic acid (S10 $)^{23}$<smiles>CCOC(=O)C(NC(=O)OC(C)(C)C)C(=O)O</smiles> 
To a solution of diethyl 2-((tert-butoxycarbonyl)amino)malonate (S9) $(10.0 \mathrm{~mL}, 39.2 \mathrm{mmol})$ in ethanol $(50 \mathrm{~mL})$ was added solid potassium hydroxide $(2.25 \mathrm{~g}, 40.1 \mathrm{mmol})$. The suspension was stirred at $22{ }^{\circ} \mathrm{C}$ for 12 hours before concentrating under reduced pressure. The suspension was redissolved in $1 \mathrm{M} \mathrm{NaHCO}_{3}(75 \mathrm{~mL})$ and washed with EtOAc $(2 \times 40 \mathrm{~mL})$. The solution was cooled to $0{ }^{\circ} \mathrm{C}$, acidified with solid $\mathrm{KHSO}_{4}$ to $\mathrm{pH} 2$ and extracted with EtOAc $(3 \mathrm{x} 40 \mathrm{~mL})$. The combined organic fractions were washed with brine $(20 \mathrm{~mL})$ and dried over $\mathrm{Na}_{2} \mathrm{SO}_{4}$. The solvent was removed under reduced pressure to provide the title compound as an amorphous colourless solid $(7.66 \mathrm{~g}, 77 \%)$. ${ }^{1}$ H NMR: $\delta\left(400 \mathrm{MHz}\right.$, DMSO-d $\left._{6}\right) 7.49$ (d, J=7.9 Hz, 1H, NH), 4.73 (d, J=7.9 Hz, 1H, CH), 4.15 (q, $\left.J=7.0 \mathrm{~Hz}, 2 \mathrm{H}, \mathrm{CH}_{2}\right), 1.41\left(\mathrm{~s}, 9 \mathrm{H}, 3 \mathrm{xCH}_{3}\right), 1.21\left(\mathrm{t}, J=7.0 \mathrm{~Hz}, 3 \mathrm{H}, \mathrm{CH}_{3}\right) . \mathrm{COOH}$ signal not detected. ${ }^{13} \mathbf{C}$ NMR: $\delta\left(101 \mathrm{MHz}, \mathrm{DMSO}_{6}\right) 167.8(\mathrm{CO}), 167.2(\mathrm{CO}), 156.3(\mathrm{CO}), 78.9(\mathrm{C}), 61.3\left(\mathrm{CH}_{2}\right), 57.6$ $(\mathrm{CH}), 28.1\left(\mathrm{CH}_{3}\right), 13.9\left(3 \mathrm{xCH}_{3}\right) . \mathbf{v}_{\text {max }}$ (neat): 3264, 2984, 1756, 1733, $1652 \mathrm{~cm}^{-1} \cdot \mathbf{m} / z:\left(\mathrm{ES}^{+}\right) 248$ $\left(\mathrm{M}+\mathrm{H}^{+}, 6 \%\right), 148$ (100\%). M.pt.: $84-85{ }^{\circ} \mathrm{C}$ (lit.: 93-95 ${ }^{\circ} \mathrm{C}$ [diethyl ether/ hexane]). ${ }^{23} \mathbf{R}_{\mathbf{f}}$ : (EtOAc) 0.53 .

\section{General procedure for acid chloride formation}

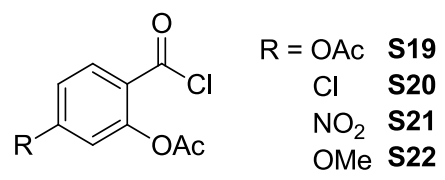

To a suspension of carboxylic acid (1.0 eq.) in anhydrous toluene $(10 \mathrm{~mL} / \mathrm{g})$ under a $\mathrm{N}_{2}$ atmosphere in a flame dried flask at $22{ }^{\circ} \mathrm{C}$ was added $(\mathrm{COCl})_{2}(2.0$ eq.) and anhydrous DMF (0.1 eq.). The reaction mixture was heated to $40{ }^{\circ} \mathrm{C}$ and stirred for 2 hours. The reaction mixture was concentrated under reduced pressure and the resulting crude residue was used in the next stage of the synthesis without further purification.

General procedure for the coupling of 2-(tert-butoxycarbonylamino)-3-ethoxy-3-oxopropanoic acid (S10) with acid chlorides S19-S22

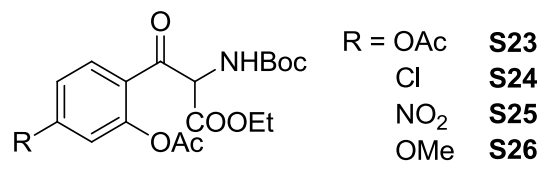

To an ice-cooled solution of 2-(tert-butoxycarbonylamino)-3-ethoxy-3-oxopropanoic acid (S10) (1.0 eq.) in anhydrous tetrahydrofuran $\left(8 \mathrm{~mL} / \mathrm{g}\right.$ ) under an $\mathrm{N}_{2}$ atmosphere was added triethylamine (5.0 eq.) and anhydrous magnesium chloride (3.0 eq.). The resulting slurry was stirred vigorously at $4{ }^{\circ} \mathrm{C}$ for 2 hours. A solution of the previously prepared crude acid chloride (theoretical amount 1 eq.) in anhydrous tetrahydrofuran $(5 \mathrm{~mL} / \mathrm{mmol})$ was then added and the resulting suspension stirred for 2 hours. The reaction mixture was quenched with saturated aqueous ammonium chloride 
$(5 \mathrm{~mL} / \mathrm{mmol})$ and extracted with ethyl acetate $(3 \times 50 \mathrm{~mL})$. The combined organic fractions were washed with brine $(10 \mathrm{~mL})$ and dried over $\mathrm{Na}_{2} \mathrm{SO}_{4}$. The solvent was removed under reduced pressure to provide a brown solid which was used in the next stage of the synthesis without further purification.

\section{General procedure for the synthesis of $N$-Boc aminocoumarin derivatives $(\mathrm{S27}-\mathrm{S30})^{17}$}

To a solution of crude coupling product (S23-S26) (1.0 eq., theoretical) in methanol $(10 \mathrm{~mL} / \mathrm{g})$ was added aqueous $1 \mathrm{M} \mathrm{NaOH}$ (5.0 eq.) and the reaction mixture was stirred at $22{ }^{\circ} \mathrm{C}$ for 4 hours. The reaction mixture was acidified with $2 \mathrm{M} \mathrm{HCl}$ to $\mathrm{pH} 3$ and extracted with EtOAc $(3 \times 100 \mathrm{~mL})$. The combined organic fractions were washed with brine $(20 \mathrm{~mL})$, dried over $\mathrm{MgSO}_{4}$ and the solvent removed under reduced pressure. The resulting solid was recrystallised from EtOAc to provide the title compounds.

tert-Butyl (4,7-dihydroxy-2-oxo-2H-chromen-3-yl) carbamate $(\mathbf{S} 27)^{17}$<smiles>CC(C)(C)OC(=O)Nc1c(O)c2ccc(O)cc2oc1=O</smiles>

Isolated as a pale orange crystalline solid (3.57 g, 58\% over 3 stages). ${ }^{1} \mathbf{H}$ NMR: $\delta$ (400 MHz, DMSOd 6 ) 7.79 (br. s, $1 \mathrm{H}, \mathrm{NH}), 7.66$ (d, $J=8.7 \mathrm{~Hz}, 1 \mathrm{H}, \mathrm{Ar}-\mathrm{H}), 6.79$ (dd, $\left.J_{l}=8.7, J_{2}=2.2 \mathrm{~Hz}, 1 \mathrm{H}, \mathrm{Ar}-\mathrm{H}\right), 6.70$ $(\mathrm{d}, J=2.2 \mathrm{~Hz}, 1 \mathrm{H}, \mathrm{Ar}-\mathrm{H}), 1.44\left(\mathrm{~s}, 9 \mathrm{H}, 3 \mathrm{xCH}_{3}\right) . \mathrm{OH}$ signals not detected. ${ }^{13} \mathbf{C}$ NMR: $\delta(101 \mathrm{MHz}$, DMSO-d $\left.{ }_{6}\right) 165.4(\mathrm{CO}), 161.2(\mathrm{CO}), 161.2(\mathrm{C}), 157.9(\mathrm{C}), 154.7(\mathrm{C}), 125.0(\mathrm{CH}), 112.8(\mathrm{CH}), 106.3$ $(\mathrm{C}), 101.8(\mathrm{CH}), 79.3(\mathrm{C}), 77.3(\mathrm{C}), 28.2\left(3 \mathrm{xCH}_{3}\right) \cdot v_{\max }$ (neat): 3370, 1612, $1575 \mathrm{~cm}^{-1} \cdot \boldsymbol{m} / \mathbf{z}:\left(\mathrm{ES}^{+}\right) 294$ $\left(\mathrm{M}+\mathrm{H}^{+}, 9 \%\right), 238(100 \%) . \mathbf{R}_{f}:(1: 1 \mathrm{EtOAc} /$ heptane $)$ 0.38. M.pt.: $208-210{ }^{\circ} \mathrm{C}$.

tert-Butyl (7-chloro-4-hydroxy-2-oxo-2H-chromen-3-yl) carbamate (S28)<smiles>CC(C)(C)OC(=O)Nc1c(O)c2ccc(Cl)cc2oc1=O</smiles>

Isolated as a colourless crystalline solid $(0.20 \mathrm{~g}, 28 \%$ over 3 stages $) .{ }^{1} \mathbf{H}$ NMR: $\delta$ (400 MHz, DMSOd $\mathrm{d}_{6} 12.24$ (br. s, 1H, OH), 7.98 (br. S. 1H, NH), 7.86 (d, 1H, J=8.5 Hz, Ar-H), 7.59 (d, J=2.0 Hz, 1H, Ar-H), $7.43\left(\mathrm{dd}, J_{l}=8.5, J_{2}=2.0 \mathrm{~Hz}, 1 \mathrm{H}, \mathrm{Ar}-\mathrm{H}\right), 1.42$ (s, 9H, 3xCH$)_{3}{ }^{13} \mathrm{C}$ NMR: $\delta(101 \mathrm{MHz}, \mathrm{DMSO}-$ d $\left.\mathrm{d}_{6}\right) 160.0(\mathrm{CO}), 157.9(\mathrm{CO}), 154.0(\mathrm{C}), 151.5(\mathrm{C}), 135.8(\mathrm{C}), 124.8(\mathrm{CH}), 124.0(\mathrm{CH}), 115.8(\mathrm{CH})$, $115.2(\mathrm{C}), 103.3(\mathrm{C}), 78.8(\mathrm{C}), 27.7\left(3 \mathrm{xCH}_{3}\right) \cdot \mathbf{v}_{\max }$ (neat): 3287, 1705, $1602 \mathrm{~cm}^{-1} \cdot \boldsymbol{m} / z:\left(\mathrm{ES}^{+}\right) 310$ $\left(\mathrm{M}+\mathrm{H}^{+}, 10 \%\right), 236(100 \%)$. HRMS: $\mathrm{C}_{14} \mathrm{H}_{15} \mathrm{ClN}_{2} \mathrm{O}_{5}\left[\mathrm{M}+\mathrm{H}^{+}\right]$requires 312.0633, found 312.0643. $\mathbf{R}_{f}$ : (1:1 EtOAc/ heptane) 0.54. M.pt.: $162{ }^{\circ} \mathrm{C}$. 
<smiles>CC(C)(C)OC(=O)Nc1c(O)c2ccc([N+](=O)[O-])cc2oc1=O</smiles>

Isolated as a crystalline yellow solid $(0.5 \mathrm{~g}, 70 \%) .{ }^{1} \mathbf{H}$ NMR $\delta\left(400 \mathrm{MHz}, \mathrm{DMSO}-\mathrm{d}_{6}\right) 12.57(\mathrm{~s}, 1 \mathrm{H}$, $\mathrm{OH}), 8.22(\mathrm{~d}, J=2.2 \mathrm{~Hz}, 1 \mathrm{H}, \mathrm{Ar}-\mathrm{H}), 8.18\left(\mathrm{dd}, J_{l}=2.2, J_{2}=8.7 \mathrm{~Hz}, 1 \mathrm{H}, \mathrm{Ar}-\mathrm{H}\right), 8.12$ (s, 1H, NH) 8.09 (d, $J=8.7 \mathrm{~Hz}, 1 \mathrm{H}, \mathrm{Ar}-\mathrm{H}), 1.42\left(\mathrm{~s}, 9 \mathrm{H}, 3 \mathrm{xCH}_{3}\right) .{ }^{13} \mathrm{C}$ NMR $\delta\left(101 \mathrm{MHz}, \mathrm{DMSO}-\mathrm{d}_{6}\right) 160.0(\mathrm{CO}), 157.9(\mathrm{C})$, $154.1(\mathrm{CO}), 151.0(\mathrm{C}), 148.9(\mathrm{C}), 125.3(\mathrm{CH}), 121.8(\mathrm{C}), 118.7(\mathrm{CH}), 111.8(\mathrm{CH}), 105.5(\mathrm{C}), 79.1$ (C), $28.1\left(3 \mathrm{xCH}_{3}\right) \cdot \mathbf{v}_{\text {max }}$ (neat): 3286, 1703, 1633, 1523, $1347 \mathrm{~cm}^{-1} \cdot \mathbf{m} / z:\left(\mathrm{ES}^{+}\right) 323\left(\mathrm{M}+\mathrm{H}^{+}, 4 \%\right), 247$ (M-Boc+Na $\left.{ }^{+} 100 \%\right)$. HRMS: $\mathrm{C}_{14} \mathrm{H}_{15} \mathrm{~N}_{2} \mathrm{O}_{7}\left[\mathrm{M}+\mathrm{H}^{+}\right]$requires 323.0874, found 323.0883. $\mathbf{R}_{f}$ : (20\% EtOAc in heptane) 0.23. M.pt.: decomp. $>210^{\circ} \mathrm{C}$.

tert-Butyl (7-methoxy-4-hydroxy-2-oxo-2H-chromen-3-yl) carbamate (S30)<smiles>COc1ccc2c(O)c(NC(=O)OC(C)(C)C)c(=O)oc2c1</smiles>

Isolated as a colourless crystalline solid (0.68 g, 23\%). ${ }^{1}$ H NMR: $\delta\left(400 \mathrm{MHz}, \mathrm{DMSO}-\mathrm{d}_{6}\right) 11.82$ (br. s, 1H, OH), $7.84(\mathrm{~s}, 1 \mathrm{H}, \mathrm{NH}), 7.75(\mathrm{~d}, J=8.9 \mathrm{~Hz}, 1 \mathrm{H}, \mathrm{Ar}-\mathrm{H}), 6.96(\mathrm{~m}, 2 \mathrm{H}, \mathrm{Ar}-\mathrm{H}), 3.86\left(\mathrm{~s}, 3 \mathrm{H}, \mathrm{CH}_{3}\right)$, 1.43 (br. s, 9H, 3xCH 3 ). ${ }^{13} \mathrm{C}$ NMR: $\delta\left(101 \mathrm{MHz}, \mathrm{DMSO}_{6}\right) 162.5(\mathrm{CO}), 161.1(\mathrm{CO}), 154.6(\mathrm{C})$, $153.3(\mathrm{C}), 124.7(\mathrm{CH}), 112.1(\mathrm{CH}), 109.1(\mathrm{C}), 100.4(\mathrm{CH}), 78.7(\mathrm{C}), 55.9\left(\mathrm{CH}_{3}\right), 28.2\left(3 \mathrm{xCH}_{3}\right)$. Two C signals not detected. $\mathbf{v}_{\text {max }}$ (neat): 3397, 1690, $1611 \mathrm{~cm}^{-1} . \mathbf{m} / z:\left(\mathrm{ES}^{+}\right) 308\left(\mathrm{M}+\mathrm{H}^{+}, 45 \%\right), 252(100 \%)$. HRMS: $\mathrm{C}_{15} \mathrm{H}_{18} \mathrm{NO}_{6}\left[\mathrm{M}+\mathrm{H}^{+}\right]$requires 308.1129 , found 308.1139. $\mathbf{R}_{\boldsymbol{f}}:(1: 1 \mathrm{EtOAc} /$ heptane) 0.48 . M.pt.: $149-150{ }^{\circ} \mathrm{C}$.

\section{General procedure for synthesis of aminocoumarins (S31-S34)}

To an ice cooled solution of the $N$-Boc protected aminocoumarin (1.0 eq.) in tert-butylmethyl ether (TBME) $(20 \mathrm{~mL} / \mathrm{g})$ and methanol $(5 \mathrm{~mL} / \mathrm{g})$ was added $\mathrm{HCl}$ in cyclopentylmethyl ether $(3 \mathrm{M}$, 15.0 eq.) and the mixture stirred at $22{ }^{\circ} \mathrm{C}$ for 24 hours. The solvent was removed under reduced pressure and the residue triturated with TBME $(10 \mathrm{~mL})$. The suspension was filtered to provide the title compounds.

\section{3-Amino-4,7-dihydroxy-2H-chromen-2-one hydrochloride $(\mathbf{S 3 1})^{17}$}<smiles>Nc1c(O)c2ccc(O)cc2oc1=O</smiles>

- $\mathrm{HCl}$ 
Isolated as an off-white amorphous solid (1.94 g, 99\%). ${ }^{1} \mathbf{H}$ NMR: $\delta\left(400 \mathrm{MHz}, \mathrm{DMSO}-\mathrm{d}_{6}\right) 7.78$ (d, $J=8.6 \mathrm{~Hz}, 1 \mathrm{H}, \mathrm{Ar}-\mathrm{H}), 6.75\left(\mathrm{dd}, J_{I}=8.6, J_{2}=2.3 \mathrm{~Hz}, 1 \mathrm{H}, \mathrm{Ar}-\mathrm{H}\right), 6.64(\mathrm{~d}, J=2.3 \mathrm{~Hz}, 1 \mathrm{H}, \mathrm{Ar}-\mathrm{H})$. OH and $\mathrm{NH}_{2}$ signals not detected. ${ }^{13} \mathrm{C}$ NMR: $\delta\left(101 \mathrm{MHz}, \mathrm{DMSO}-\mathrm{d}_{6}\right) 161.4(\mathrm{CO}), 160.2(\mathrm{C}), 159.6(\mathrm{C}), 153.8$ (C), $125.7(\mathrm{C}), 112.8(\mathrm{C}), 110.3(\mathrm{CH}), 102.3(\mathrm{CH}), 94.3(\mathrm{CH}) . \mathbf{v}_{\max }$ (neat): 3336, $1710 \mathrm{~cm}^{-1} . \mathrm{m} / z$ : $\left(\mathrm{ES}^{+}\right) 194\left(\mathrm{M}^{+}, 100 \%\right) . \mathbf{R}_{f}$ : (EtOAc) 0.03. M.pt.: $240-241^{\circ} \mathrm{C}$.

\section{3-Amino-7-chloro-4-hydroxy-2H-chromen-2-one hydrochloride (S32)}<smiles>Nc1c(O)c2ccc(Cl)cc2oc1=O</smiles>

$\cdot \mathrm{HCl}$

Isolated as an off-white amorphous solid (136 mg, 95\%). ${ }^{1} \mathbf{H}$ NMR: $\delta\left(400 \mathrm{MHz}, \mathrm{DMSO}-\mathrm{d}_{6}\right) 7.88$ (d, $J=8.3 \mathrm{~Hz}, 1 \mathrm{H}, \mathrm{Ar}-\mathrm{H}$ ), 7.64 (br. s. $2 \mathrm{H}, \mathrm{NH}_{2}$ ), 7.43 (s, 1H, Ar-H), 7.32 (d, J=8.3, 1H, Ar-H). OH signals not detected. ${ }^{13}$ C NMR: $\delta\left(101 \mathrm{MHz}, \mathrm{DMSO}-\mathrm{d}_{6}\right) 159.8(\mathrm{CO}), 152.4(\mathrm{C}), 134.5(\mathrm{C}), 125.6(\mathrm{CH}), 123.2$ $(\mathrm{CH}), 120.5(\mathrm{C}), 116.0(\mathrm{CH})$. Two C signals not detected.v ${ }_{\text {max }}$ (neat): $2900,1733 \mathrm{~cm}^{-1} \cdot \mathbf{m} / \mathbf{z}:\left(\mathrm{ES}^{+}\right) 212$ $\left(\mathrm{M}^{+}, 100 \%\right)$. HRMS: $\mathrm{C}_{9} \mathrm{H}_{7} \mathrm{ClNO}_{3}\left[\mathrm{M}^{+}\right]$requires 212.6092 , found 212.212.0109. $\mathbf{R}_{f}$ : (1:1 EtOAc/ heptane) 0.08. M.pt.: $241^{\circ} \mathrm{C}$.

\section{3-Amino-7-nitro-4-hydroxy-2H-chromen-2-one hydrochloride (S33)}<smiles>Nc1c(O)c2ccc([N+](=O)[O-])cc2oc1=O</smiles>

. $\mathrm{HCl}$

Isolated as a pale yellow solid (78 mg, 97\%). ${ }^{1} \mathbf{H}$ NMR $\delta\left(400 \mathrm{MHz}, \mathrm{DMSO}-\mathrm{d}_{6}\right) 8.37$ (br. s., 3H, $\left.\mathrm{NH}_{3}\right), 8.10(\mathrm{~m}, 2 \mathrm{H}, 2 \mathrm{xAr}-\mathrm{H}), 8.02(\mathrm{~m}, 1 \mathrm{H}, \mathrm{Ar}-\mathrm{H}) . \mathrm{OH}$ signal not detected. ${ }^{13} \mathbf{C}$ NMR $\delta(400 \mathrm{MHz}$, DMSO-d $\left._{6}\right) 159.6(\mathrm{CO}), 157.8(\mathrm{C}), 154.5$ (C), 152.9 (C), 131.9 (C), 128.8 (C), $124.0(\mathrm{CH}), 118.2$ $(\mathrm{CH}), 111.5(\mathrm{CH}) . v_{\max }$ (neat): 2968, 1668, 1539, $1356 \mathrm{~cm}^{-1} . \mathrm{m} / z:\left(\mathrm{ES}^{+}\right) 223\left(\mathrm{M}^{+}, 100 \%\right)$. HRMS: $\mathrm{C}_{9} \mathrm{H}_{7} \mathrm{~N}_{2} \mathrm{O}_{5}\left[\mathrm{M}^{+}\right]$requires 223.0350, found 223.0354. $\mathbf{R}_{f}$ : (EtOAc) 0.06. M.pt.: decomp. $>215{ }^{\circ} \mathrm{C}$.

\section{3-Amino-7-methoxy-4-hydroxy-2H-chromen-2-one hydrochloride (S34)}<smiles>COc1ccc2c(O)c(N)c(=O)oc2c1</smiles>

Isolated as a pale yellow solid (0.35 g, 89\%). ${ }^{1} \mathbf{H}$ NMR $\delta$ (400 MHz, DMSO-d 6 ,) 9.20 (br. s, 4H, OH and $\left.\mathrm{NH}_{3}\right), 7.93(\mathrm{~d}, J=8.2 \mathrm{~Hz}, 1 \mathrm{H}, \mathrm{Ar}-\mathrm{H}), 6.94(\mathrm{~m}, 2 \mathrm{H}, \mathrm{Ar}-\mathrm{H}), 3.85\left(\mathrm{~s}, 3 \mathrm{H}, \mathrm{CH}_{3}\right) .{ }^{13} \mathbf{C}$ NMR: $\delta(101$ 
MHz, DMSO-d $\left.{ }_{6}\right) 162.4(\mathrm{CO}), 159.9(\mathrm{C}), 153.5(\mathrm{C}), 125.4(\mathrm{CH}), 124.9(\mathrm{C}), 111.7(\mathrm{CH}), 100.6(\mathrm{CH})$, 96.1 (C), $94.8(\mathrm{C}), 55.8\left(\mathrm{CH}_{3}\right) \cdot \mathbf{v}_{\text {max }}$ (neat): 2914, 1706, 1243, $1194 \mathrm{~cm}^{-1} \cdot \mathbf{m} / z:\left(\mathrm{ES}^{+}\right) 208\left(\mathrm{M}^{+}, 100 \%\right)$. HRMS: $\mathrm{C}_{10} \mathrm{H}_{10} \mathrm{NO}_{4}\left[\mathrm{M}^{+}\right]$requires 208.0604, found 208.0605. $\mathbf{R}_{f}$ : (EtOAc) 0.04. M.pt.: decomp. $>250{ }^{\circ} \mathrm{C}$.

\section{General procedure for the synthesis of aminocoumarin substrates 6 and S1-S4}

To a solution of S31-S34 (1.0 eq.) in EtOAc (12 mL/ mmol) was added benzoyl chloride (5.0 eq.) and triethylamine (10.0 eq.). The suspension was stirred at $22{ }^{\circ} \mathrm{C}$ for 3 hours before being filtered. The filtrate was concentrated under reduced pressure and the residue dissolved in methanol $(25 \mathrm{~mL})$. Aqueous $1 \mathrm{M} \mathrm{NaOH}(25 \mathrm{~mL}, 25.0 \mathrm{mmol})$ was added and the reaction was stirred at $22{ }^{\circ} \mathrm{C}$ for 12 hours before acidifying to $\mathrm{pH} 3$ with aqueous $2 \mathrm{M} \mathrm{HCl}$. The reaction mixture was extracted with EtOAc $(3 \times 50 \mathrm{~mL})$ and the combined organic fractions were washed with brine $(50 \mathrm{~mL})$ and dried over $\mathrm{Na}_{2} \mathrm{SO}_{4}$. The solvent was removed under reduced pressure and the crude solid washed with EtOAc $(10 \mathrm{~mL})$ and filtered to provide the title compounds.

$N$-(4,7-Dihydroxy-2-oxo-2H-chromen-3-yl) benzamide (6) ${ }^{17}$<smiles>O=C(Nc1c(O)c2ccc(O)cc2oc1=O)c1ccccc1</smiles>

Isolated as a pale yellow amorphous solid $(0.43 \mathrm{~g}, 67 \%) .{ }^{1} \mathbf{H}$ NMR: $\delta(400 \mathrm{MHz}$, DMSO-d 6 ) 11.82 (br. s, 1H, OH), 10.54 (s, 1H, OH), 9.41 (s, 1H, NH), 8.01 (d, J=7.3 Hz, 2H, Ar-H), 7.73 (d, J=8.7 Hz, $1 \mathrm{H}, \mathrm{Ar}-\mathrm{H}$ ), 7.60 (app. t, J=7.3 Hz, 1H, Ar-H), 7.52 (m, 2H, Ar-H), 6.84 (dd, $J_{l}=8.7, J_{2}=2.3 \mathrm{~Hz}, 1 \mathrm{H}$, Ar-H), 6.74 (d, J=2.3 Hz, 1H, Ar-H). ${ }^{13}$ C NMR: $\delta$ (101 MHz, DMSO-d d $\left._{6}\right) 166.5$ (CO), $161.4(\mathrm{CO})$, $160.8(\mathrm{C}), 160.4(\mathrm{C}), 153.5(\mathrm{C}), 133.9(\mathrm{C}), 131.5(\mathrm{CH}), 128.1(2 \mathrm{xCH}) 128.0(2 \mathrm{xCH}), 125.0(\mathrm{CH})$, $112.9(\mathrm{CH}), 108.0(\mathrm{C}), 101.9(\mathrm{CH}), 100.1(\mathrm{C}) . \mathbf{v}_{\text {max }}$ (neat): 3176, 1665, $1625 \mathrm{~cm}^{-1} \cdot \boldsymbol{m} / z:\left(\mathrm{ES}^{+}\right) 298$ $\left(\mathrm{M}+\mathrm{H}^{+}, 100 \%\right) . \mathbf{R}_{f}:(1: 1 \mathrm{EtOAc} /$ heptane $)$ 0.31. M.pt.: $283-285^{\circ} \mathrm{C}\left(\right.$ lit.: $\left.283-285{ }^{\circ} \mathrm{C}\right) .{ }^{17}$

$N$-(4-Chloro, 7-hydroxy-2-oxo-2H-chromen-3-yl) benzamide (S1)<smiles>O=C(Nc1c(O)c2ccc(Cl)cc2oc1=O)c1ccccc1</smiles>

Isolated as a pale yellow amorphous solid (74 mg, 58\%). ${ }^{1} \mathbf{H}$ NMR: $\delta\left(400 \mathrm{MHz}, \mathrm{DMSO}-\mathrm{d}_{6}\right) 12.30$ (s, 1H, OH), 9.55 (s, 1H, NH), 8.01 (d, J=7.3 Hz, 2H, Ar-H), 7.91 (d, J=8.5 Hz, 1H, Ar-H), 7.64 (d, $J=2.0 \mathrm{~Hz}, 1 \mathrm{H}, \mathrm{Ar}-\mathrm{H}), 7.59$ (d, J=7.3 Hz, 1H, Ar-H), $7.56-7.50$ (m, 2H, 2xAr-H), 7.47 (dd, $J_{l}=2.0$, $\left.J_{2}=8.5 \mathrm{~Hz}, 1 \mathrm{H}, \mathrm{Ar}-\mathrm{H}\right) .{ }^{13} \mathrm{C}$ NMR: $\delta\left(101 \mathrm{MHz}, \mathrm{DMSO}_{-}\right.$, $)$: 166.4 (CO), 159.9 (CO), $159.2(\mathrm{C}), 152.0$ 
(C), $136.5(\mathrm{C}), 133.7(\mathrm{C}), 131.7(\mathrm{CH}), 128.1(2 \times \mathrm{CH}), 128.0(2 \times \mathrm{CH}), 125.3(\mathrm{CH}), 124.6(\mathrm{CH}), 116.4$ $(\mathrm{CH}), 115.4(\mathrm{C}), 103.0(\mathrm{C}) . \mathbf{v}_{\max }$ (neat): 3352, 1695, 1623, $701 \mathrm{~cm}^{-1}$. HRMS: $\mathrm{C}_{16} \mathrm{H}_{11} \mathrm{ClNO}_{4}\left[\mathrm{M}+\mathrm{H}^{+}\right]$ requires 316.0371, found 316.0377. $\mathbf{R}_{f}:\left(1: 1 \mathrm{EtOAc} /\right.$ heptane): 0.25. M.pt.: $233^{\circ} \mathrm{C}$.

\section{$N$-(4-Nitro, 7-hydroxy-2-oxo-2H-chromen-3-yl) benzamide (S2)}<smiles>O=C(Nc1c(O)c2ccc([N+](=O)[O-])cc2oc1=O)c1ccccc1</smiles>

Isolated as a pale yellow amorphous solid (40 mg, 63\%). ${ }^{1} \mathbf{H}$ NMR: $\delta\left(400 \mathrm{MHz}, \mathrm{DMSO}-\mathrm{d}_{6}\right) 9.71$ (s, $1 \mathrm{H}, \mathrm{NH}), 8.27$ (d, $J=2.1 \mathrm{~Hz}, 1 \mathrm{H}, \mathrm{Ar}-\mathrm{H}), 8.21$ (dd, $\left.J_{l}=2.1, J_{2}=8.7 \mathrm{~Hz}, 1 \mathrm{H}, \operatorname{Ar}-\mathrm{H}\right), 8.15$ (d, J=8.7, 1H, Ar-H), 8.02 (d, J=7.1 Hz, 2H, Ar-H), 7.61 (t, J=7.3 Hz, 1H, Ar-H), 7.53 (t, J=7.6 Hz, 2H, Ar-H). OH signal not detected. ${ }^{13} \mathrm{C}$ NMR: $\delta\left(101 \mathrm{MHz}, \mathrm{DMSO}_{-}\right.$) 166.3 (CO), 159.7 (C), 158.2 (CO), 151.1 (C), $149.0(\mathrm{C}), 133.6(\mathrm{C}), 131.8(\mathrm{CH}), 128.2(2 \mathrm{xCH}), 128.0(2 \mathrm{xCH}), 125.4(\mathrm{CH}), 121.9(\mathrm{C}), 118.8$ $(\mathrm{CH}), 111.8(\mathrm{CH}), 105.2(\mathrm{C}) . v_{\text {max }}$ (neat): 1698, 1630, 1524, $1341 \mathrm{~cm}^{-1}$. HRMS: $\mathrm{C}_{16} \mathrm{H}_{11} \mathrm{~N}_{2} \mathrm{O}_{6}\left[\mathrm{M}+\mathrm{H}^{+}\right]$ requires 327.0612, found 327.0622. $\mathbf{R}_{f}$ : (1:1 EtOAc/ heptane): 0.28. M.pt.: 296 C.

$N$-(4-Amino, 7-hydroxy-2-oxo-2 $\mathrm{H}$-chromen-3-yl) benzamide (S3)<smiles>Nc1ccc2c(O)c(NC(=O)c3ccccc3)c(=O)oc2c1</smiles>

To a suspension of $N$-(4-nitro, 7-hydroxy-2-oxo-2H-chromen-3-yl) benzamide (9) (100 mg, 0.307 $\mathrm{mmol})$ in acetic acid $(5 \mathrm{~mL})$ was added iron powder $(171 \mathrm{mg}, 3.07 \mathrm{mmol})$. The reaction mixture was heated to $50{ }^{\circ} \mathrm{C}$ and stirred for 4 hours before concentrating under reduced pressure. The mixture was acidified to $\mathrm{pH} 1$ with aqueous $2 \mathrm{M} \mathrm{HCl}$ and EtOAc $(5 \mathrm{~mL})$ was added. The resulting suspension was filtered to provide the title compound as a yellow solid (63 mg, 69\%). ${ }^{1} \mathbf{H}$ NMR: $\delta(400 \mathrm{MHz}$, DMSO-d $\left.{ }_{6}\right) 11.48$ (s, 1H, OH), 9.33 (s, 1H, NH), 8.00 (d, J=5.7 Hz, 2H, Ar-H), 7.53 (m, 4H, Ar-H), $6.59(\mathrm{~d}, J=7.0 \mathrm{~Hz}, 1 \mathrm{H}, \mathrm{Ar}-\mathrm{H}), 6.43(\mathrm{~s}, 1 \mathrm{H}, \mathrm{Ar}-\mathrm{H}) . N H_{2}$ signal not detected. ${ }^{13} \mathbf{C}$ NMR: $\delta(101 \mathrm{MHz}$, DMSO-d $\left.\mathrm{d}_{6}\right) 166.6(\mathrm{C}), 161.0(\mathrm{CO}), 160.7(\mathrm{CO}), 154.0(\mathrm{C}), 153.2(\mathrm{C}), 134.0(\mathrm{C}), 131.5(\mathrm{CH}), 128.1$ (2xCH), $128.0(2 \times C H), 124.6(\mathrm{CH}), 111.3(\mathrm{CH}), 104.2(\mathrm{C}), 98.4(\mathrm{C}), 98.2(\mathrm{CH}) . v_{\max }$ (neat): 3349, 1664, 1608, 1539, $1381 \mathrm{~cm}^{-1}$. HRMS: $\mathrm{C}_{16} \mathrm{H}_{13} \mathrm{~N}_{2} \mathrm{O}_{4}\left[\mathrm{M}+\mathrm{H}^{+}\right]$requires 297.0870, found 297.0879. $\mathbf{R}_{f}$ : (1:1 EtOAc/ heptane): 0.2. M.pt.: decomp. $>260^{\circ} \mathrm{C}$.

$N$-(4-Methoxy, 7-hydroxy-2-oxo-2H-chromen-3-yl) benzamide (S4) 
<smiles>COc1ccc2c(O)c(NC(=O)c3ccccc3)c(=O)oc2c1</smiles>

Isolated as a pale yellow solid (50 mg, 39\%). ${ }^{1} \mathbf{H}$ NMR: $\delta$ (DMSO-d 6 , $\left.400 \mathrm{MHz}\right) 11.95(\mathrm{~s}, 1 \mathrm{H}, \mathrm{OH})$, 9.45 (s, 1H, NH), 8.01 (d, J=7.1 Hz, 2H, Ar-H), 7.81 (d, J=8.7 Hz, 1H, Ar-H), 7.58 (t, J=7.3 Hz, 1H, Ar-H), 7.51 (d, J=7.6 Hz, 2H, Ar-H), 7.02 (m, 2H, Ar-H), 3.88 (s, 3H, $\left.\mathrm{CH}_{3}\right) .{ }^{13}$ C NMR: $\delta(101 \mathrm{MHz}$, DMSO-d $\left.\mathrm{d}_{6}\right) 166.5(\mathrm{CO}), 162.6(\mathrm{CO}), 153.5(\mathrm{C}), 133.9(\mathrm{CH}), 131.6(\mathrm{CH}), 128.2(2 \mathrm{xCH}), 128.0$ $(2 \mathrm{xCH}), 124.8(\mathrm{C}), 112.2(\mathrm{CH}), 109.4(\mathrm{C}), 100.5(\mathrm{CH}), 55.9\left(\mathrm{CH}_{3}\right)$. Three C signals not detected.v ${ }_{\max }$ (neat): 3299, 1674, 1609, 1372, 1294, $688 \mathrm{~cm}^{-1}$. HRMS: $\mathrm{C}_{17} \mathrm{H}_{14} \mathrm{NO}_{5}\left[\mathrm{M}+\mathrm{H}^{+}\right]$requires 312.0866, found 312.0883. $\mathbf{R}_{f}$ : (1:1 EtOAc/ heptane): 0.4. M.pt.: decomp. $>240{ }^{\circ} \mathrm{C}$.

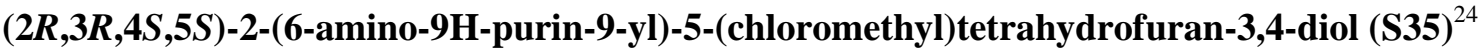<smiles>Nc1ncnc2c1ncn2[C@@H]1O[C@H](CCl)[C@@H](O)[C@H]1O</smiles>

To an ice cooled suspension of adenosine $(1.00 \mathrm{~g}, 3.74 \mathrm{mmol})$ in acetonitrile $(10 \mathrm{~mL})$ was added pyridine $(0.61 \mathrm{~mL}, 7.48 \mathrm{mmol})$ and thionyl chloride $(1.40 \mathrm{~mL}, 18.7 \mathrm{mmol})$ was added dropwise over 5 minutes. The reaction mixture was stirred at $0{ }^{\circ} \mathrm{C}$ for 3 hours before being warmed to $22{ }^{\circ} \mathrm{C}$ and stirred for 16 hours. The resulting precipitate was filtered and dissolved in water/ methanol (5:1). Aqueous ammonia $(25 \%, 2.00 \mathrm{~mL})$ was added and the reaction mixture stirred at $22{ }^{\circ} \mathrm{C}$ for 30 minutes. The solvent was removed under reduced pressure to provide the title compound as a colourless amorphous solid (1.05 g, 98\%). ${ }^{1} \mathbf{H}$ NMR: $\delta$ (400 MHz, DMSO-d $\left.{ }_{6}\right) 8.34$ (s, 1H, Ar-H,), $8.16(\mathrm{~s}, 1 \mathrm{H}, \mathrm{Ar}-\mathrm{H}), 7.29$ (s, 2H, NH$)_{2}, 5.93(\mathrm{~d}, J=5.7 \mathrm{~Hz}, 1 \mathrm{H}, \mathrm{CH}), 5.58(\mathrm{~s}, 1 \mathrm{H}, \mathrm{OH}), 5.44(\mathrm{~s}, 1 \mathrm{H}$, $\mathrm{OH}), 4.75$ (t, J=5.3 Hz, 1H, CH), 4.24 (t, J=4.3 Hz, $1 \mathrm{H}, \mathrm{CH}), 4.08$ (q, J=5.3 Hz, 1H, CH), 3.96 (dd, $\left.J_{l}=5.1, J_{2}=11.6 \mathrm{~Hz}, 1 \mathrm{H}, \mathrm{CH}_{2}\right), 3.84\left(\mathrm{dd}, J_{l}=6.4, J_{2}=11.6 \mathrm{~Hz}, 1 \mathrm{H}, \mathrm{CH}_{2}\right) .{ }^{13} \mathbf{C}$ NMR: $\delta(101 \mathrm{MHz}$, DMSO-d $\left._{6}\right) 156.1(\mathrm{C}), 152.7(\mathrm{CH}), 149.4(\mathrm{C}), 139.7(\mathrm{CH}), 119.1(\mathrm{C}), 87.4(\mathrm{CH}), 83.63(\mathrm{CH}), 72.6$ $(\mathrm{CH}), 71.2(\mathrm{CH}), 44.8\left(\mathrm{CH}_{2}\right) \cdot \mathrm{m} / z:\left(\mathrm{ES}^{+}\right) 286\left(\mathrm{M}^{35} \mathrm{Cl}+\mathrm{H}^{+}, 100 \%\right), 288\left(\mathrm{M}^{37} \mathrm{Cl}+\mathrm{H}^{+}, 35 \%\right)$. Mpt.: 72 ${ }^{\circ} \mathrm{C}$. (lit. $\left.75-80{ }^{\circ} \mathrm{C}\right) .{ }^{25} \boldsymbol{v}_{\max }$ (neat): $3148,1648,1601 \mathrm{~cm}^{-1}$. $\mathbf{R}_{f}:$ (EtOAc) 0.20 . 


\section{Enzymatic assays using Novo}

All protein concentrations were measured on a Trinean Xpose micro-volume spectrometer, using an E1\% of 11.308 for NovO. HPLC analysis was carried out on an Agilent 1100 series instrument using the following method:

Column: Waters Xbridge $\mathrm{C} 18$ column $\left(50 \mathrm{~mm} \times 4.6 \mathrm{~mm}\right.$ i.d. $3 \mu \mathrm{m}$ packing diameter) at $40{ }^{\circ} \mathrm{C}$.

Method: $\quad \mathbf{A}=10 \mathrm{mM}$ ammonium bicarbonate in water adjusted to $\mathrm{pH} 10$ with ammonia solution.

$\mathbf{B}=$ Acetonitrile.

Flow rate: $3 \mathrm{~mL} / \mathrm{min}$.

\section{Gradient profile:}

\begin{tabular}{ccc} 
Time (min) & \% A & \% B \\
\hline 0 & 99 & 1 \\
\hline 0.1 & 99 & 1 \\
\hline 4 & 3 & 97 \\
\hline 5 & 3 & 97
\end{tabular}

Detection: Detection wavelength of $320 \mathrm{~nm}$ used for all aminocoumarin substrates and methylated products.

\section{General Procedure for KIE Measurements}

All reactions were carried out in triplicate in 96 well plate on format $200 \mathrm{uL}$ scale using a multichannel pipette for reagent addition and sampling of aliquots.

To a solution of $N$-(4,7-Dihydroxy-2-oxo- $2 \mathrm{H}$-chromen-3-yl) benzamide (6) (final concentration 0.5 $\mathrm{mM}), \quad(2 R, 3 R, 4 S, 5 S)$-2-(6-amino-9H-purin-9-yl)-5-(chloromethyl)tetrahydrofuran-3,4-diol (CIDA, S35) (from a $100 \mathrm{mM}$ stock solution in DMSO, final concentration $2 \mathrm{mM}$ ) and methionine,

methionine- ${ }^{13} \mathrm{C}$ or methionine- $\mathrm{d}_{3}$ as appropriate (from a $100 \mathrm{mM}$ stock solution in $250 \mathrm{mM}$ aqueous $\mathrm{NaOH}$, final concentration $2.5 \mathrm{mM}$ ) in phosphate buffer $\left(50 \mathrm{mM}, \mathrm{pH}\right.$ 6.5) was added SalL ${ }^{13,14}$ (final concentration $0.1 \mathrm{mg} / \mathrm{ml}$ ). The reaction was incubated at $37^{\circ} \mathrm{C}, 750 \mathrm{rpm}$ for 2 hours. Methyltransfer reactions were initiated by the addition of $20 \mu \mathrm{L} \mathrm{NovO}$ (final concentration $0.5 \mathrm{mg} / \mathrm{mL}$ ) and quenched after 3 minutes by transferring $50 \mu \mathrm{L}$ of the reaction into a preheated vial and incubated at $97{ }^{\circ} \mathrm{C}$ for 10 minutes before clarifying by centrifugation $\left(15\right.$ minutes, $\left.13.2 \mathrm{k} \mathrm{rpm}, 4{ }^{\circ} \mathrm{C}\right)$. The supernatant was transfered to an HPLC insert vial and $5 \mathrm{uL}$ injected directly onto the HPLC according to the above method. \% conversion was calculated by the ratio of area/area\% of starting material $(\mathrm{RT}=2.528 \mathrm{~min})$ to product $(\mathrm{RT}=2.664 \mathrm{~min})$.

\section{Methyl transfer assay using NovO or NovO mutants}

To a $1.5 \mathrm{~mL}$ Eppendorf vial containing in sodium phosphate buffer $(50 \mathrm{mM}$, pH 6.5 to a total volume of $0.5 \mathrm{~mL}$ ), $100 \mu \mathrm{M}$ substrate (from a $50 \mathrm{mM}$ stock solution in DMSO), $2 \mathrm{mM} \mathrm{SAM}$ (from a $20 \mathrm{mM}$ 
stock solution in sodium phosphate buffer) and bovine serum albumin $(0.1 \mathrm{mg} / \mathrm{mL}$, taken from $2 \mathrm{mg} / \mathrm{mL}$ stock solution in sodium phosphate buffer) was added $250 \mu \mathrm{g}$ purified enzyme (final concentration $=1.9 \mu \mathrm{M}$ ) in SEC buffer (see above) containing $40 \%$ glycerol. Reactions were incubated at $35^{\circ} \mathrm{C}, 1000 \mathrm{rpm}$ using a thermomixer and quenched after 24 hours by heating to $80{ }^{\circ} \mathrm{C}$ for 15 minutes. Samples were cooled to $4{ }^{\circ} \mathrm{C}$ for 10 minutes, clarified by centrifugation (10 minutes, $13200 \mathrm{rpm}, 4^{\circ} \mathrm{C}$ ) and $5 \mu \mathrm{L}$ injected directly onto the HPLC instrument for analysis. HPLC analysis was carried out on an Agilent 1100 series instrument using the following method:

Column: Waters Xbridge C18 column (50mm x $4.6 \mathrm{~mm}$ i.d. $3 \mu \mathrm{m}$ packing diameter) at $40{ }^{\circ} \mathrm{C}$.

Method: $\quad \mathbf{A}=10 \mathrm{mM}$ ammonium bicarbonate in water adjusted to $\mathrm{pH} 10$ with ammonia solution.

$\mathbf{B}=$ Acetonitrile.

Flow rate: $3 \mathrm{~mL} / \mathrm{min}$.

\section{Gradient profile:}

\begin{tabular}{ccc} 
Time (min) & \% A & \% B \\
\hline 0 & 99 & 1 \\
\hline 0.1 & 99 & 1 \\
\hline 4 & 3 & 97 \\
\hline 5 & 3 & 97
\end{tabular}

Detection: Detection wavelength of $320 \mathrm{~nm}$ used for all aminocoumarin substrates and methylated products.

Conversions were calculated by area/area\% conversion from starting material to methylated product (Figure S10).

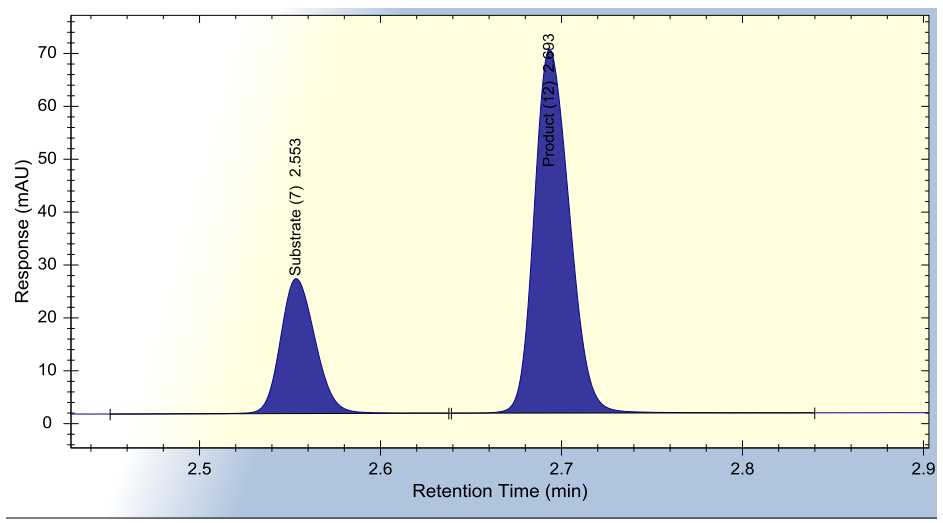

Figure S10. Exemplar HPLC spectrum for the MT assay used to determine the catalytic activity of NovO WT and mutants. 


\section{Analysis of NovO mutants by methyl transfer assay}

Assays were carried out as described in Section 12. Percentage (\%) conversion calculated by HPLC area/area\% observed for each mutant (Table 1).<smiles>O=C(Nc1c(O)c2ccc(O)cc2oc1=O)c1ccccc1</smiles>

6

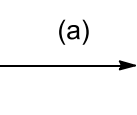

$\mathrm{HO}$<smiles>Cc1c(O)ccc2c(O)c(NC(=O)c3ccccc3)c(=O)oc12</smiles>

4a

\begin{tabular}{cc} 
Mutant & \% Conversion after 24 h \\
\hline WT & 98 \\
\hline F14M & 19 \\
\hline F14L & 30 \\
\hline R24F & 15 \\
\hline R116L & 1 \\
\hline R116K & $<1$ \\
\hline N117A & $<1$ \\
\hline H120A* & 0 \\
\hline H120N & $<1$ \\
\hline R121L & $<1$ \\
\hline R121Q/G108D & $<1$ \\
\hline Y216F & 20 \\
\hline Control** & 0
\end{tabular}

Table 2. Analysis of NovO WT and mutant library. Reagents and conditions: (a) NovO WT or mutant, SAM, bovine serum albumin, $50 \mathrm{mM}$ sodium phosphate buffer $\mathrm{pH} 6.5,35^{\circ} \mathrm{C}, 24 \mathrm{~h}$. $*$ Cell lysate used due to poor solubility of H120A mutant. **Reactions were carried out next to a negative control in which no MT was added.

\section{Preparative scale methylation of 6 using NovO}

\section{N-(4,7-dihydroxy-8-methyl-2-oxo-2H-chromen-3-yl)benzamide ${ }^{17}$}<smiles>O=C(Nc1c(O)c2ccc(O)c([N+](=O)[O-])c2oc1=O)c1ccccc1</smiles>

To a $40 \mathrm{~mL}$ aliquot of $E$. coli cell lysate from the overexpression of NovO in phosphate buffer (50 mM, pH 6.5, resupended at $10 \mathrm{~mL} / \mathrm{g}$ cell pellet) was added bovine serum albumin (final concentration $1 \mathrm{mg} / \mathrm{mL}), \mathrm{SAM}(72.0 \mathrm{mg}$ in $2.5 \mathrm{~mL}$ phosphate buffer, $0.126 \mathrm{mmol})$ and $\mathrm{N}$-(4,7dihydroxy-2-oxo-2H-chromen-3-yl)benzamide 6 (20 mg in $2.5 \mathrm{~mL}$ dimethyl sulfoxide, $0.084 \mathrm{mmol}$ ). The reaction was incubated at $35{ }^{\circ} \mathrm{C}, 350 \mathrm{rpm}$ for 24 hours, before adding a further portion of SAM (72.0 $\mathrm{mg}$ in $1 \mathrm{~mL}$ phosphate buffer, $0.126 \mathrm{mmol}$ ). The reaction mixture was incubated for a further 16 hours at $35{ }^{\circ} \mathrm{C}, 350 \mathrm{rpm}$ before adding aqueous $5 \mathrm{M} \mathrm{HCl}$ to $\mathrm{pH} 2$ and clarifying the suspension by 
centrifugation (4000 rpm, $20 \mathrm{~min}$ ). HPLC conversion at end of reaction: 90\%. The supernatant was concentrated by lyophilisation and the residue purified by mass-directed automated purification (MDAP). The product was precipitated by the addition of $\mathrm{MeOH}(5 \mathrm{~mL})$ and filtered to provide the title compound as a pale yellow amorphous solid $(14 \mathrm{mg}, 67 \%) .{ }^{1} \mathbf{H}$ NMR: $\delta$ (400 MHz, DMSO-d $\left.{ }_{6}\right) 11.71$ (br. s., 1H, OH), 10.42 (s, 1H, OH), 9.41 (s, 1H, NH), 8.01 (d, J=7.4 Hz, 2H, Ar-H), 7.48-7.62 (m, 2x2H, Ar-H), 6.89 (d, J=8.7 Hz, 1H, Ar-H), $2.18\left(\mathrm{~s}, 3 \mathrm{H}, \mathrm{CH}_{3}\right) .{ }^{13} \mathbf{C}$ NMR: $\delta$ (101 MHz, DMSO-d $\left.{ }_{6}\right) 166.5$ (CO), 160.8 (CO), 160.5 (C), 159.1 (C), 151.5 (C), 133.9 (C), 131.6 $(\mathrm{CH}), 128.1(2 \mathrm{xCH}), 128.0(2 \mathrm{xCH}), 121.5(\mathrm{CH}), 111.8(\mathrm{CH}), 110.4(\mathrm{C}), 107.9(\mathrm{C}), 99.9(\mathrm{C}), 8.1$ $\left(\mathrm{CH}_{3}\right) . v_{\text {max }}$ (neat): $3215,1567,1534,1369,1312 \mathrm{~cm}^{-1}$. HRMS: $\mathrm{C}_{17} \mathrm{H}_{14} \mathrm{NO}_{5}\left[\mathrm{M}+\mathrm{H}^{+}\right]$requires 312.0868, found 312.0866. $\mathbf{R}_{f}$ : (EtOAc): 0.28. M.pt.:. $310-312{ }^{\circ} \mathrm{C}$.

\section{General procedure for the preparation of Nov0 mutants by Site-Directed Mutagenesis}

Site-directed mutagenesis (SDM) was accomplished by a modified QuickChange protocol using primers bearing desired mutations (see below). Colonies containing the desired mutation were identified by gene sequencing using T7 forward and reverse primers. Colonies bearing the desired mutation were amplified using a Qiagen Miniprep kit according to the manufacturer's instructions, eluting with $100 \mu \mathrm{L}$ elution buffer. The gene sequence for all mutants was confirmed by gene sequencing using the gene sequencing primers detailed below.

\section{SDM Primers (5' to 3')}

$\begin{array}{ll}\text { F14M fwd } & \text { GGTTCCGAAGCAGAAGCAATGCACCGCATGGGCTCG } \\ \text { F14M rev } & \text { CGAGCCCATGCGGTGCATTGCTTCTGCTTCGGAACC } \\ \text { F14L fwd } & \text { GGTTCCGAAGAGAAGCACTCCACCGCATGGGCTCG } \\ \text { F14L rev } & \text { CGAGCCCATGCGGTGGAGTGCTTCTGCTTCGGAACC } \\ \text { R24M fwd } & \text { GGCTCGCAAGCATCGCACATGTATGACGAATTGTT } \\ \text { R24M rev } & \text { AACAAATTCGTCATACATGTGCGATGCTTGCGAGCC } \\ \text { R24F fwd } & \text { GGCTCGCAAGCATCGCACUTCTATGACGAATTTTT } \\ \text { R24F rev } & \text { AACAAATTCGTCATAGAAGTGCGATGCTTGCGAGCC } \\ \text { H120F fwd } & \text { GTGAGTCGTAATGCCTTTTCCGTCTGACCCGCCTG } \\ \text { H120F rev } & \text { CAGGCGGGTCAGACGGAAAAAGGCATTACGACTCAC } \\ \text { H120N fwd } & \text { GTGAGTCGTAATGCCTTTAACCGTCTGACCCGCCTG } \\ \text { H120N rev } & \text { CAGGCGGGTCAGACGGTTAAAGGCATTACGACTCAC } \\ \text { H120A fwd } & \text { GTGAGTCGTAATGCCTTTGCCCGTCTGACCCGCCTG } \\ \text { H120A rev } & \text { CAGGCGGGTCAGACGGGCAAAGGCATTACGACTCAC } \\ \mathbf{N 1 1 7 A ~ f w d ~} & \text { CTGGTCGTGAGTCGTGCTGCCTTTCACCGTCTGACC } \\ \mathbf{N 1 1 7 A ~ r e v ~} & \text { GGTCAGACGGTGAAAGGCAGCACGACTCACGACCAG } \\ \mathbf{R 1 2 1 Q} \text { fwd } & \text { CGTAATGCCTTTCACCAGCTGACCCGCCTGCCG }\end{array}$




$\begin{array}{ll}\text { R121Q rev } & \text { CGGCAGGCGGGTCAGCTGGTGAAAGGCATTACG } \\ \text { R121L fwd } & \text { CGTAATGCCTTTCACCTTCTGACCCGCCTGCCG } \\ \text { R121L rev } & \text { CGGCAGGCGGGTCAGAAGGTGAAAGGCATTACG } \\ \text { Y216F fwd } & \text { GTGTGGATCGATGACCAAGGCTTCGGTGTGCCGACGGTT } \\ \text { Y216F rev } & \text { AACCGTCGGCACACCGAAGCCTTGGTCATCGATCCACAC }\end{array}$

Gene sequencing primers (5' to 3')

$\begin{array}{ll}\text { NovO } 1 \text { fwd } & \text { CAATCACGGGTTCCGAAG } \\ \text { NovO } 1 \text { rev } & \text { CTTCGGAACCCGTGATTG } \\ \text { NovO } 2 \text { fwd } & \text { CGGTATTGCAGATGGCC } \\ \text { NovO } 2 \text { rev } & \text { GGCCATCTGCAATACCG } \\ \text { NovO } 3 \text { fwd } & \text { GTCGATCTGAGCGAAGAC } \\ \text { NovO } 3 \text { rev } & \text { GTCTTCGCTCAGATCGAC } \\ \text { NovO } 4 \text { fwd } & \text { AGGCATGGAAGATCTGG } \\ \text { NovO } 4 \text { rev } & \text { CCAGATCTTCCATGCCT } \\ \text { NovO } 5 \text { fwd } & \text { GCTGCGCCTGGCTAAAC } \\ \text { NovO } 5 \text { rev } & \text { GTTTAGCCAGGCGCAGC } \\ \text { NovO 6 fwd } & \text { CATGGGTTACGTTCCTG } \\ \text { NovO } 6 \text { rev } & \text { CAGGAACGTAACCCATG } \\ \text { NovO } 7 \text { fwd } & \text { CTATGCGCCGCGTCTGG } \\ \text { NovO } 7 \text { rev } & \text { CCAGACGCGGCGCATAG } \\ \text { NovO } 8 \text { fwd } & \text { GTGCCGACGGTTAAATG } \\ \text { NovO } 8 \text { rev } & \text { CATTTAACCGTCGGCAC }\end{array}$

\section{Gene synthesis and cloning}

The gene for NovO with a C-terminal 6-His tag was synthesized by GenScript with codon optimization and subcloned into a pET26b(+) plasmid using NdeI and XhoI restriction sites. The plasmid was received from GenScript in the lyophilised form and was resuspended in $40 \mu \mathrm{L}$ water. E.coli TOP10 competent cells were transformed using the heat shock method with $5 \mu \mathrm{L}$ of DNA solution. Transformants were plated on LB agar containing $50 \mu \mathrm{g} / \mathrm{mL}$ kanamycin and grown at $37^{\circ} \mathrm{C}$ overnight. Colonies were inoculated into $10 \mathrm{~mL} \mathrm{LB}$ media containing $50 \mu \mathrm{g} / \mathrm{mL}$ kanamycin and grown overnight at $30{ }^{\circ} \mathrm{C}$. The DNA was then extracted and purified using a Qiagen Miniprep kit according to the manufacturer's instructions, eluting with $100 \mu \mathrm{L}$ elution buffer.

\section{General procedure for the expression of NovO and NovO mutants}

The plasmid pET26b(+)-NovO was transformed into E. coli BL21 DE3 competent cells (Invitrogen) for protein expression. Transformants harbouring the plasmids were grown at $37{ }^{\circ} \mathrm{C}$ in $\mathrm{LB}$ medium supplemented with $50 \mu \mathrm{g} / \mathrm{mL}$ kanamycin and $1 \%$ glucose overnight. This seed culture was used to inoculate Magic Media supplemented with kanamycin (final concentration of $50 \mu \mathrm{g} / \mathrm{mL}$ ) and 
Component B (5\% v/v) using $2 \%$ inoculant. The cultures were incubated at $30{ }^{\circ} \mathrm{C}, 200 \mathrm{rpm}$ and grown to an OD of $\sim 2$ before the incubating at $18{ }^{\circ} \mathrm{C}, 200 \mathrm{rpm}$ overnight. The cells were harvested by centrifugation (4400 rpm, $4{ }^{\circ} \mathrm{C}, 20$ minutes), the supernatant discarded and the cell pellets stored at $80{ }^{\circ} \mathrm{C}$ for further use.

\section{Preparation of SelMet labeled Nov0}

The plasmid pET26b(+)-NovO was transformed into E. coli BL21 DE3 competent cells (Invitrogen) for protein expression. Transformants harbouring the plasmids were grown at $37{ }^{\circ} \mathrm{C}$ in $100 \mathrm{~mL} \mathrm{LB}$ medium supplemented with $50 \mu \mathrm{g} / \mathrm{mL}$ kanamycin and $1 \%$ glucose for 7 hours at $37{ }^{\circ} \mathrm{C}, 240 \mathrm{rpm}$. This seed culture was used to inoculate 1 L Modified Terrific Broth (MTB) supplemented with kanamycin (final concentration of $50 \mu \mathrm{g} / \mathrm{mL}$ ) and $4 \%$ glucose, using $2 \%$ inoculant. The culture was grown overnight at $30{ }^{\circ} \mathrm{C}, 180 \mathrm{rpm}$. The culture was spun $\left(4700 \mathrm{rpm}, 22{ }^{\circ} \mathrm{C}, 30\right.$ minutes $)$ and the supernatant was discarded. The pellet was resuspended in G1X minimal media supplemented with sorbitol $(440 \mathrm{mM})$ betaine $(1.5 \mathrm{mM})$ glycerol $(1 \% \mathrm{v} / \mathrm{v})$ kanamycin $(50 \mu \mathrm{g} / \mathrm{mL})$ and amino acids threonine, lysine, phenylalanine (each at $100 \mu \mathrm{g} / \mathrm{mL}$ ) and leucine, isoleucine, valine and selenomethionine (each at $50 \mu \mathrm{g} / \mathrm{mL}$ ). The culture was incubated at $37{ }^{\circ} \mathrm{C}, 180 \mathrm{rpm}$ for 30 minutes and then at $18{ }^{\circ} \mathrm{C}, 180 \mathrm{rpm}$ for 30 minutes before inducing with isopropyl $\beta-D-1$ thiogalactopyranoside (IPTG) (final concentration of $100 \mu \mathrm{M}$ ) and incubating overnight at $18{ }^{\circ} \mathrm{C}$, $180 \mathrm{rpm}$. The cells were harvested by centrifugation (4400 rpm, $4{ }^{\circ} \mathrm{C}, 20$ minutes), the supernatant discarded and the cell pellets stored at $-80{ }^{\circ} \mathrm{C}$ for further use.

\section{Purification of SelMet NovO and NovO mutants}

\section{General procedure for the purification of NovO, NovO mutants and SelMet NovO by affinity chromatography}

Binding Buffer (Buffer A): $50 \mathrm{mM}$ Tris-HCl, $300 \mathrm{mM} \mathrm{NaCl}, \mathrm{pH} 8.0$

Elution Buffer (Buffer B): 50 mM Tris-HCl, 300 mM NaCl, 500 mM imidazole, pH 8.0

The cell pellet ( $\sim 30 \mathrm{~g}$ ) was resuspended in $200 \mathrm{~mL}$ binding buffer and the cells lysed by sonication on ice using a $19 \mathrm{~mm}$ probe for 5 minutes ( $9.9 \mathrm{~s}$ on, $9.9 \mathrm{~s}$ off) at $40 \%$ intensity. The resulting cell lysate was separated by centrifugation ( $100000 \mathrm{~g}, 4{ }^{\circ} \mathrm{C}, 90$ minutes) and the supernatant collected. A $5 \mathrm{~mL}$ HisTRAP HP column (GE Healthcare 17-5248-02) was washed with 10 column volumes (CV) of elution buffer before being equilibrated with binding buffer. The clear cell lysate was loaded onto the column and eluted as follows:

Step 1: 0-20 mM imidazole (0-4\% elution buffer) for $10 \mathrm{CV}$ 
Step 2: 20-50 mM imidazole (4-10\% elution buffer) for $10 \mathrm{CV}$

Step 3: 50-500 mM imidazole (10-100\% elution buffer) for $10 \mathrm{CV}$

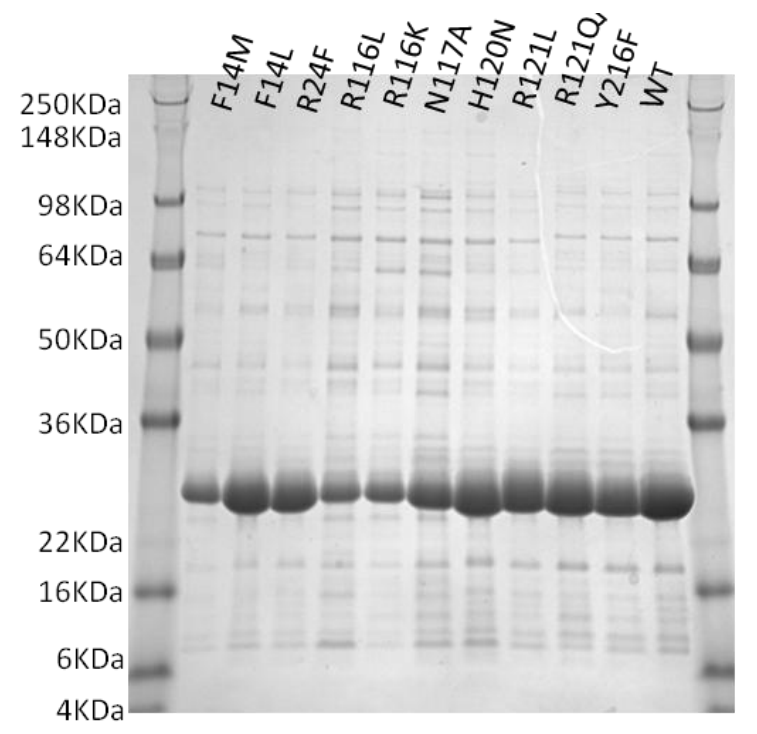

Figure S7. SDS-PAGE gel from purification of NovO mutant library. Theoretical mass of NovO WT: 26.23 KDa.

\section{General procedure for the purification of NovO by Size Exclusion Chromatography (SEC)}

SelMet labeled protein was additionally purified by SEC according to following procedure (SEC buffer: $100 \mathrm{mM}$ Tris-HCl, $150 \mathrm{mM} \mathrm{NaCl}, 5 \%$ glycerol, $\mathrm{pH}$ 8):

A HiLoad 26/60 $320 \mathrm{~mL}$ Superdex 75 prep grade SEC Column was equilibrated with SEC buffer and loaded with $10 \mathrm{~mL}$ of the pooled fractions from the affinity chromatography pool. The column was eluted over with SEC buffer, collecting $2 \mathrm{~mL}$ fractions, which were analysed by SDS-PAGE. Fractions containing NovO were concentrated as required using an Amicon Ultra 15 centrifugal filter with a $10 \mathrm{KDa}$ retention limit.

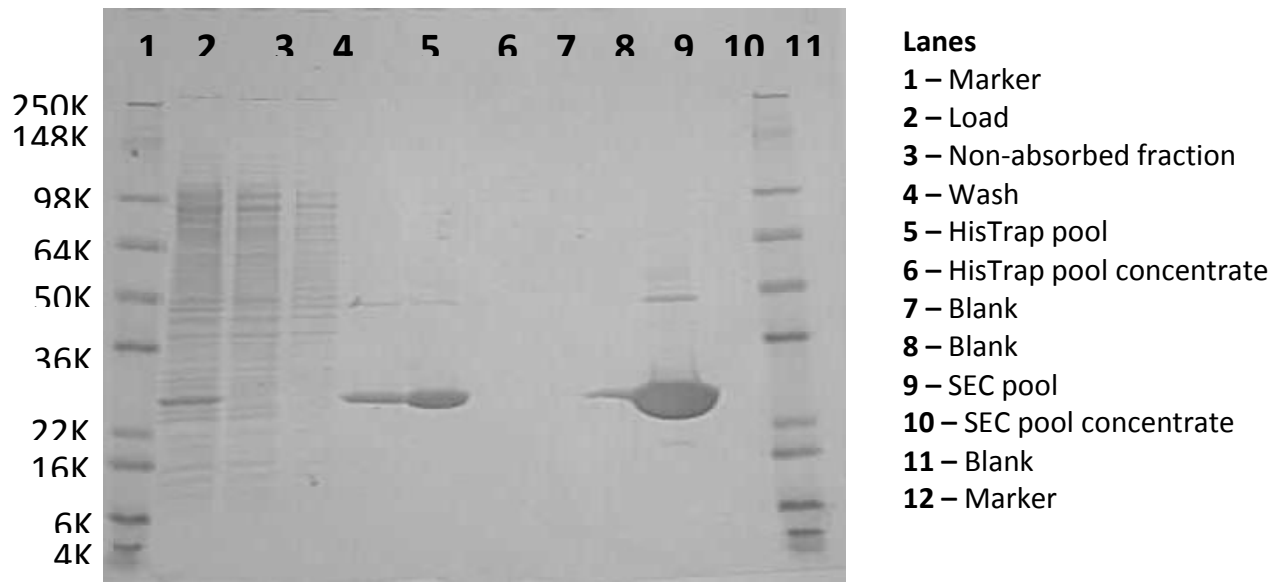

Figure S9. SDS-PAGE gel from purification of SelMet NovO. Theoretical mass of NovO WT: 26.23 KDa. 


\section{$18{ }^{1} \mathrm{H}$ and ${ }^{13} \mathrm{C}$ NMR Spectra of Novel Compounds}

tert-Butyl (7-chloro-4-hydroxy-2-oxo-2H-chromen-3-yl) carbamate (S28)

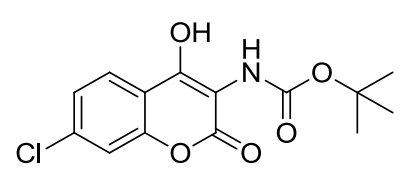

${ }^{1} \mathrm{H} \mathrm{NMR}_{\text {(DMSO-d }}, 400 \mathrm{MHz}$ ): $\delta=12.24$ (br. s., $1 \mathrm{H}$ ), 7.98 (br. s., $1 \mathrm{H}$ ), 7.86 (d, $\left.J=8.5 \mathrm{~Hz}, 1 \mathrm{H}\right), 7.59$ (d, J=2.0 Hz, $\left.1 \mathrm{H}\right), 7.44$ (dd, $\left.J=8.6,2.0 \mathrm{~Hz}, 1 \mathrm{H}\right), 1.42 \mathrm{ppm}$

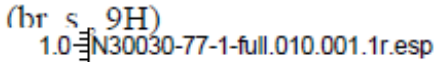

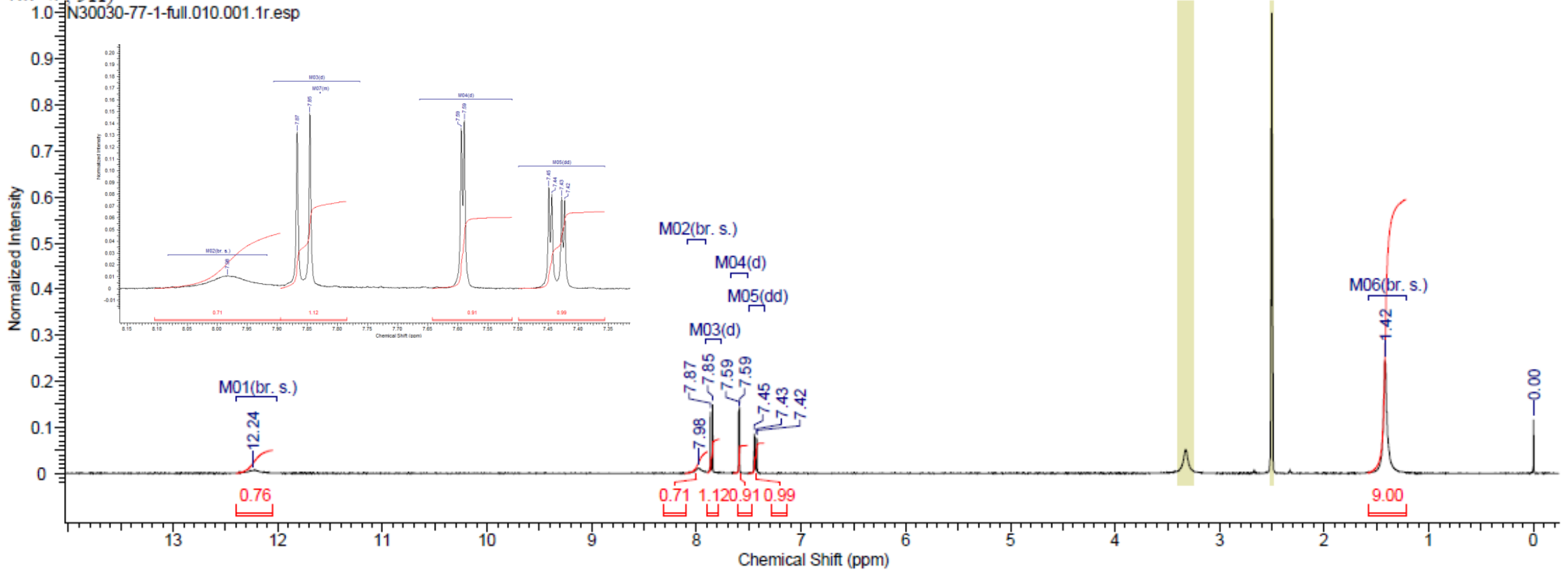




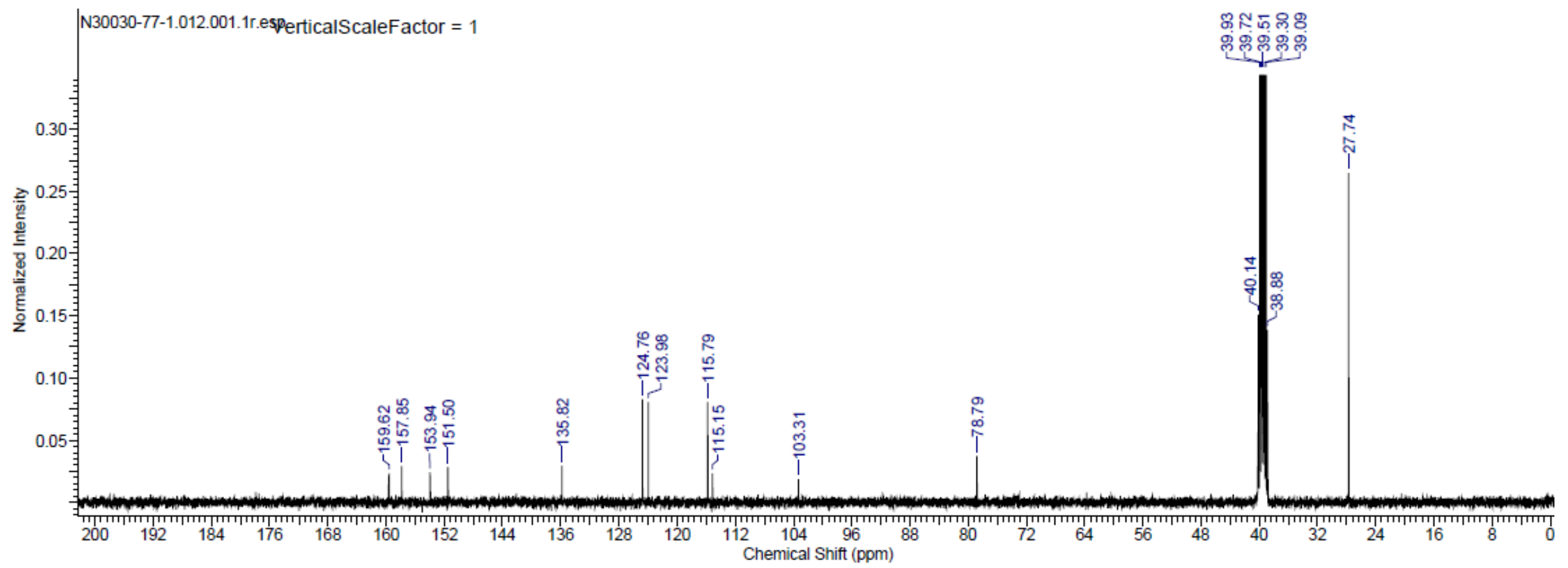


tert-Butyl (7-nitro-4-hydroxy-2-oxo-2H-chromen-3-yl) carbamate (S29)

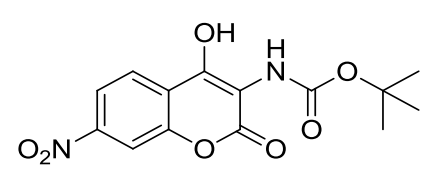

${ }^{1} \mathrm{H} \mathrm{NMR}\left(\mathrm{DMSO}_{6}, \mathrm{~d}_{6}, 400 \mathrm{MHz}\right): \delta=12.57$ (br. s., $\left.1 \mathrm{H}\right), 8.22(\mathrm{~d}, J=2.2 \mathrm{~Hz}, 1 \mathrm{H}), 8.16-8.20(\mathrm{~m}, 1 \mathrm{H}), 8.09(\mathrm{~d}, J=8.7 \mathrm{~Hz}, 1 \mathrm{H}), 8.11(\mathrm{~s}, 1 \mathrm{H}), 1.24-1.59 \mathrm{ppm}(\mathrm{m}, 9 \mathrm{H})$

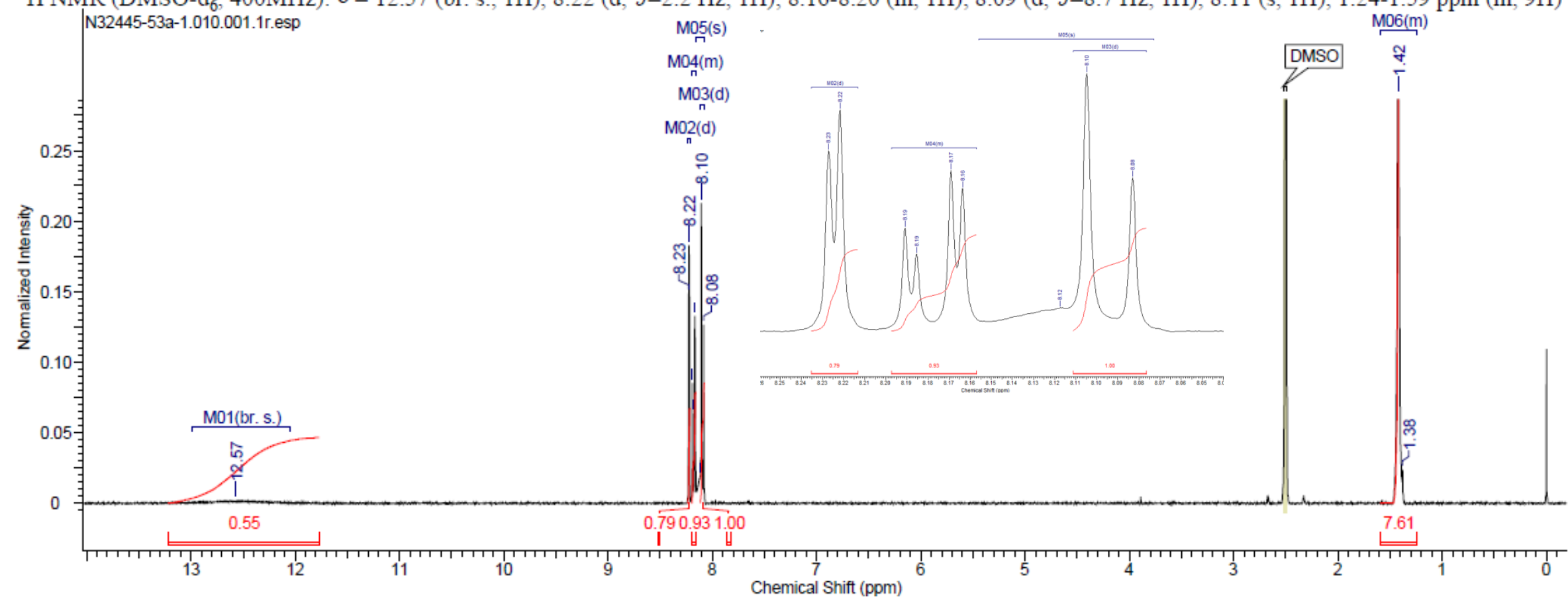




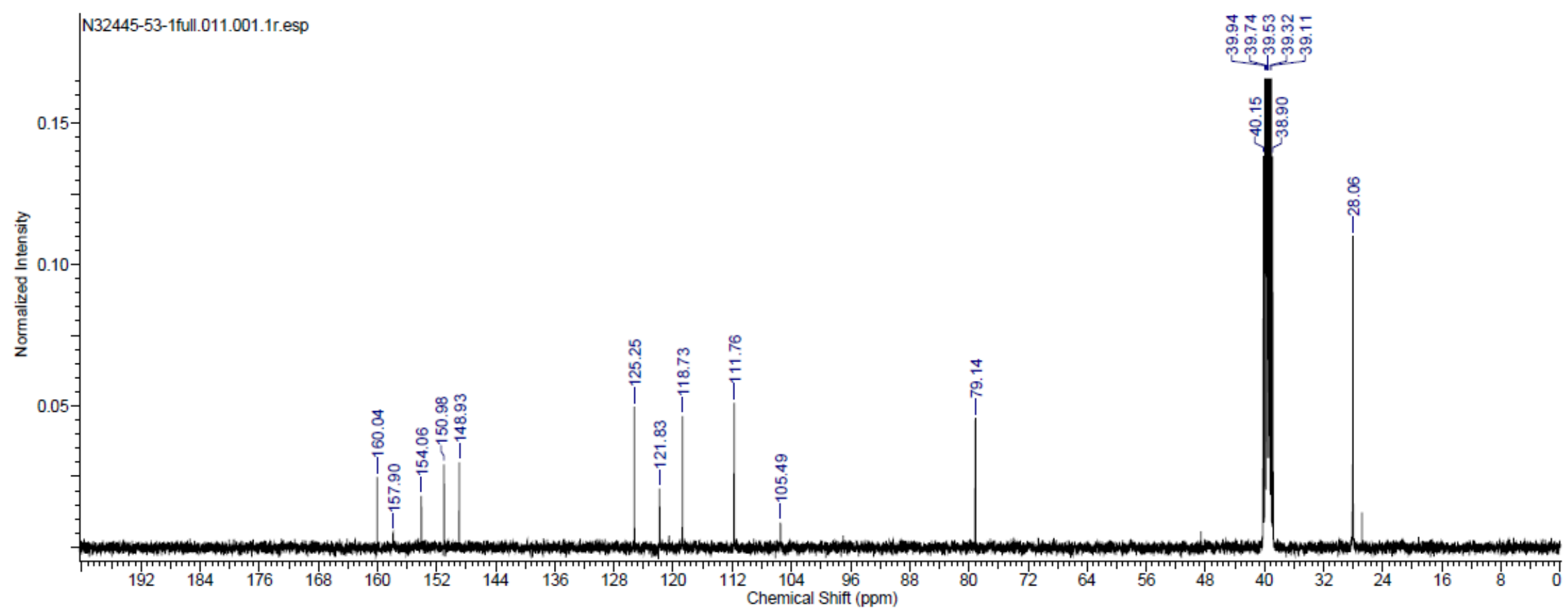


tert-Butyl (7-methoxy-4-hydroxy-2-oxo-2H-chromen-3-yl) carbamate (S30)

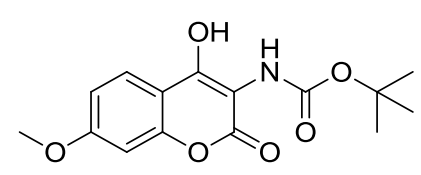

${ }^{1} \mathrm{H}$ NMR (DMSO-d $\left.6,400 \mathrm{MHz}\right): \delta=11.82$ (br. s., $\left.1 \mathrm{H}\right), 7.79-7.88(\mathrm{~m}, 1 \mathrm{H}), 7.75$ (d, J=8.9 Hz, 1H), $6.93-6.99$ (m, $\left.2 \mathrm{H}\right), 3.86(\mathrm{~s}, 3 \mathrm{H}), 1.43$ ppm (br. s., $\left.9 \mathrm{H}\right)$

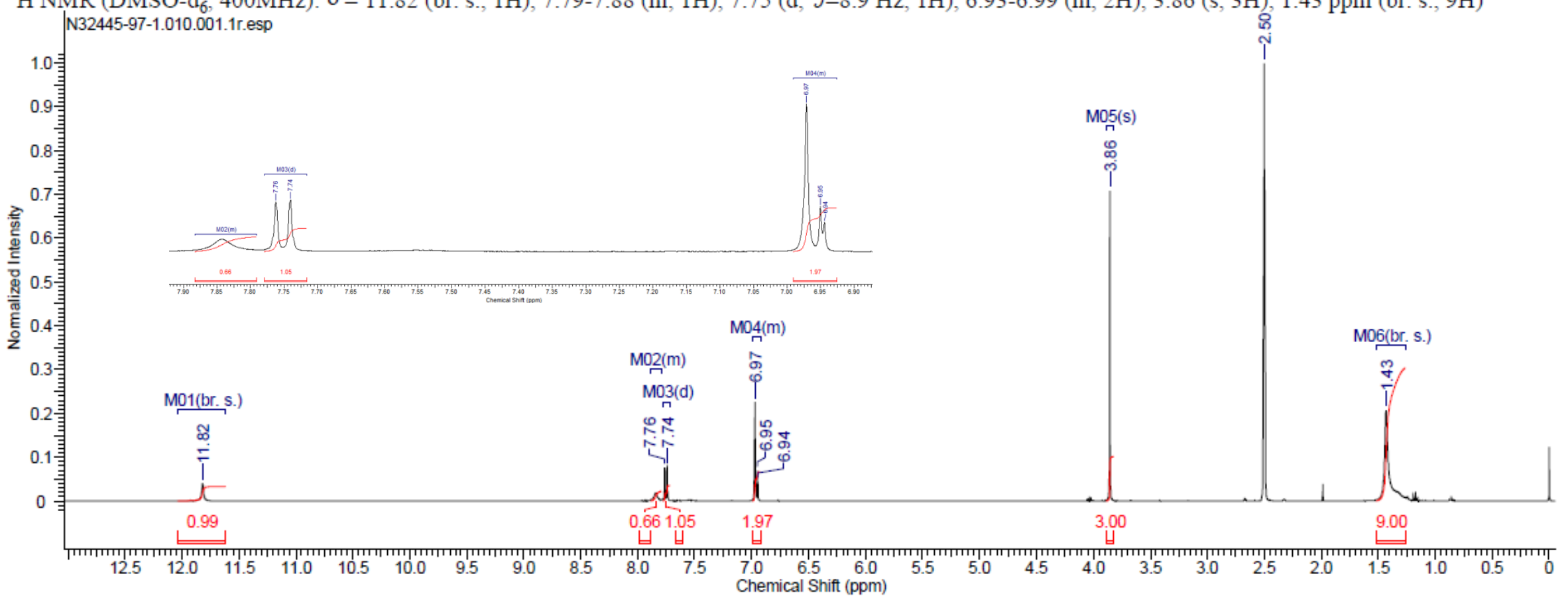




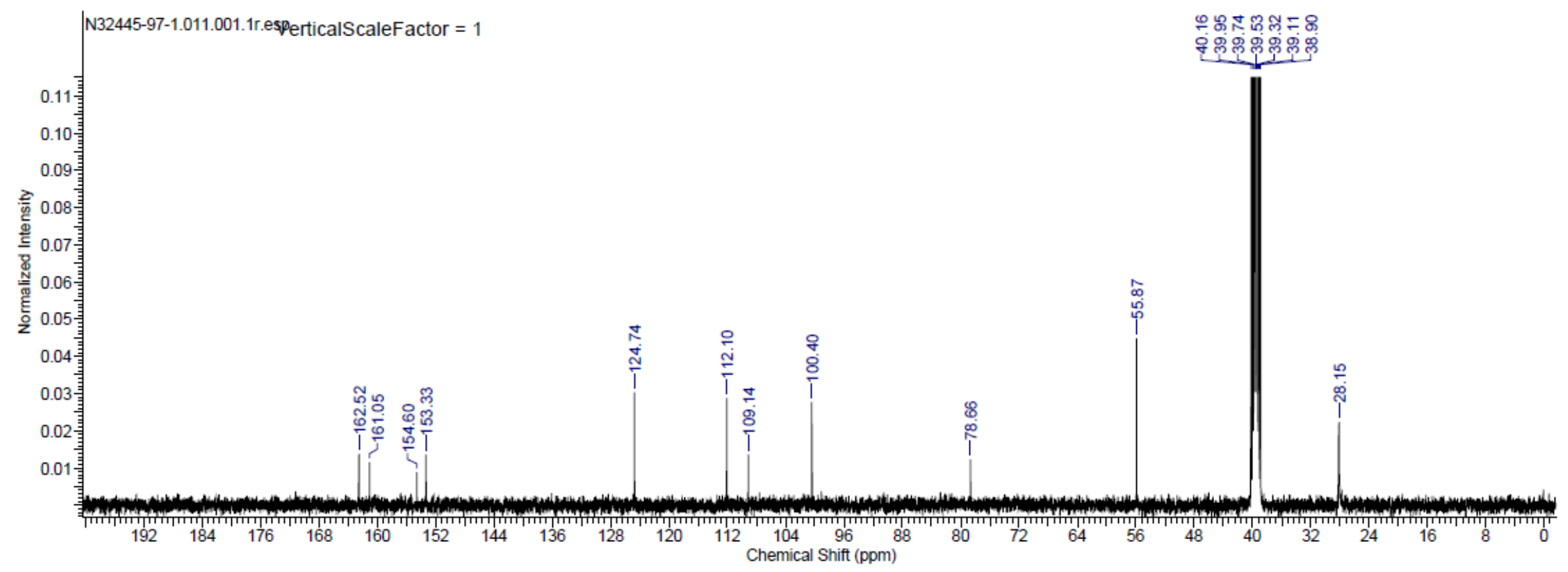


3-Amino-7-chloro-4-hydroxy-2H-chromen-2-one hydrochloride (S32)

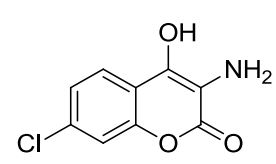

- $\mathrm{HCl}$

${ }^{1} \mathrm{H} \mathrm{NMR}_{(\mathrm{DMSO}} \mathrm{d}_{6,400 \mathrm{MHz}):} \delta=7.88$ (d, $\left.J=8.3 \mathrm{~Hz}, 1 \mathrm{H}\right), 7.64$ (br. s., $\left.2 \mathrm{H}\right), 7.43(\mathrm{~s}, 1 \mathrm{H}), 7.32 \mathrm{ppm}(\mathrm{d}, J=8.3 \mathrm{~Hz}, 1 \mathrm{H})$

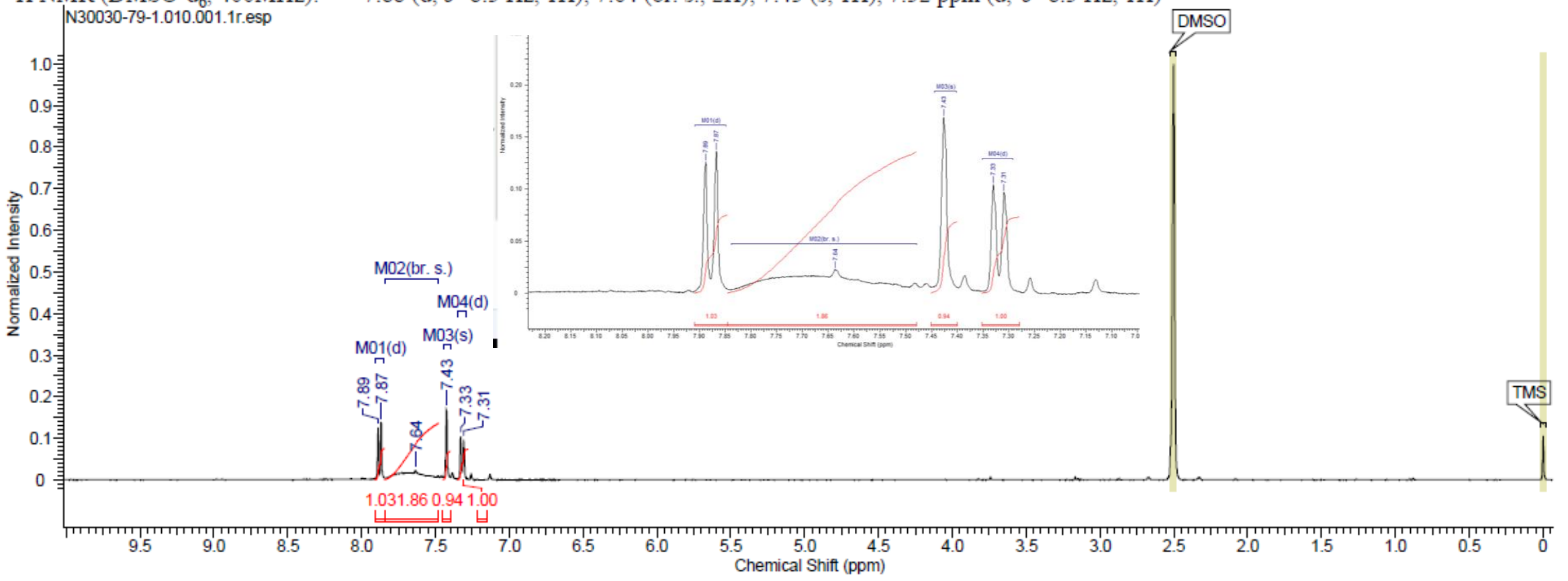




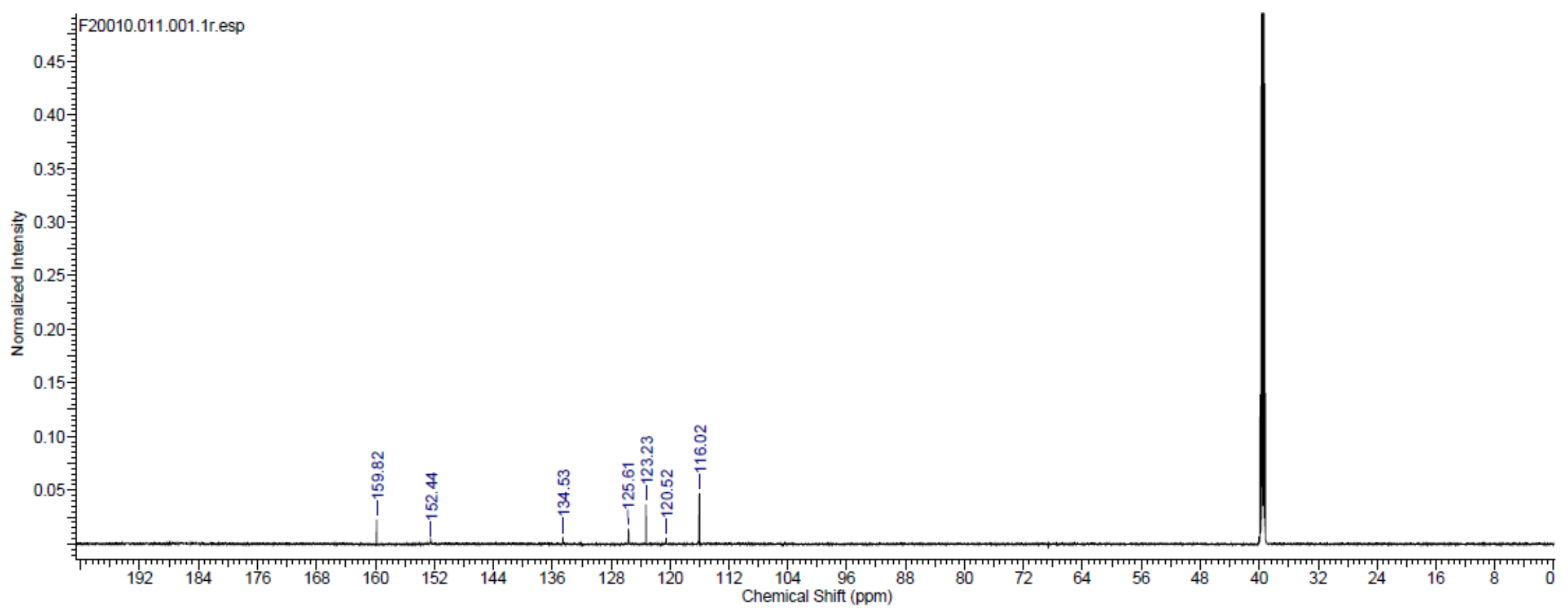


3-Amino-7-nitro-4-hydroxy-2H-chromen-2-one hydrochloride (S33)
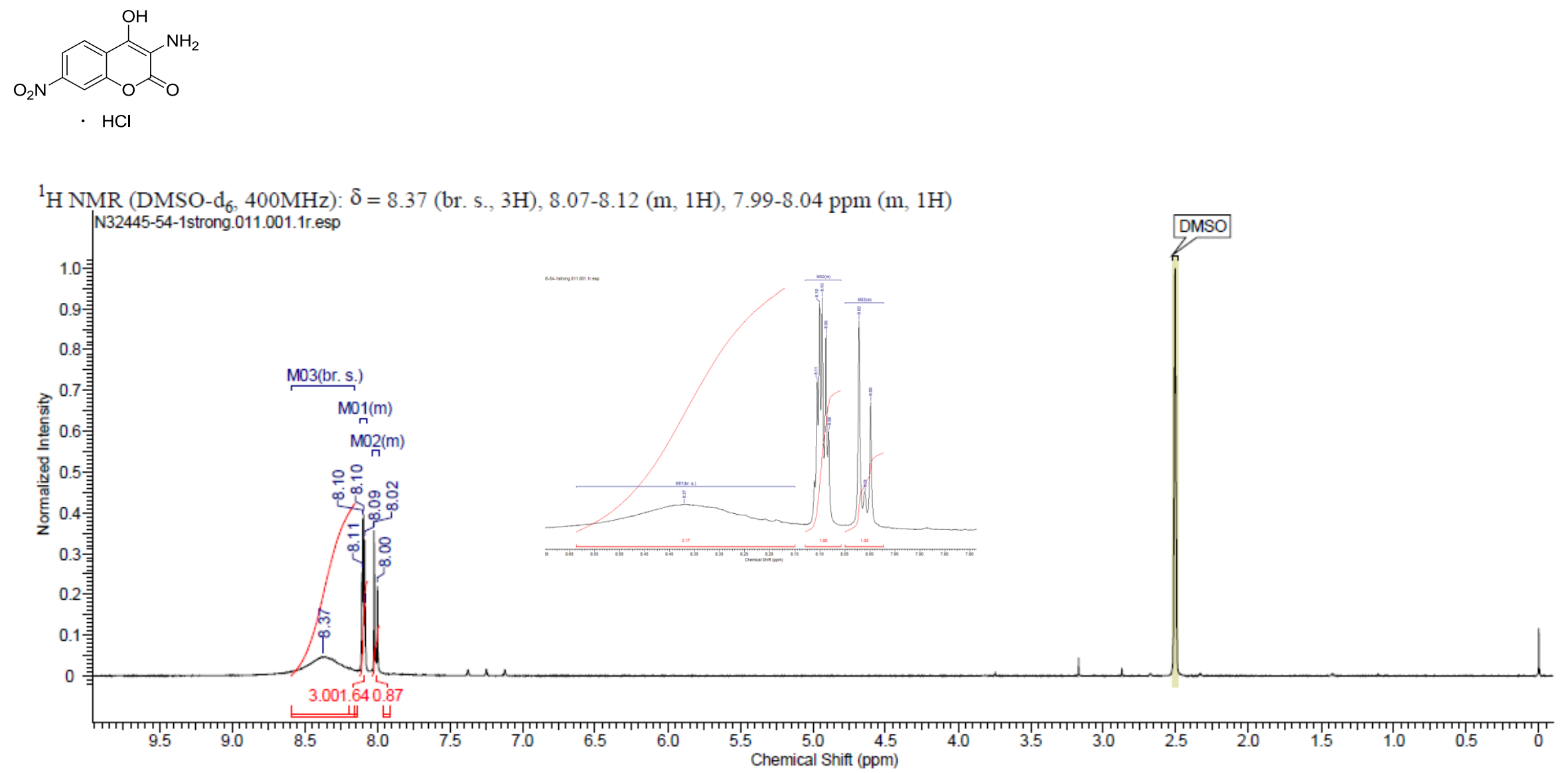


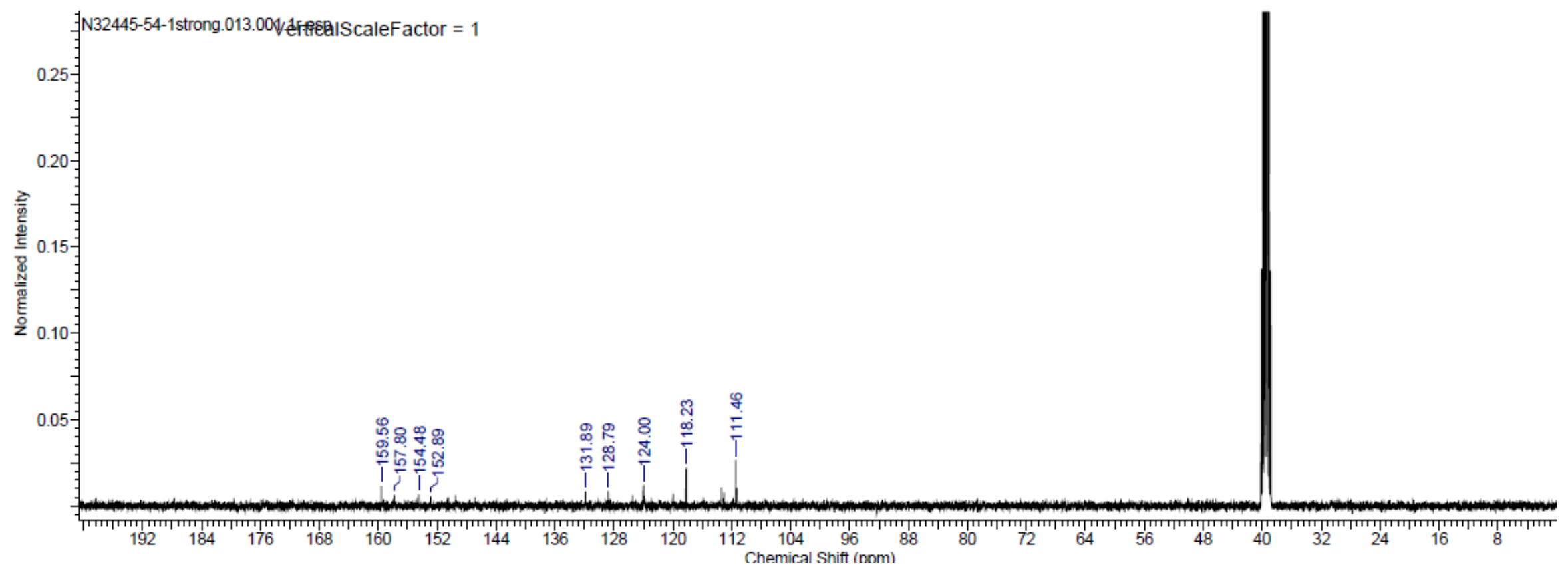


3-Amino-7-methoxy-4-hydroxy-2H-chromen-2-one hydrochloride (S34)

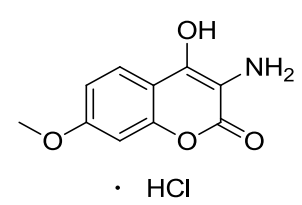

${ }^{1} \mathrm{H}$ NMR (DMSO-d $\left.6,400 \mathrm{MHz}\right): \delta=9.20$ (br. s., $\left.4 \mathrm{H}\right), 7.93$ (d, J=8.2 Hz, 1H), 6.91-6.96 (m, 2H), 3.85 ppm $(\mathrm{s}, 3 \mathrm{H})$

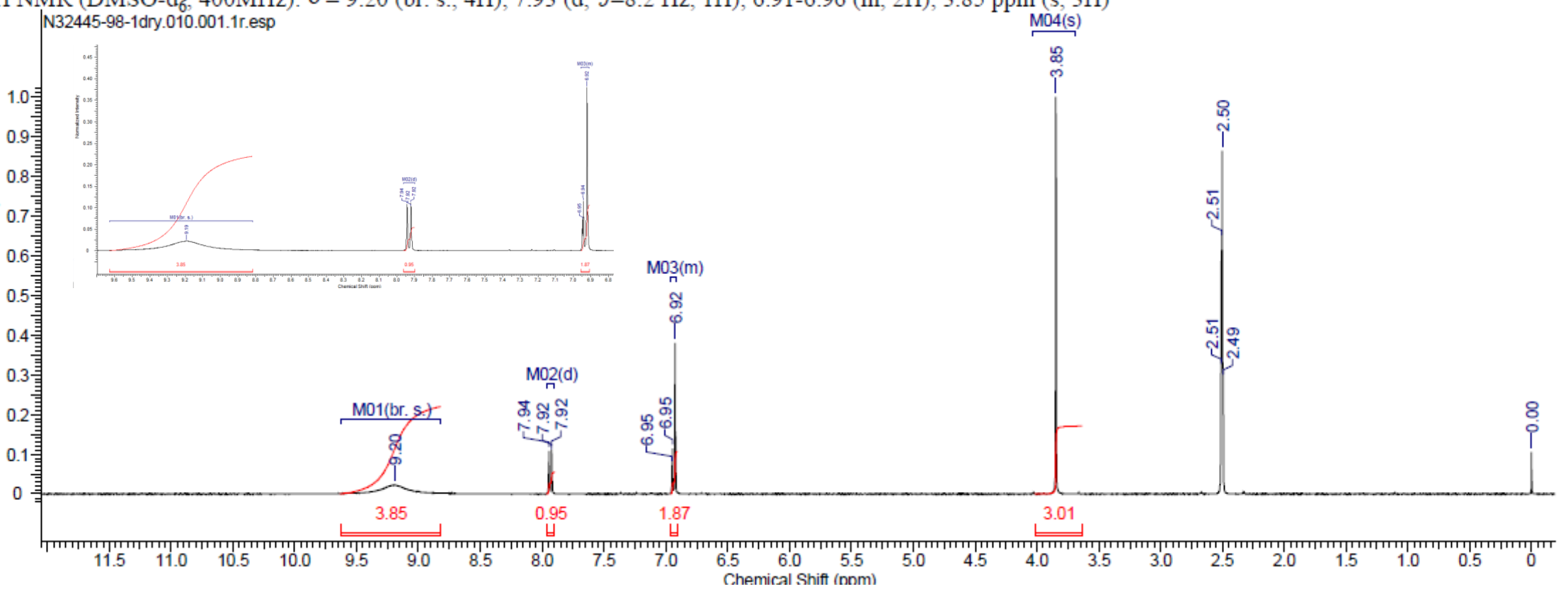




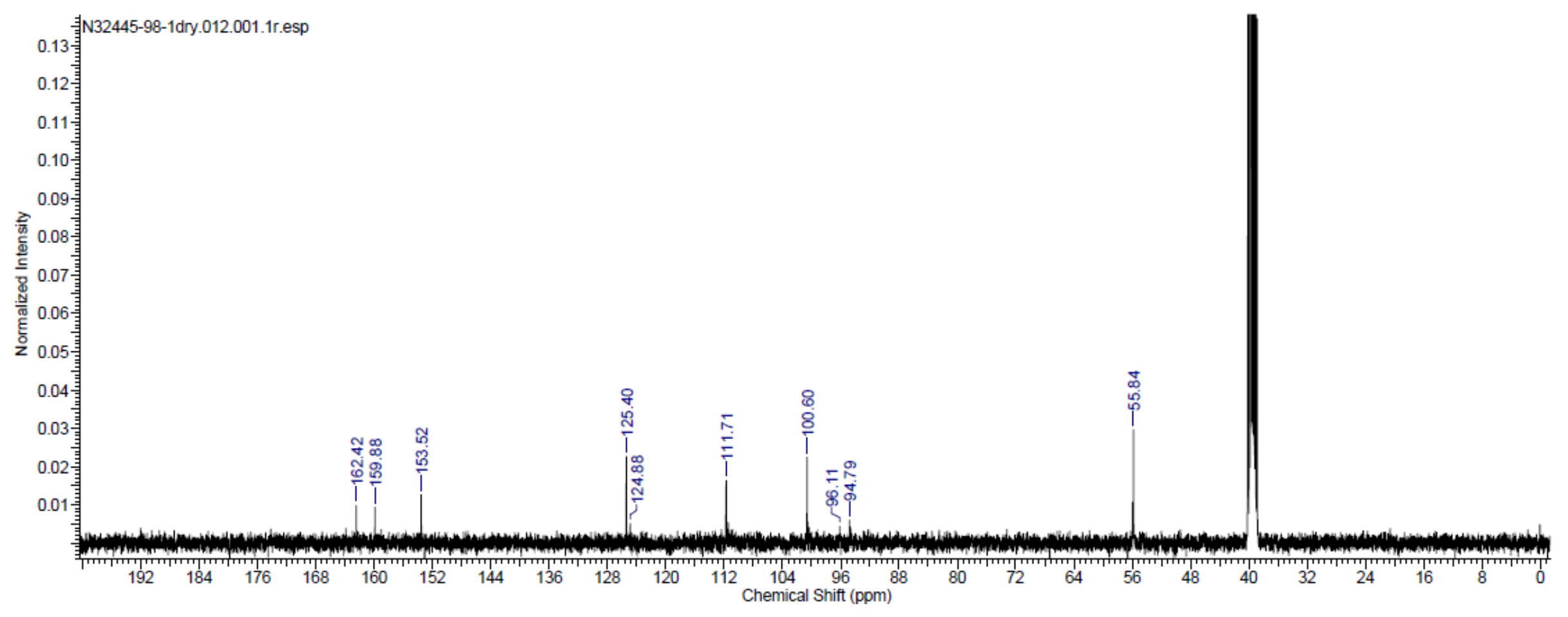


N-(4-Chloro, 7-hydroxy-2-oxo-2H-chromen-3-yl) benzamide (S1)

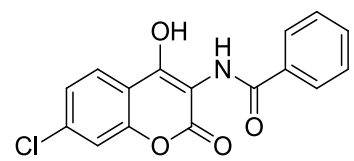

$\left.{ }^{1} \mathrm{H} \mathrm{NMR}_{\text {NMSO-d }}, 400 \mathrm{MHz}\right): \delta=12.30$ (br. s., $1 \mathrm{H}$ ), 9.55 (s, 1H), 8.01 (d, $\left.J=7.3 \mathrm{~Hz}, 2 \mathrm{H}\right), 7.91(\mathrm{~d}, J=8.5 \mathrm{~Hz}, 1 \mathrm{H}), 7.64(\mathrm{~d}, J=2.0 \mathrm{~Hz}, 1 \mathrm{H}), 7.59$ (d, $J=7.3 \mathrm{~Hz}$ 1H) $7.49-7.56(\mathrm{~m}, 2 \mathrm{H}), 7.47 \mathrm{ppm}(\mathrm{dd}, J=8.5,2.0 \mathrm{~Hz}, 1 \mathrm{H})$

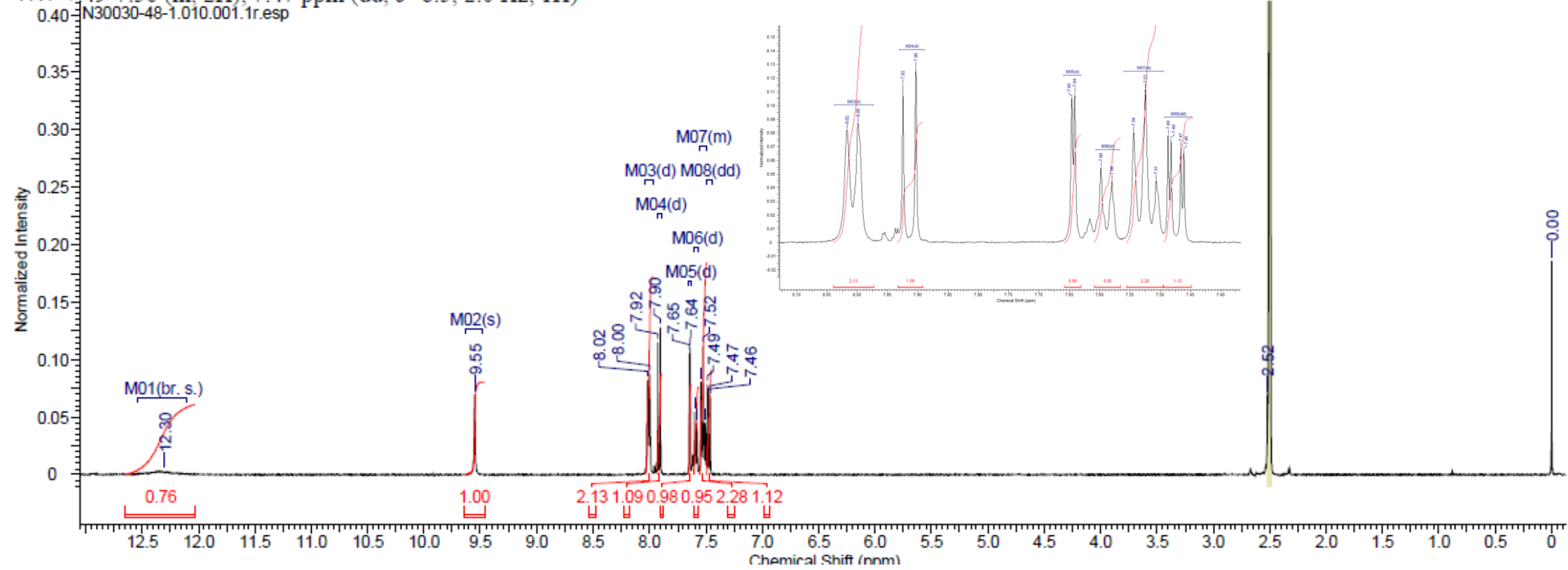




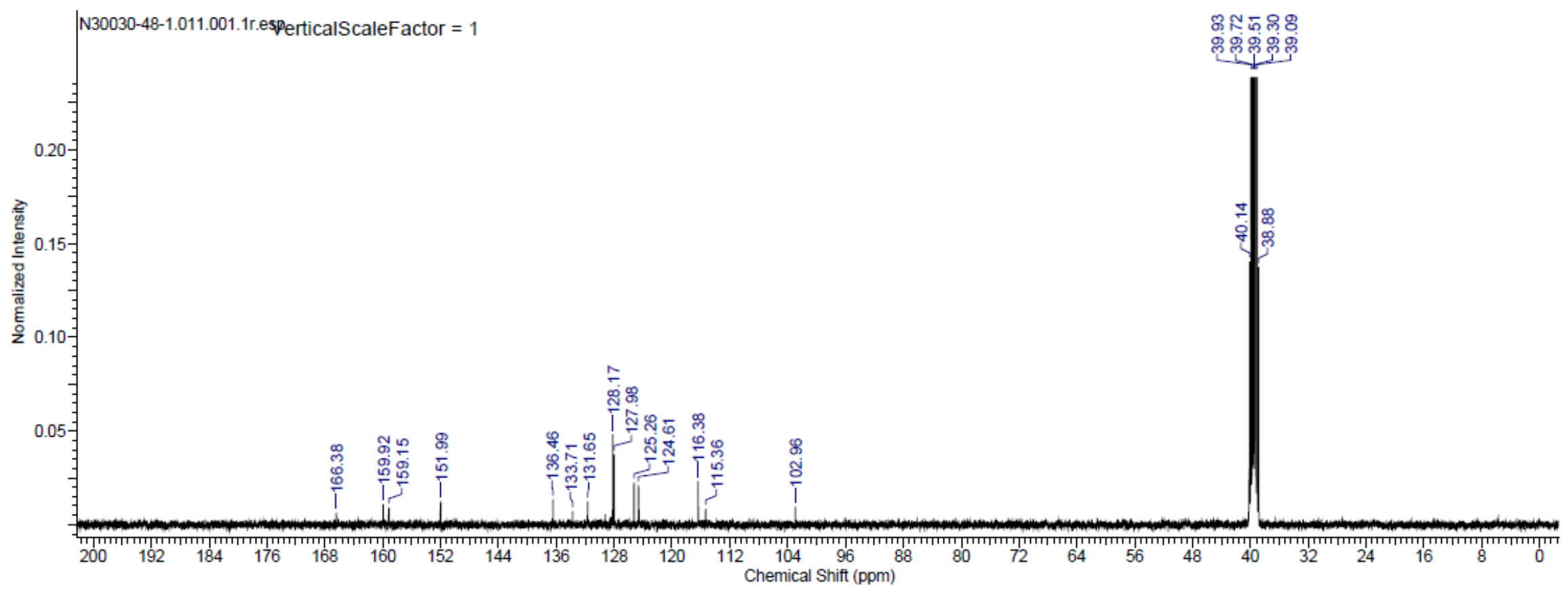


N-(4-Nitro, 7-hydroxy-2-oxo-2H-chromen-3-yl) benzamide (S2)

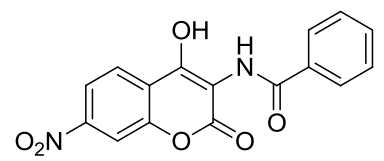

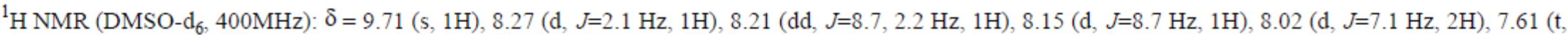
$J=73 \mathrm{~Hz}, 1 \mathrm{H}), 7.53 \mathrm{ppm}(\mathrm{t}, J=7.6 \mathrm{~Hz}, 2 \mathrm{H})$

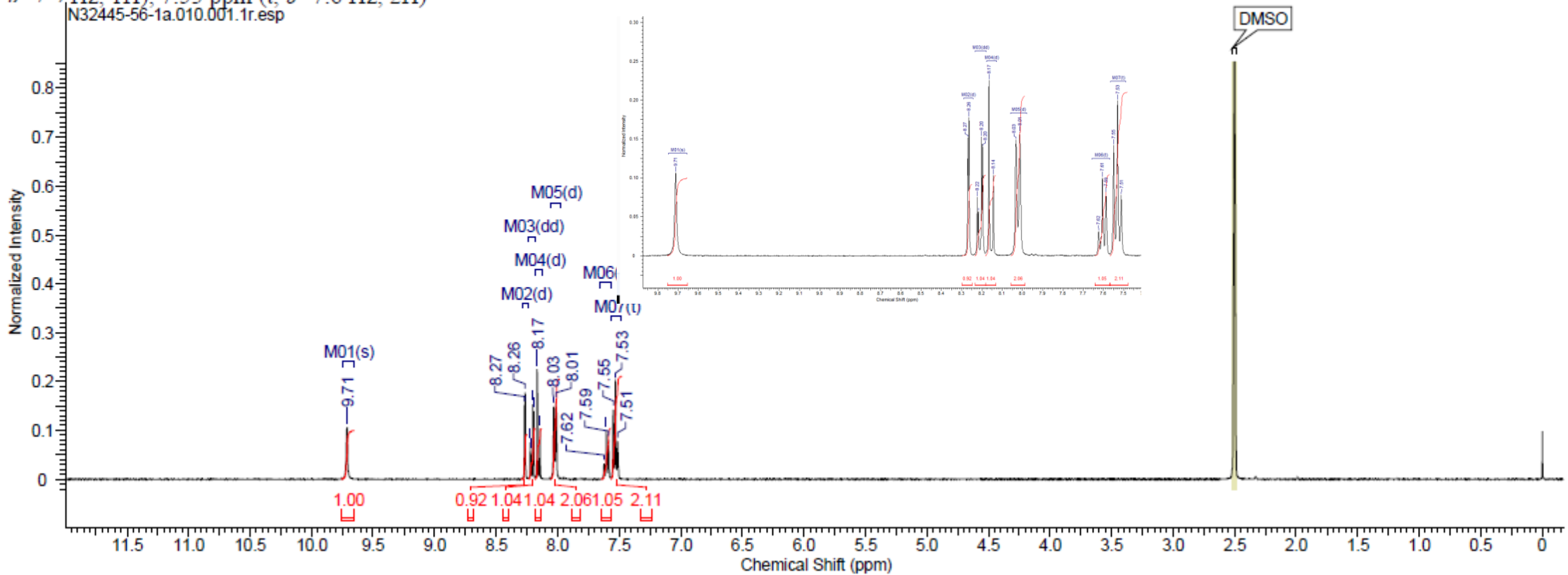




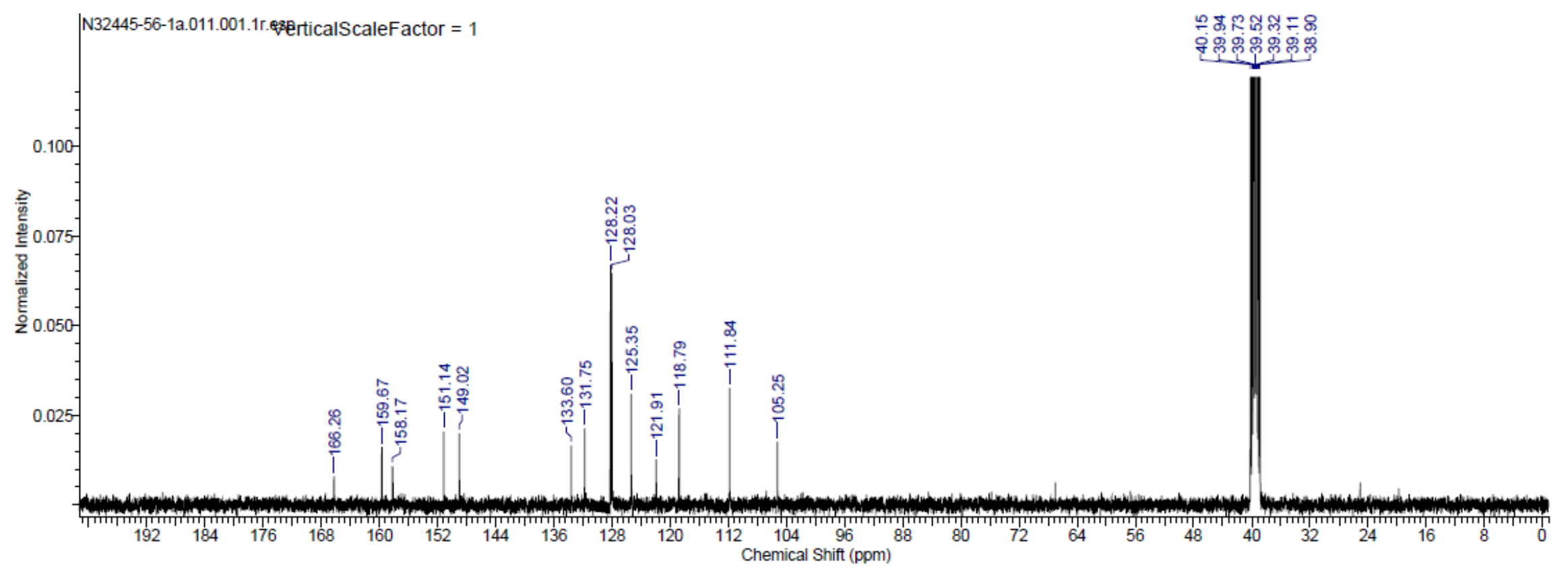


N-(4-Amino, 7-hydroxy-2-oxo-2H-chromen-3-yl) benzamide (S3)

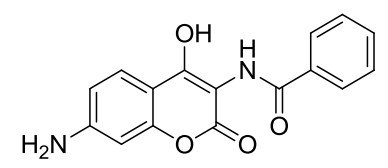

$\left.{ }^{1} \mathrm{H} \mathrm{NMR}_{\text {(DMSO-d }}, 400 \mathrm{MHz}\right): \delta=11.48$ (br. s., $\left.1 \mathrm{H}\right), 9.33$ (br. s., $\left.1 \mathrm{H}\right), 8.00$ (d, $\left.J=5.7 \mathrm{~Hz}, 2 \mathrm{H}\right), 7.39-7.68$ (m, $\left.4 \mathrm{H}\right), 6.59(\mathrm{~d}, J=7.0 \mathrm{~Hz}, 1 \mathrm{H}), 6.43$ ppm (br. s.,

1H)

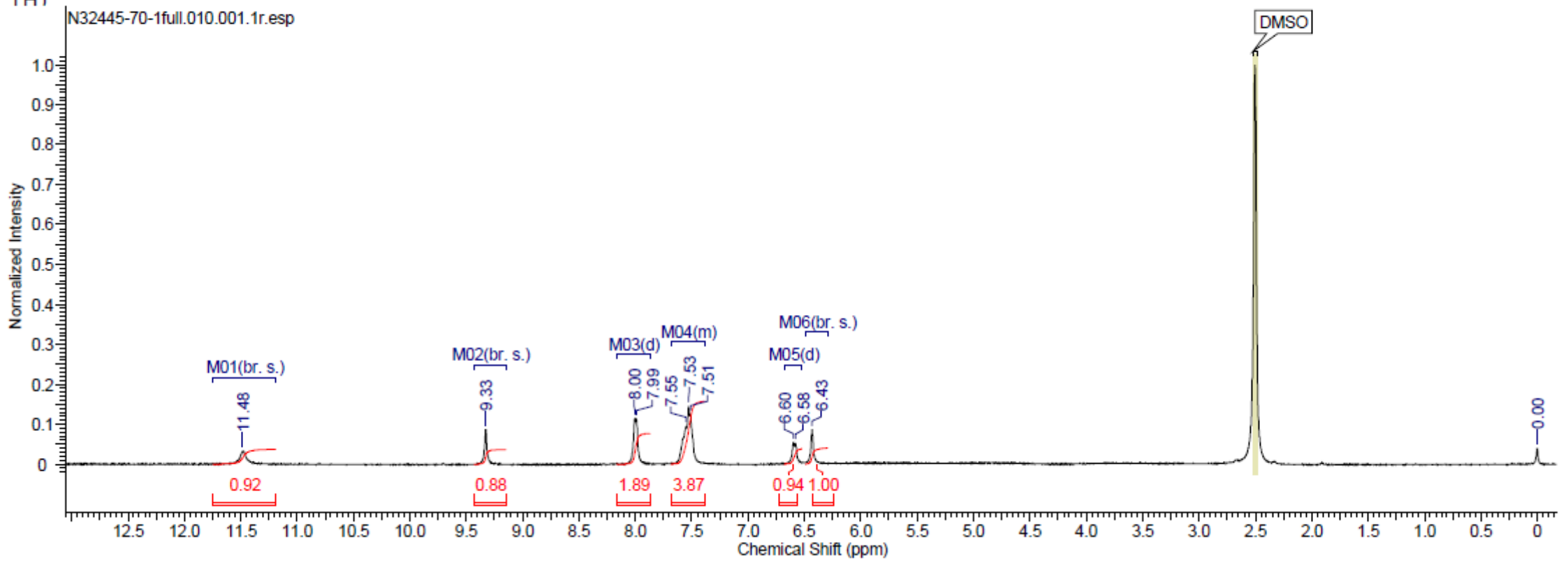




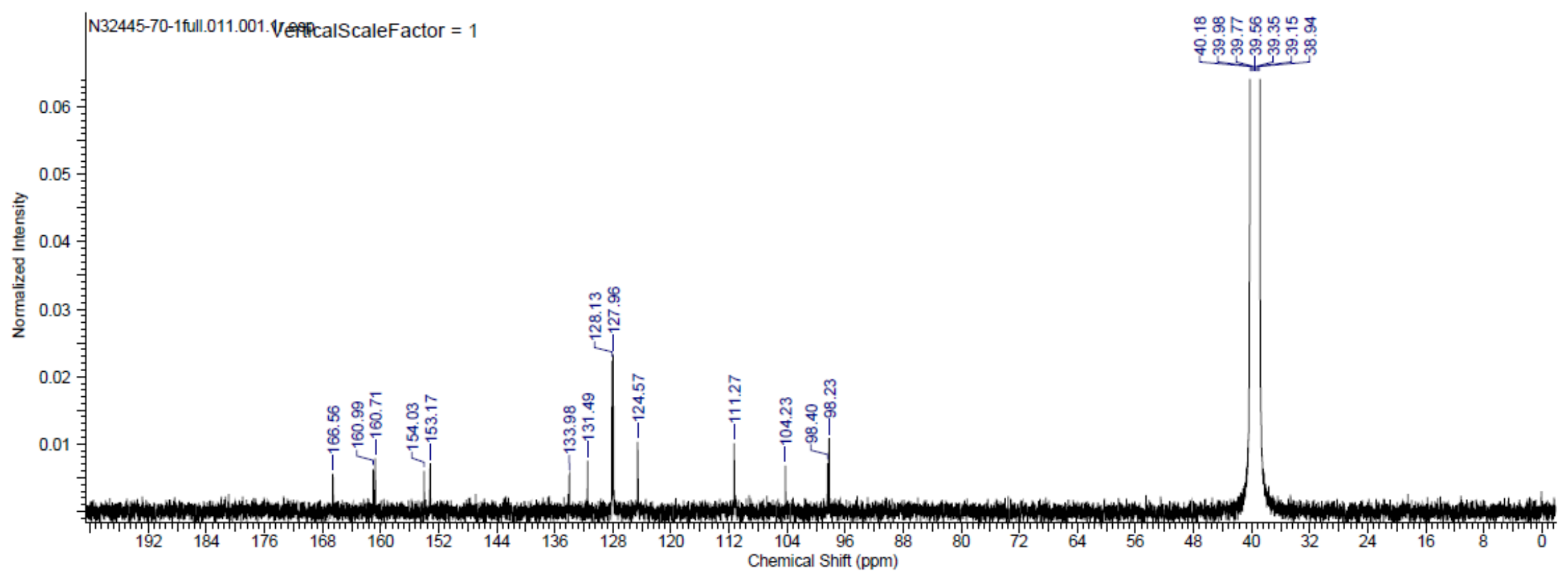


N-(4-Methoxy, 7-hydroxy-2-oxo-2H-chromen-3-yl) benzamide (S4)

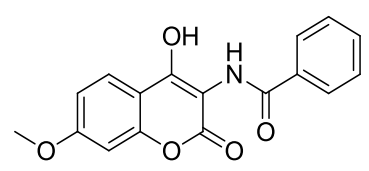

${ }^{1} \mathrm{H}$ NMR (DMSO-d $\left.6,400 \mathrm{MHz}\right): \delta=11.95$ (br. s., $\left.1 \mathrm{H}\right), 9.45(\mathrm{~s}, 1 \mathrm{H}), 8.01(\mathrm{~d}, J=7.1 \mathrm{~Hz}, 2 \mathrm{H}), 7.81(\mathrm{~d}, J=8.7 \mathrm{~Hz}, 1 \mathrm{H}), 7.58(\mathrm{~d}, J=7.3 \mathrm{~Hz}, 1 \mathrm{H}), 7.51(\mathrm{~d}, J=7.6 \mathrm{~Hz}$, 2H) 6.97-7.04 (m, 2H), $3.88 \mathrm{ppm}(\mathrm{s}, 3 \mathrm{H})$

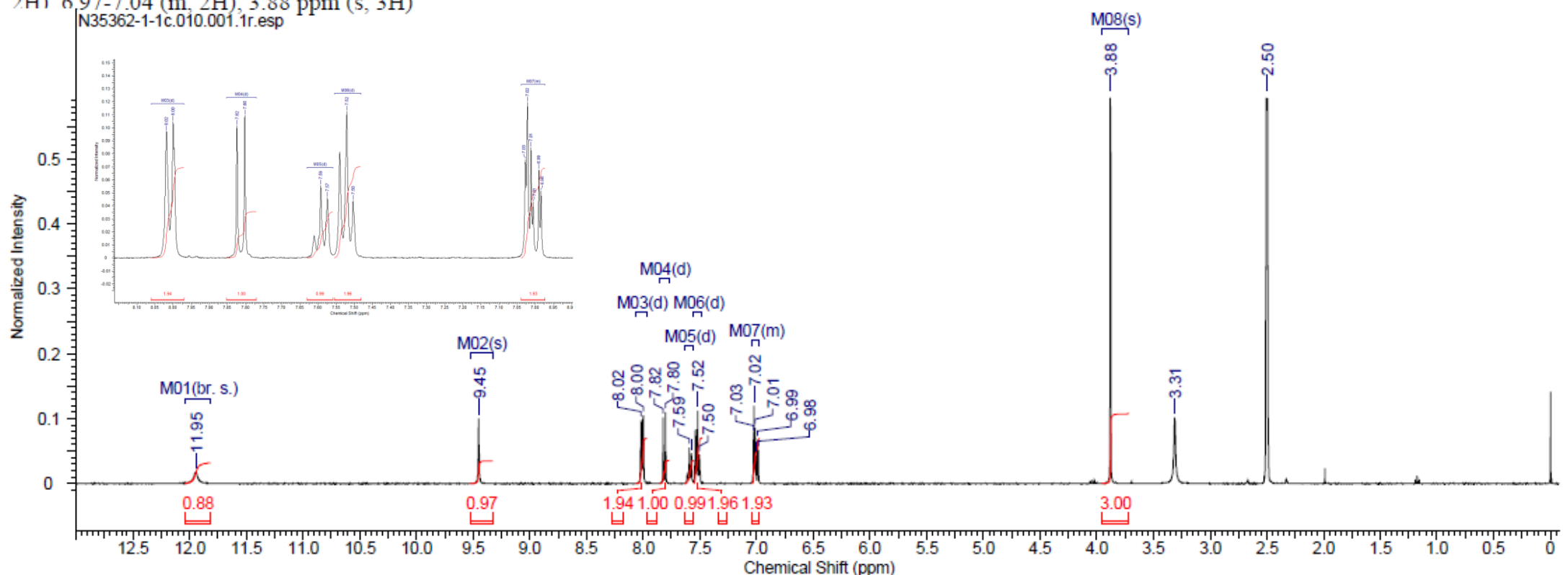




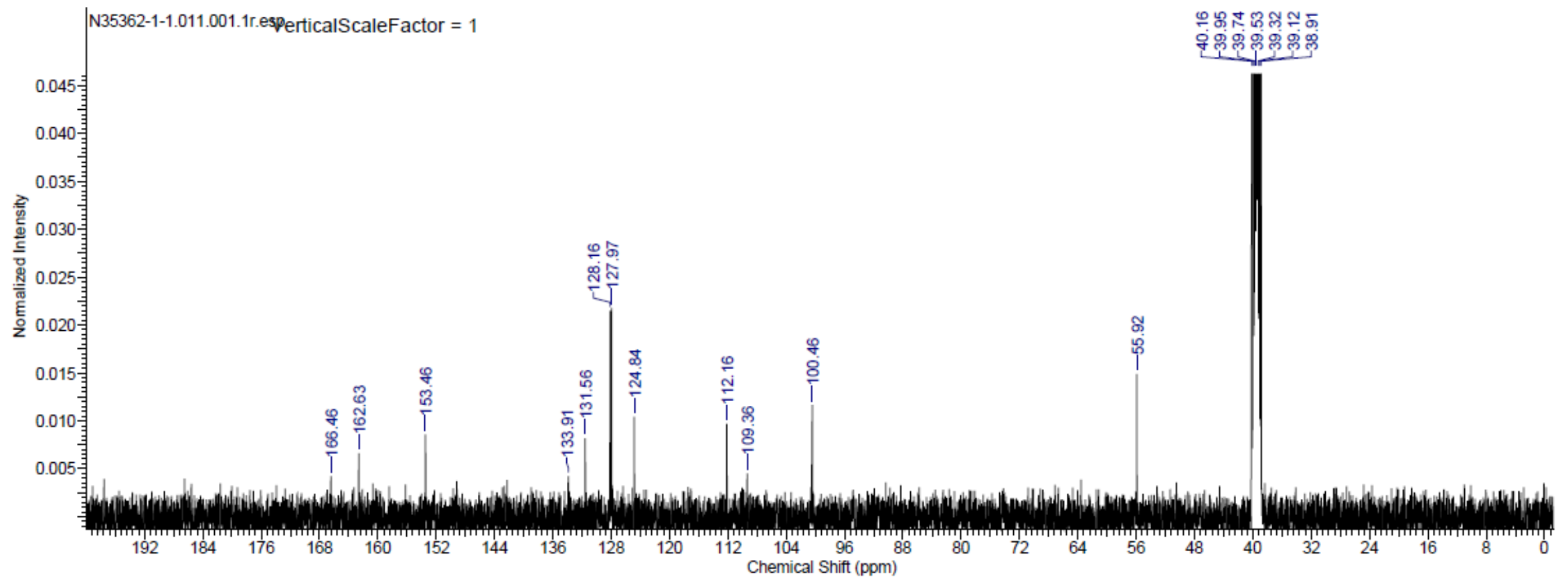




\section{N-(4,7-dihydroxy-8-methyl-2-oxo-2H-chromen-3-yl)benzamide ${ }^{17}$}

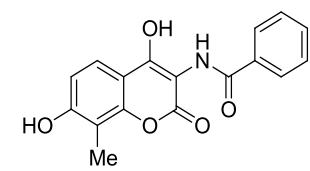

${ }^{1} \mathrm{H} \mathrm{NMR}_{\text {(DMSO-d }}, 400 \mathrm{MHz}$ ): $\delta=11.71$ (br. s., $1 \mathrm{H}$ ), 10.42 (s, 1H), 9.42 (s, 1H), 8.01 (d, J=7.1 Hz, 2H), 7.38-7.75 (m, 4H), 6.89 (d, J=8.7 Hz, $\left.1 \mathrm{H}\right), 2.18$ $\operatorname{mim}_{10}(\mathrm{SS} 3 \mathrm{H})$

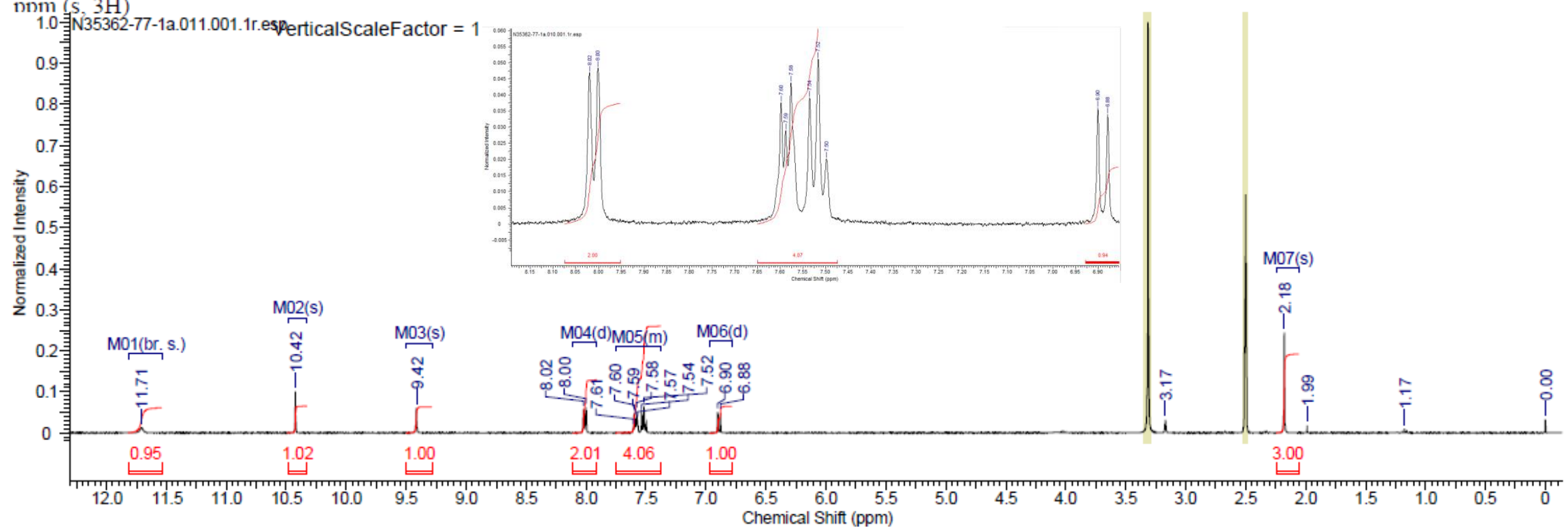




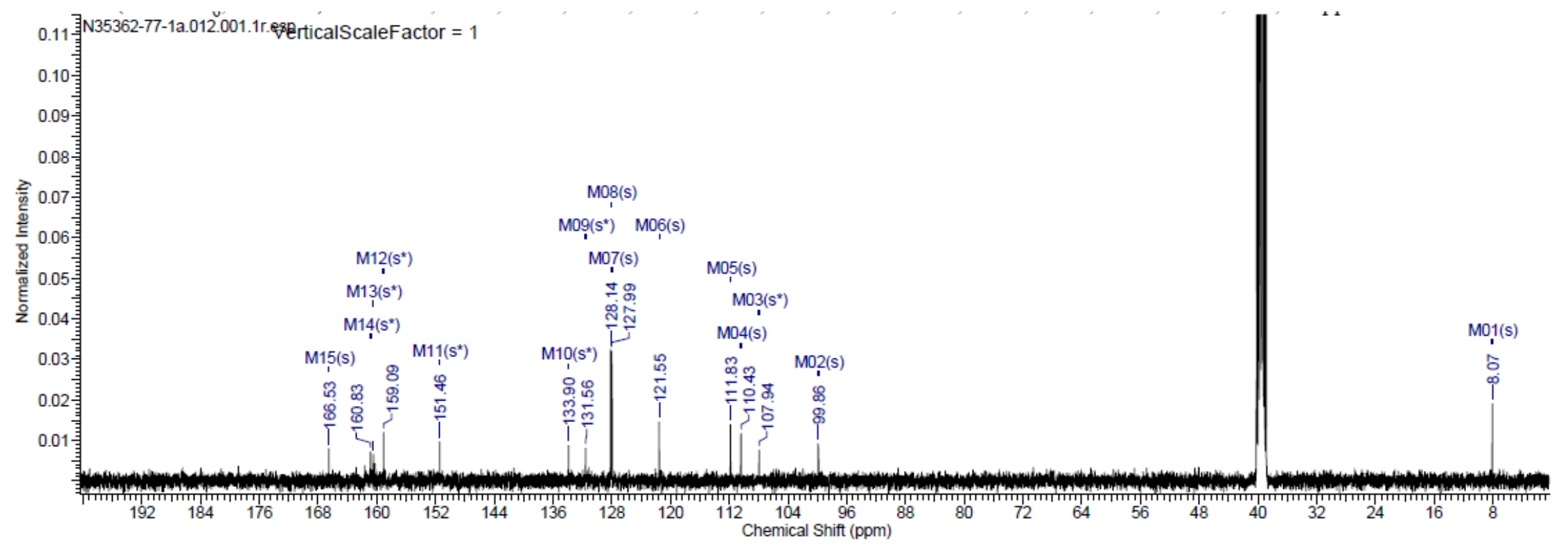




\section{References}

(1) Inc., C. C. G. (2015) Molecular Operating Environment (MOE). 1010 Sherbooke St. West, Suite \#910, Montreal, QC, Canada, H3A 2R7.

(2) Vonrhein C., Flensburg C., Keller P., Sharff A., Smart O., Paciorek W., W. T. and B. G. (2011) No Title. Acta Crystallogr. Sect. D Biol. Crystallogr. 67, 293-302.

(3) Vonrhein C., Blanc E., Roversi P., B. G. (2007) Methods in Molecular Biology. Methods Mol. Biol.

(4) Collaborative Computational Project. (1994) Collaborative Computational Project. Acta Cryst. D50 4, 760-763.

(5) Emsley P., Lohkamp B., S. W. G. and C. K. (2010) Features and development of Coot. Acta Crystallogr. D. Biol. Crystallogr. 66, 486-501.

(6) Bricogne, G. et al. (2009) BUSTER. Global Phasing Ltd., Cambridge, United Kingdom.

(7) Murshudov G. N., Skubák P., Lebedev A. A., Pannu N. S., Steiner R. A., Nicholls R. A., Winn M. D., L. F. and V. A. A. (2011) REFMAC5 for the refinement of macromolecular crystal structures. Acta Crystallogr. Sect. D Biol. Crystallogr. 67, 355-367.

(8) Labute, P. (2009) Protonate3D: Assignment of ionization states and hydrogen coordinates to macromolecular structures. Proteins Struct. Funct. Bioinforma. 75, 187-205.

(9) Paul Labute and Martin Santavy. Locating Binding Sites in Protein Structures. Chem. Comput. Gr. Inc.

(10) Soga, S., Shirai, H., Kobori, M., and Hirayama, N. (2007) Use of Amino Acid Composition to Predict Ligand-Binding Sites. J. Chem. Inf. Model. 47, 400-406.

(11) Cornforth, J. W., Reichard, S. A., Talalay, P., Carrell, H. L., and Gluskerld, J. P. (1977) SCarboxymethyl-(S)-methionine 7292-7300.

(12) Origin (OriginLab, Northampton, MA).

(13) Eustáquio, A. S., Pojer, F., Noel, J. P., and Moore, B. S. (2008) Discovery and characterization of a marine bacterial SAM-dependent chlorinase. Nat. Chem. Biol. 4, 69-74.

(14) Lipson, J. M., Thomsen, M., Moore, B. S., Clausen, R. P., La Clair, J. J., and Burkart, M. D. (2013) A tandem chemoenzymatic methylation by S-adenosyl-L-methionine. Chembiochem 14, 950 3.

(15) Tengg, M., Stecher, H., Remler, P., Eiteljörg, I., Schwab, H., and Gruber-Khadjawi, M. (2012) Molecular characterization of the C-methyltransferase NovO of Streptomyces spheroides, a valuable enzyme for performing Friedel-Crafts alkylation. J. Mol. Catal. B Enzym. 84, 2-8.

(16) (2015) ACD/Structure Elucidator. Advanced Chemistry Development, Inc., Toronto; ON; Canada.

(17) Stecher, H., Tengg, M., Ueberbacher, B. J., Remler, P., Schwab, H., Griengl, H., and GruberKhadjawi, M. (2009) Biocatalytic Friedel-Crafts alkylation using non-natural cofactors. Angew. Chem. Int. Ed. Engl. 48, 9546-8.

(18) Simokoriyama, M. (1941) On the formation of the partial acetates of flavones, flavanones, anthraquinones and similar compounds. Bull. Chem. Soc. Jpn. 16, 284-91.

(19) Athanasellis, G., Melagraki, G., Afantitis, A., Makridima, K., and Igglessi-Markopoulou, O. (2006) A simple synthesis of functionalized 2-amino-3-cyano-4-chromones by application of the Nhydroxybenzotriazole methodology. Arkivoc 2006, 28.

(20) da Silva, M., Menezes, C. M. S., Ferreira, E. I., Leite, C. Q. F., Sato, D. N., Correia, C. C., Pimenta, C. P., and Botelho, K. C. A. (2008) Topliss method in the optimization of salicylic Acid derivatives as potential antimycobacterial agents. Chem. Biol. Drug Des. 71, 167-72.

(21) Fersht, A. R., and Kirby, A. J. (1967) Hydrolysis of aspirin. Intramolecular general base catalysis of ester hydrolysis. J. Am. Chem. Soc. 89, 4857-4863.

(22) Brophy, J. J., Diakiw, V., Goldsack, R. J., Nelson, D., and Shannon, J. S. (1979) Anomalous ions in the chemical ionization mass spectra of aromatic nitro and nitroso compounds. Org. Mass Spectrom. 14, 201-203.

(23) Kawai, M., Nyfeler, R., Berman, J. M., and Goodman, M. (1982) Peptide sweeteners. 5. Side chain homologs relating zwitterionic and trifluoroacetylated amino acid anilide and dipeptide sweeteners. J. Med. Chem. 25, 397-402.

(24) Anglin, J. L., Deng, L., Yao, Y., Cai, G., Liu, Z., Jiang, H., Cheng, G., Chen, P., Dong, S., and 
Song, Y. (2012) Synthesis and structure-activity relationship investigation of adenosine-containing inhibitors of histone methyltransferase DOT1L. J. Med. Chem. 55, 8066-74.

(25) Jahn, W. (1965) Synthese 5'-substituierter Adenosinderivate. Chem. Ber. 98, 1705-1708. 